\title{
THE SPECIFIC SURFACE OF HARDENED PORTLAND CEMENT PASTE AS MEASURED BY LOW-ANGLE $X$-RAY SCATTERING
}

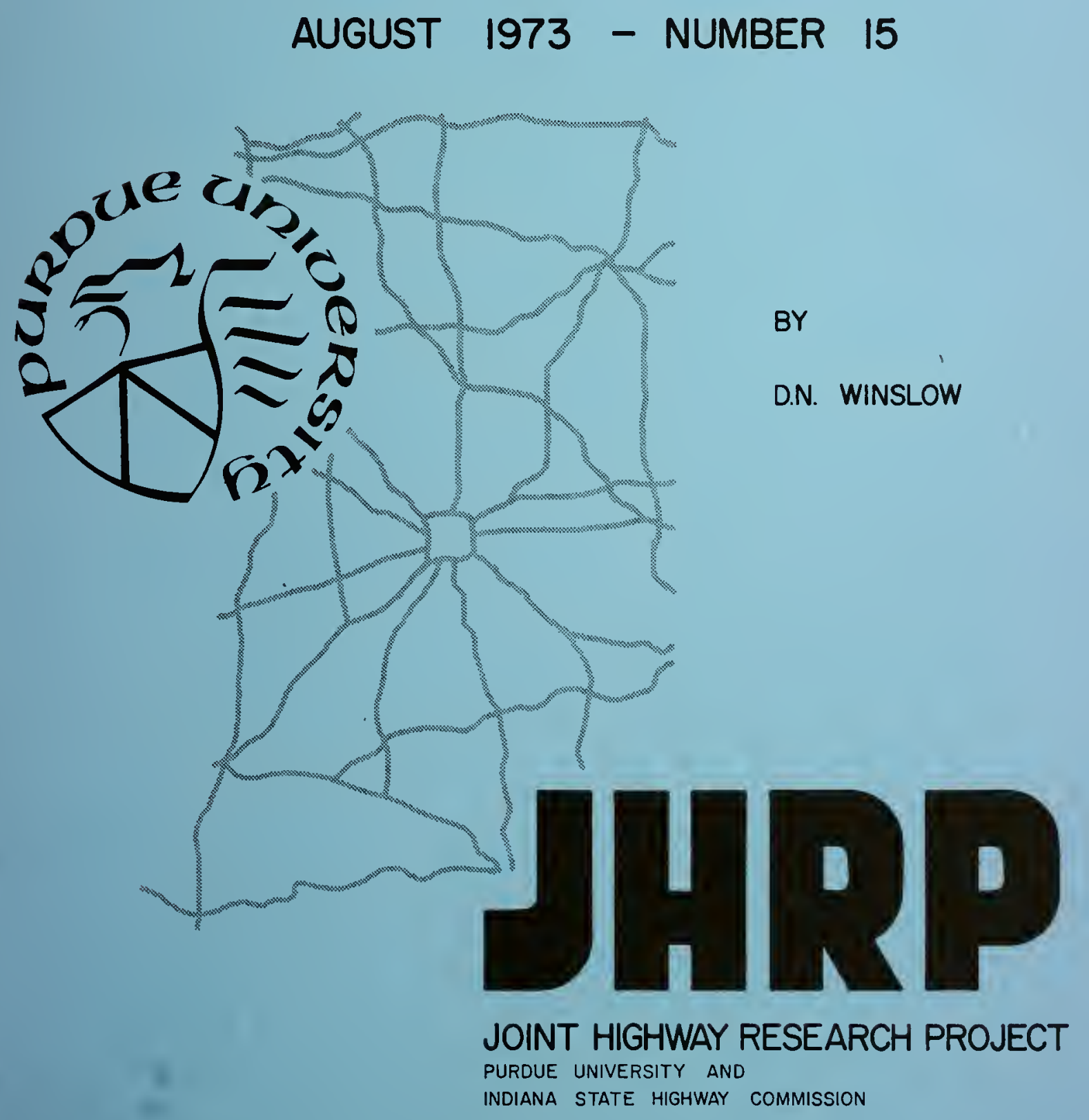



Final Report

THE SPECIFIC SURFACE OF HARDENED PORTLAND CEMENT PASTE

AS MEASURED BY LOW-ANGLE X-RAY SCATTERING

TO: J. F. McLaughlin, Director

Joint Highway Research Project

August 29,1973

FROM: H. L. Michael, Associate Director Joint Highway Research Project

Ffle: $\quad 5-14-5$

Attached is a Final Report titled "The Specific Surface of Hardened Portland Cement Paste as Measured by Low-Angle $X$-Ray Scattering". It has been authored by Mr. Douglas N. Winslow, a Graduate Instructor in Research on our staff during the conduct of the Study and was financed by the Purdue Research Foundation. Mr. Winslow also used the research report as his thesis for the Ph.D. degree.

As this research is closely related to other research being supported in the area by the Indiana State Highway Commisston and the Federal Highway Administration it is reported to the Advisory Board for information.

Respectfully submitted,

HLM:ms

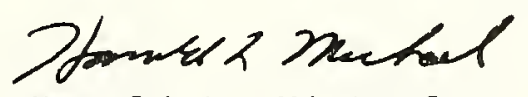

Harold L. Michael

Associate Director

$\begin{array}{lll}\text { cC: W. L. Dolch } & \text { R. H. Harrell } & \text { C. F. Scholer } \\ \text { R. L. Eskew } & \text { M. L. Hayes } & \text { M. B. Scott } \\ \text { G. D. Glbson } & \text { C. W. Lovell } & \text { J. A. Spooner } \\ \text { W. H. Goetz } & \text { G. W. Marks } & \text { N. W. Steinkamp } \\ \text { M. J. GutzWliler } & \text { R. D. Miles } & \text { H. R. J. Walsh } \\ \text { G. K. Hallock } & \text { G. T. Satterly } & \text { E. J. Yoder }\end{array}$




\section{Final Report}

THE SPECIFIC SURFACE OF HARDENED PORTLAND CEMENT PASTE AS MEASURED BY LOW-ANGLE X-RAY SCATTERING

by

Douglas N. Winslow Graduate Instructor in Research

Joint Highway Research Project

File No.: 5-14-5

The Research Reported Herein was Financed

By

the Purdue Research Foundation

Purdue University

West Lafayette, Indiana

August 29, 1973 


\section{ACKNOWLEDGMENTS}

The author wishes to express his appreciation for the continual guidance and support of his major professor, Dr. Sidney Diamond, without which this research would not have been possible. He also wishes to thank the other members of his advisory committee, Dr. W. L. Dolch, Dr. G. L. Liedl and Dr. R. W. Vest, for their assistance. Dr. L. E. Copeland of the Portland Cement Association provided early assistance and encouragement for which the author is very grateful.

A great amount of scientific and technical help was received from several other sources. The author wishes to extend his appreciation to Dr. O. Kratky, Dr. G. Porod and Dr. H. Leopold of the University of Graz, Austria, and Dr. J. Cohen of Northwestern University for their time consuming and patient answering of his many, many questions. The difficult and time consuming electronic alterations to the X-ray equipment carried out by Mr. Nicholas Coburn were invaluable to this research.

The assistance of Mrs. Carolyn Brendel and Mr. Richard Burns in making many laboratory measurements is gratefully acknowledged. 
TABLE OF CONTENTS

Page

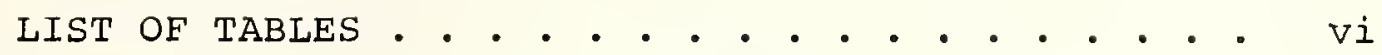

LIST OF FIGURES • • • . . . . . . . . . . . . . viii

ABSTRACT • . . . . . . . . . . . . . . . ix

INTRODUCTION • • . . . . . . . . . . . . . . . 1

LOW-ANGLE X-RAY SCATTERING THEORY • . • . . • . 11

EXPERIMENTAL PROCEDURES . . . . . . . . . . 20

Materials . . . . . . . . . . . . . 20

Preparation of Cement and Alite Pastes . . . 20

Preparation of $\mathrm{X}$-Ray Scattering Samples

of Cement Paste... . . . . . . . . . . . 21

Drying of the Cement Paste Samples . . . . . 23

Special Treatments . . . . . . . . . . . 25

Preparation of Samples Other Than Cement Paste 27

X-Ray Apparatus and Modifications . . . . . 28

X-Ray Intensity Measuring Strategy . . . . . 37

Parasitic Scatter . . . . . . . . . . . 44

Sample Porosity . . . . . . . . . . . . 48

Sorption Measurements . . . . . . . . . . 53

X-RAY SCATTERING DATA . . . . . . . . . . 59

X-RAY SCATTERING CORRECTIONS AND CALCULATIONS • • 65

RESULTS . . . . . . . . . . . . . . . 84

Illite and Activated Charcoal . . . . . . . 84

Tests on Mature, $w / c=0.4$ Cement Pastes . . 84

DISCUSSION . . . • • • • . . • • • • 92

Cement Paste Microstructure . . . . . . . . 92

Vapor Sorption and X-Ray Surface
Area Comparisons . . . . . . . . . . . 9 92

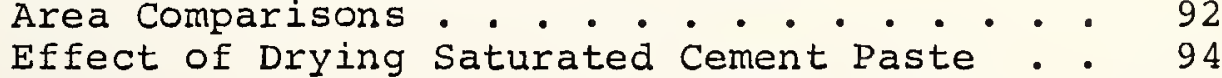

Surface Area of Saturated Cement Paste . . 95

Effect of Progressive Drying of Cement Paste 98 
Digitized by the Internet Archive in 2011 with funding from

LYRASIS members and Sloan Foundation; Indiana Department of Transportation 
TABLE OE CONTENTS, cont.

Page

Effect of Resaturation of Cement Paste . . 99

Effect of Heating Cement Paste . . . . . 101

Surface Area of Alite Paste . . . . . . . 102

Effect of Degree of Hydration . . . . . . 102

General Matter of Interpretation of $\mathrm{x}$-Ray

Scattering Results . . . . . . . . . . . 104

Reproducibility of $\mathrm{x}$-Ray Scattering

Measurements . . . . . . . . . . . . 104

Comparison of Sorption and $x$-Ray Scattering

Results on Illite Clay and Activated Charcoal 105

Interpretation of Guinier's Law . . . . . 107

Sensitivity of Porod Method to Small

Surface Separations . . . . . . . . . 111

CONCLUSIONS • • . . . . . . . . . . . . . . 113

LIST OF REFERENCES . . . . . . . . . . . . . 115

APPENDICES

Appendix A . . . . . . . . . . . . . . 117

Appendix B . . . . . . . . . . . . . . . . . 119

Appendix C . . . . . . . . . . . . . . . . . 124

Appendix D . . . . . . . . . . . . . . . 131

VITA •. . . . . . . . . . . . . . . 148 


\section{IIST OF TABLES}

Table

Page

1. Physical Parameters and Calculated Porosities for All Cement Paste Samples . . . . . . .

2. Raw X-Ray Scattering Data Direct from $X-R a y$ Machine . . . . . . . . . . . . . . .

3. Raw X-Ray Scattering Data Direct from $x-$ Ray Machine . . . . . . . . . . . . . . .

4. Total and Parasitic Scattering Curves after Combination of Multiple Scans . . . . . .

5. Values for Guinier Plot . . . . . . . . 70

6. Extrapolated Values from Guinier Plot . . . 72

7. Calculations for Initial Porod Plot . . . . 74

8. Non-Interfacial Scatter Corrections to Porod Plot . . . . . . . . . . . . .

9. Very-Large-Angle Extrapolation of Porod's Invariant . . . . . . . . . . . . . .

10. Complete, Corrected Listing of Scattered Intensities.

11. Calculation of Porod's Invariant . . . .

12. Specific Surface of Illite Clay and Activated Charcoal . . . . . . . 85

13. Results of Drying Cement Paste . . . . . 86

14. Results of Resaturating Cement Paste . . . 87

15. Results of Heating Cement Paste . . . . . 87

16. Surface Area of Other $w / s=0.4$ Cement Pastes 89

17. Surface Area of Different $w / C$ Cement Pastes . 90 
LIST OF TABLES, cont.

Table

Page

18. Comparison of Specific Surfaces Measured by $\mathrm{X}$-Ray Scattering and Vapor Sorption Techniques 107

19. "Average" Guinier Law Pore Size of Cement Pastes . . . . . . . . . . . 110

Appendix

Tables

20. Laboratory Report of Purdue Lab Cement No. 317 . . . . . . . . . . . . .

21. Analysis of Alite cement . . . . . . 118

22. Optimum Thickness of Cement Paste Samples for X-Ray Scattering with Mo Ka Radiation . . 122

23. Observed and Dead Time Corrected $\mathrm{X}$-Ray Intensities... . . . . . . . . . 130

24. Index to $x$-Ray Scattering Data Listed in Table 25 ............... 131

25. Complete Listing of Scattering Test Data . . 133 
1. Pores in a Solid Matrix . . . . . . . . 17

2. Suspended Particles . . . . . . . . . 17

3. Cement Paste Plug and slice specimens in Drying Racks . . . . . . . . . . . 23

4. Schematic of Low-Angle $x$-Ray Scattering Geometry . . . . . . . . . . . 29

5. General Electric XRD-5 Diffractometer and Attendant Accessories . . . . . . . . 31

6. Low-Angle $X$-Ray Scattering Slits and Sample Holder Mounted for Scattering . . . . . . 31

7. Disassembled Sample Holder with Cement Paste Slice Specimen . . . . . . . . . 36

8. Assembled Sample Holder with Cement Paste Slice Specimen Installed . . . . . . . 36

9. Summary of X-Ray Counting strategy . . . . 40

10. Technique for Parasitic Scatter Measurement - 46

11. Guinier Plot . . . . . . . . . . 71

12. Initial Porod Plot . . . . . . . . . 75

13. Final Porod Plot . . . . . . . . . 78 Appendix

Figures

14. Scattered Intensity vs. Specimen Thickness - 123 15. Plot to Determine Dead Time . . . . . . 129 


\section{ABSTRACT}

Winslow, Douglas Nathaniel, Ph.D., Purdue University, May 1973, The Specific Surface of Hardened Portland Cement Paste as Measured by Low-Angle X-Ray Scattering, Major Professor: Sidney Diamond.

A number of aspects of the ultimate microstructure of hardened portland cement paste (the binder in portland cement concrete) are not completely understood, and are currently the subject of much debate. The central facet of this debate concerns the magnitude of the specific surface, conflicting results being obtained depending on the method of measurement. Surface area is commonly measured by vapor sorption on previously dried specimens, the results being interpreted by the B.E.T. theory. Two adsorbates have been predominantly used: nitrogen vapor at $77^{\circ} \mathrm{K}$, which yields surface areas of $10-50 \mathrm{~m}^{2} / \mathrm{g}$ of hardened cement paste, and water vapor at room temperature, which yields surface areas of $150-250 \mathrm{~m}^{2} / \mathrm{g}$. The microstructural debate revolves around the specific interactions of these two vapors with cement paste. There is a sharp difference of opinion as to which vapor yields the "correct" value.

Low-angle $\mathrm{x}$-ray scattering, not previously applied to this material, offers the possibility of measuring the 
surface area of cement paste in a manner not subject to the assumptions inherent in analyzing sorption data, and is free from the possibility of specific interactions between adsorbent and adsorbate. Further, it permits specific surface measurements to be made on saturated, i.e., undisturbed samples.

Low-angle $\mathrm{x}$-ray scattering experiments were carried out on a number of hardened cement pastes. The theory of Porod was used to relate the $\mathrm{x}$-ray scattering to the specific surface of the material being tested. Tests with two "reference" materials, illite clay and activated charcoal, yielded values close to those for water and nitrogen vapor sorption, thus indicating that the $x-r a y$ technique was being properly applied. A number of determinations were carried out on a mature cement paste prepared from a typical ASTM Type I portland cement mixed at a water to cement weight ratio of 0.4 , and hydrated for about 18 months. Low-angle scattering measurements were made on the original saturated paste, after a number of drying treatments of increasing severity, and after resaturation following some of these treatments.

The specific surface of the saturated cement paste was found to be approximately $700 \mathrm{~m}^{2} / \mathrm{g}$ of ignited cement paste (ignited at $1050^{\circ} \mathrm{C}$ ); the equivalent value expressed on a basis of ' $D$ '-dried weight is about $580 \mathrm{~m}^{2} / \mathrm{g}$. Comparisons made on an ignited weight basis are used to 
provide a common basis for comparing samples of varying water contents.

Drying treatments were found to significantly reduce the measured surface area with the reduction being related to the severity of drying. The surface areas were found to range from $272 \mathrm{~m}^{2} / \mathrm{g}$ (ignited) for ' $\mathrm{P}$ '-dried paste down to $138 \mathrm{~m}^{2} / \mathrm{g}$ (ignited) for paste dried at $105^{\circ} \mathrm{C}$ under vacuum.

Similar results were obtained for pastes made at other water to cement ratios and for pastes made from alite. This indicates that the water to cement ratio does not seriously alter the surface area, and that the measured surface is primarily that of the hydration products of the calcium silicates.

The surface area lost on drying was found to be completely recoverable on resaturation, unless the samples had been heated. Oven arying caused an approximately 8\% permanent loss in surface area that was not recoverable on resaturation and eivdence was found that hydrated cement particles "sinter" when heated.

It is clear that nitrogen adsorption measurements fail to register most of the surface that is present in cement paste. Water vapor adsorption measurements are comparable in magnitude to those obtained by $x$-ray scattering for dried samples. However, the surface area of wet cement paste is very much bigher. This is the condition of the paste as found in cement structures. It is concluded 
water vapor sorption measurements are inappropriate for use in a quantitative model for the microstructure of cement paste as it exists in concrete. 


\section{INT RODUCTION}

Portland cement concrete is probably made in the largest volume of any man-made substance in the world; it is a fundamental construction material in virtually all countries. Concrete has been in use for more than one hundred years in basically the same form as it is known today. Yet despite this long history and high-volume usage, there is a surprisingly imperfect understanding of many aspects of this material.

Portland cement concrete is composed of mineral aggregates bound together with the products of the hydration of portland cement. The aggregate is employed to restrict shrinkage and to act as a filler; it is generally inert. The hydrated cement binder is, then, that part of the concrete principally responsible for such vital properties as strength and durability.

Portland cement is composed of anhydrous calcium silicates, calcium aluminates and calcium aluminoferrites, and added gypsum. When it is mixed with water it forms a readily deformable slurry known as "plastic portland cement paste". Upon addition of the water the cement commences a series of hydration reactions, in the most important of 
which the calcium silicates combine with the water to form a poorly crystallized hydration product called calcium silicate hydrate gel, and also hydrated lime, $\mathrm{Ca}(\mathrm{OH})_{2}$. Other hydration products involving the iron, aluminum and sulfur constituents are also formed. After a period of several hours the hydration reactions have proceeded sufficiently so that the plastic paste has become a rigid mass which may be called "hardened portland cement paste". In this writing the hardened portland cement paste will be referred to simply as "cement paste". The hydration reactions continue at decreasing rates for many years or until there is no more water available to continue the hydration.

Despite the considerable amount of research effort that has been expended upon hydrated portland cement, many aspects of this exceedingly complex material cannot be considered to be truly well understood. Active debate continues about some of the most fundamental points regarding its characteristics. One such discussion concerns a suitable choice of a model for its microstructure. Perhaps the single most important aspect of this debate concerns the specific surface area of the cement paste. There is no general agreement upon the magnitude of the true surface area or upon how this area should be measured. It was the purpose of this research to apply an as yet untried technique, low-angle $\mathrm{x}$-ray scattering, to the measurement 
of the specific surface of hardened portland cement paste.

Over the past decade a considerable number of papers have been written discussing various aspects of this surface area problem. The leading proponents of the two currently disputed points of view, S. Brunauer and R. Feldman, have recently summarized much of their research and findings in two papers $(1,2)$. Both workers cite large numbers of their prior papers in these two publications, and details of experimental matters are to be found in these citations.

The ideas of Brunauer and associates are founded on the earlier extensive work of Powers and represent a series of modifications to the "classical" picture of cement paste microstructure. The ideas of Feldman and his associates have evolved from interpretation of a unique series of investigations over the last decade, and have come to be synthesized as a so called "new model" of hydrated cement paste.

As regards specific surface, both models concern themselves principally with that portion of the cement paste composed of the calcium silicate hydrate gel. It has already been mentioned that hydrated lime and other products are present, and in incomplete hydrated pastes, residual anhydrous cement compounds are present as well. The influence of these phases upon the surface area is unclear 
but probably the major portion of the surface resides in calcium silicate hydrate gel.

It has been clearly established that tobermorite, a well crystallized calcium silicate hydrate considered to be related in structure to calcium silicate hydrate gel in cement paste, is a layered structure. Both Brunauer and Feldman consider that a similar sheet-like structure also exists in the much more complicated hydrates in cement paste; although they consider that it may be very much less well ordered. Both also believe that water occupies very narrow interstices between the sheets of this hydrate in saturated, never-dried cement paste. The space between these narrow sheets is usually referred to as "interlayer space".

The techniques that have been used by all workers to measure the surface area involve adsorption of vapors. All variants of this method require that the cement paste be dried and outgassed prior to beginning the experiment. Thus, only surface areas of previously dried cement pastes have been evaluated experimentally. Nitrogen and water vapor have been used as adsorbates, and the adsorption isotherms that have been produced have been interpreted with the aid of the B.E.T. theory (3). All workers making such measurements find the surface area of dried hardened cement paste to be $150-250 \mathrm{~m}^{2} / \mathrm{g}$ when water vapor is the adsorbate and 10-50 $\mathrm{m}^{2} / \mathrm{g}$ when nitrogen is used. It is the interpretation of these disparate results over which Brunauer and Feldman 
disagree and it is upon their respective interpretations that they have built their models for the microstructure of cement paste.

Brunauer has calculated theoretical estimates of the surface area of hypothetical calcium silicate hydrate gels composed of particles of unit layer thickness, and of 2and 3-layer thicknesses. The calculated estimates range from $755 \mathrm{~m}^{2} / \mathrm{g}$ for the single layer gel to respectively, 377 and $251 \mathrm{~m}^{2} / \mathrm{g}$ for the 2 - and 3 -sheet gel. He and his co-workers have measured surface areas of hardened cement, tricalcium silicate and dicalcium silicate pastes using water vapor sorption. The results have been calculated by estimating the content of calcium silicate hydrate gel in each paste and assigning all of the measured surface to the weight of this compound in each specimen. According to Brunauer, the results obtained fall between 243 and "nearly $600 " \mathrm{~m}^{2} / \mathrm{g}$ of calcium silicate hydrate gel.

Feldman agrees that the sum of the external and interlayer surface areas of calcium silicate hydrate gel is about $755 \mathrm{~m}^{2} / \mathrm{g}$, and has computed that, in mature cement paste, the sum of these is about 670 meters squared per gram of cement paste (which contains other constituents). However, he considers that measurement of surface area using water vapor is invalid in principle because he considers, in contradiction to Brunauer, that the interlayer spaces open up during the water vapor adsorption measurement 
process. Thus, there are differing amounts of surface available to water at different relative humidities. Feldman maintains that nitrogen is not adsorbed in the interlayer spaces and that the nitrogen surface area is a valid measure of the external surface of the calcium silicate hydrate gel.

The differences in interpretation are sufficiently strong and have been discussed so many times in the literature that a restatement of the principle points seems to be in order. Brunauer's ideas (1) may be summarized as follows. Upon drying, the layers of calcium silicate hydrate gel are thought to collapse upon each other and to close the interlayer space. This closure is irreversible and "the layers stick to each other with such force that even soaking in water does not separate the layers". Thus, Brunauer's picture considers the adsorption results are obtained upon a system which is locked permanently in the collapsed state. He believes that adsorption of water vapor gives the correct measurement of the external surface area of the collapsed system. The much lower value obtained with nitrogen is explained by the idea that the nitrogen is unable to reach all of the surface and nitrogen is hence recording an erroneous value. In support of these concepts he cites surface energy measurements which indicate a consistent relationship between water vapor surface areas and heats of solution measured on a series of pastes but no consistent 
relationship when nitrogen surface areas are used. He concludes that "nitrogen adsorption measures only a part of the surface, whereas water vapor measures the true and correct surface" (1).

Feldman (2) does not concur that the calcium silicate hydrate gel in cement paste maintains an unchanging character during the water vapor adsorption measurement. He does consider that the interlayer spaces do collapse upon drying. However, in a series of measurements of water vapor adsorption and desorption and associated length changes, he has found a hysteresis which he explains by the ability of water vapor to open and reenter the collapsed interlayer spaces. The extent of this reentry was considered to be related to the relative humidity (RH) and "not only had all the interlayer water reentered the sample after exposure to 85 percent $\mathrm{RH}$ but also it had done so progressively from low relative humidities". Feldman thus suggests that two different processes are taking place concurrently during a water vapor adsorption experiment. Some of the water is being adsorbed upon noninterlayer surfaces, and some is progressively reentering interlayer space. This reentering water penetrates more and more of the interlayer space as the relative humidity is increased. This being so, Feldman considers that a water vapor adsorption isotherm cannot be interpreted in the normal way and concludes that water vapor surface areas 
determined without taking the reentry into account are in error. The nitrogen measurements are taken by this worker to be valid estimates of the non-interlayer surface area. Thus, the exponents of both points of view consider that there is a larger interlayer area within calcium silicate hydrate gel. It is considered by both that water occupies the interlayer space and that this water can be removed by drying, the separated layers collapsing when the water exits. The essential point of difference rests on the question of the reversibility of this collapse. If it is taken as irreversible, then Brunauer believes that water vapor measures the correct surface area; if it is reversible, then Feldman believes that the surface area recorded for water vapor adsorption includes a contribution due to interlayer adsorption and is not a valid measurement of surface area.

It is useful to observe that the existance of interlayer spaces is based upon indirect measurement and supposition. X-ray diffraction provides a direct indication of the presence of interlayer space in the case on many clay minerals and well ordered calcium silicates such as tobermorite. However, cement paste is such a poorly cyrstalized and highly disordered system that it does not give a clear diffraction peak for a basal spacing as is found in clays and other well ordered layered systems. Nevertheless, the concept provides an explanation for a number of 
experimentally observed phenomena. Perhaps because of this, the existance of interlayer space has become increasingly accepted. However, while the concept does serve as an explanation for some phenomena and while there is no clear evidence that such spaces do not exist, there is also no hard evidence that they do. Alternate explanations for the phenomena observed are always possible.

This research was undertaken to provide a fresh approach to the question of the magnitude of the specific surface of cement paste. Low-angle x-ray scattering has been used to measure the surface area of a number of porous solids. However, it has never been applied to cement paste in an extensive investigation. I. E. Copeland of the Portland Cement Association has performed a single determination which has been cited by Brunauer but never published and details are not available. x-ray scattering offers an alternative to the sorption technique and has some significant advantages. One is that there is no drying required prior to the measurement. It is thus possible to measure the surface area of a saturated, never-dried cement paste as well as the surface area of dried pastes. Another advantage of low-angle $\mathrm{x}$-ray scattering is that it is not influenced by any specific interaction between adsorbate and adsorbent that may occur. It is also not dependant upon the assumptions that underlie the B.E.T. theory. Thus it provides an opportunity for independently assessing 
the magnitude of the surface area of cement paste and hence perhaps providing some resolution to the impasse between the two schools of thought that have been cited. 


\section{LOW-ANGLE X-RAY SCATTERING THEORY}

Low-angle $\mathrm{x}$-ray scattering has been used to determine a variety of microstructural parameters on a wide range of substances. Theoretical treatments are particularly well advanced for dilute systems, i.e. large organic molecules or small particles in dilute suspensions. Such systems do not exhibit interparticle scattering interference and permit theoretical treatment to a greater extent than do condensed systems. However, some theoretical developments have been worked out for densely packed systems that do exhibit interparticle interference. Among the parameters that can be measured is the specific surface area. The theoretical treatment used in this work was that due to Porod (4). Debye, Anderson and Brumberger (5) have also given a theoretical development which yields essentially the same result as Porod's treatment.

It is not the author's purpose here to critically discuss the details of Porod's theory, but it will be useful to briefly discuss the assumptions required and to present the resultant equations. These were used to calculate the specific surfaces reported here. 
Low-angle $\mathrm{x}$-ray scattering is closely related to the more widely known Bragg diffraction used for the study of atomic arrangements within crystals. In both cases, the reason for the scatter is the passage of the $\mathrm{X}$-rays through regions of differing electron density. The essential difference is that particles of colloidal size give rise to a diffuse scatter at low-angles in addition to the Bragg diffraction at somewhat larger angles. A consideration of the inverse relationship between the spacing, $d$, and the scattering angle, $2 \theta$, in Bragg's Law suggests that large colloidal size particles should give rise to scatter at correspondingly low angles.

Porod was able to relate the shape of the low-angle scattering curve to the specific surface of the particles giving rise to the scattering. It was necessary for him to make several assumptions about the material causing the scatter before he could do this. First, he assumed that the system was composed of only two phases, i.e. solid and pores. Secondly, it was assumed that each phase had a uniform electron density. It is seen that the theory covers cases in which the pores may be filled with any liquid or gas, as long as the electron density in the pores is uniform. The boundaries between the two phases were assumed to be sharp. In other words, the transition between one electron density and another across an interface 
was assumed to be abrupt. Lastly, the spatial orientation of the particles was assumed to be random.

With these assumptions Porod was able to show that there exists a function of the scattered $\mathrm{x}$-ray intensity at the larger angle or 'taill' portion of the low-angle scattering curve that is proportional to the specific surface of the boundary between the two phases. Specifically, he demonstrated that a particular function of the scattered intensity and the scattering angle should asymptotically approach a limiting value at increasing angle, and that this limiting value would be proportional to the specific surface. He first reexpressed the scattering angle as:

$$
h=\frac{4 \pi \sin \theta}{\lambda}
$$

$$
\text { where: } \begin{aligned}
\theta= & \begin{array}{l}
\text { one half of the angle, } 2 \theta, \text { between } \\
\text { the projection of the incident } x \text {-rays } \\
\text { and the scattered } x \text {-rays }
\end{array} \\
\lambda= & \text { the wave length of the } x \text {-rays }
\end{aligned}
$$

Then he demonstrated that:

$$
S_{V} \propto 4 \phi(1-\phi) K
$$

where: $\mathrm{S}_{\mathrm{V}}=$ the area of interface between the two phases per unit volume of irradiated sample

$\phi=$ the porosity of the sample

$K=$ the limiting value of the function $h^{3} I(h)$ as $h^{3}$ approaches infinity 
It is seen that $\mathrm{K}$ is the limiting value of the product of the intensity, $I(h)$, and $h^{3}$ as $h^{3}$ (and thus the angle $\theta$ ) becomes very large. Hence, for systems obeying Porod's Law, $h^{3} I(h)$ should reach a constant value in the 'tail' or larger angle region of the low-angle scattering curve.

This theoretical treatment must take into consideration the shape of the cross section of the incident beam of $\mathrm{x}$-rays. There are two shapes which are amenable to theoretical treatment. One is a beam with an extremely small circular cross section (called pinhole collimation), and the other is a beam with a long, extremely narrow rectangular cross section (called slit collimation). Equation 3 for the value of $k$ is given for the case of slit collimation which was the type of $\mathrm{x}$-ray beam used in this research. For the case of pinhole collimation, for which the parameters are expressed here as primed symbols, the relation for $\mathrm{K}$ becomes:

$$
K^{\prime}=\underset{h^{4} \rightarrow \infty}{\operatorname{limit}} h^{4} I^{\prime}(h)
$$

Equation 2 is expressed as a proportionality. This is so because the value of $\mathrm{K}$ is not simply a function of the specific surface, $S_{V} \cdot$ It is also related to the intensity of the beam of incident $x$-rays, a more intense primary beam yielding a larger value of $K$ for the same sample. Thus, $K$ must be normalized for the incident intensity before a surface area can be calculated. This 
normalization can be done by measuring the intensity of the primary beam. While this is simple in concept, it is experimentally very difficult because of the extremely high intensity, millions of counts per second, of any useful $x$-ray beam. Porod developed an alternative normalization method that was used in this work. He demonstrated that the area under the entire scattering curve could be used to effect the normalization. Specifically, he defined a quantity $Q$ as:

$$
Q=\int_{0}^{\infty} h I(h) d h
$$

Porod showed that $Q$ was not a function of the specific surface of the sample (an essential characteristic if it is to be used to normalize $K$ ) and called $Q$ the "invariant" for this reason. Expression 5 is for the case of slit collimation. The equivalent expression for the case of pinhole collimation is:

$$
Q^{\prime}=0^{f^{\infty}} h^{2} I^{\prime}(h) d h
$$

Thus, the complete equation used to calculate the specific surface for slit collimation is:

$$
S_{v}=\frac{4 K \phi(1-\phi)}{Q}
$$

If the surface is to be expressed on a unit weight basis rather than the unit volume basis of Equation 7 , it is 
necessary to divide by the bulk density, $\rho$, to obtain:

$$
S_{W}=\frac{4 K \phi(1-\phi)}{Q \rho}
$$

Equation 8 was used in this work with $\mathrm{K}$ being evaluated by Equation 3 and $Q$ by Equation 5 .

It is interesting to note that Porod's development does not specify which phase is to be solid and which pore. The system he considers is one such as is depicted in Figure 1 where a solid matrix A has pores or inclusions $B$. From the $\mathrm{x}$-ray scattering point of view, a completely equivalent system would be one shown in Figure 2 which has particles of A suspended in a matrix of B. If, for example, $B$ is the pore phase then the two systems are physically very different. Nevertheless, the interfacial area between phases $A$ and $B$ is identical in both figures and they will give rise to identical scattering curves. It is thus seen that pores can be thought of as scattering 'particles' suspended in a solid matrix.

One other aspect of low-angle $\mathrm{x}$-ray scattering theory was used in this research. This is Guinier's Law (6), which concerns itself with the shape of the scattering curve at very low angles. When the logarithm of the scattered intensity, $I(h)$, is plotted versus $h^{2}$ the resulting graph should become linear for exceedingly small values of $h^{2}$. Guinier's Law states that the slope of this linear portion will be proportional to the electronic 


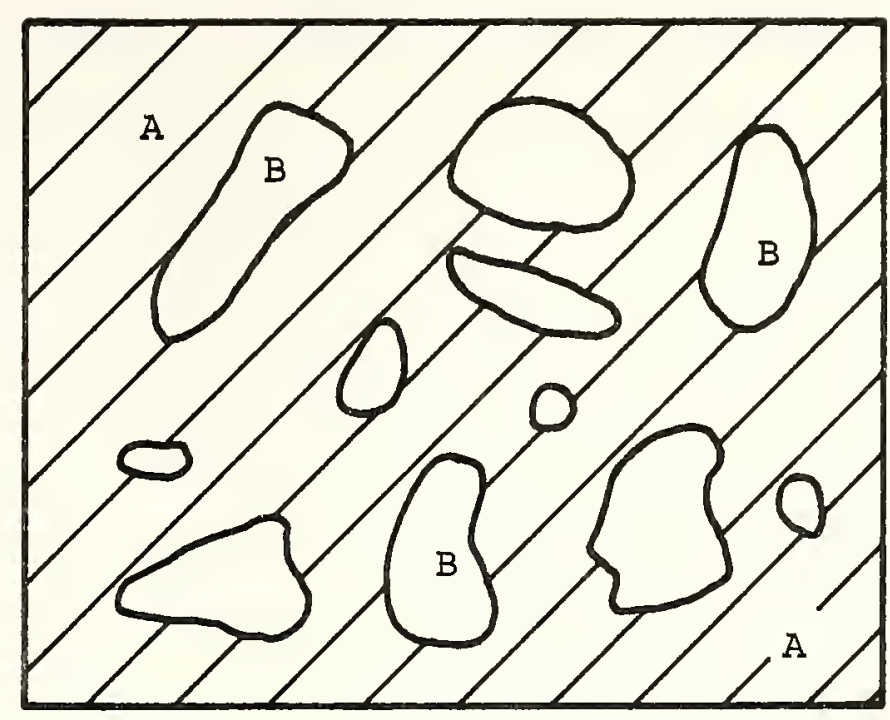

Figure 1

Pores in a Solid Matrix

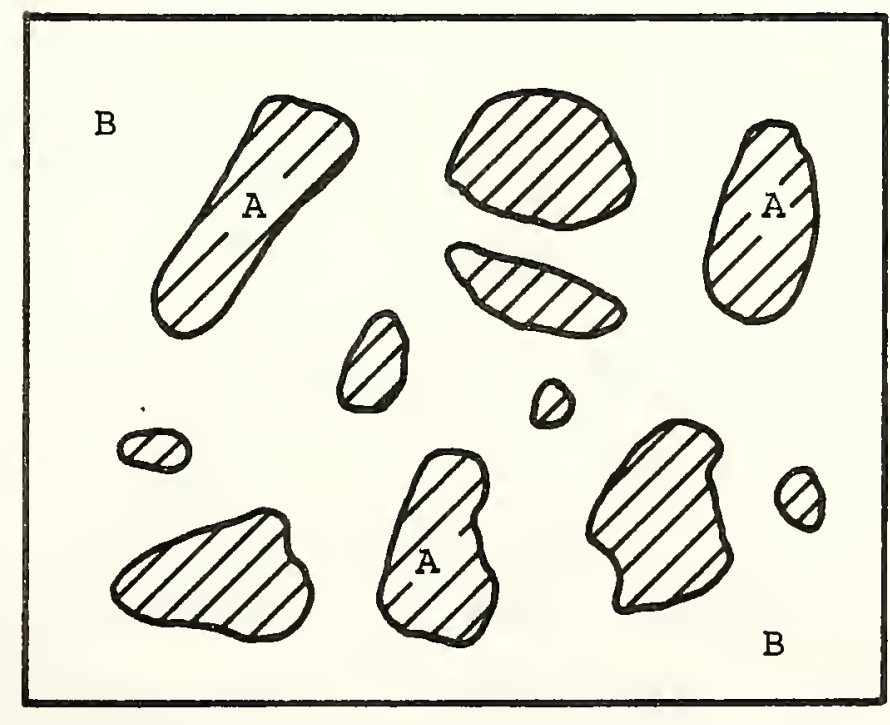

Figure 2

Suspended Particles 
radius of gyration of the scattering particles. The electronic radius of gyration is the root mean square of the distances of all the electrons from the electronic center of gravity of a particle and it is related to the size and shape of that particle. Thus, application of Guinier's Law should give an indication of the size of the scattering particles.

Guinier's Law is closely obeyed for extremely dilute systems of monodisperse, approximately spherical scattering particles. When a dilute system departs from monodispersity or from spherical shape the plot of $\log I(h)$ versus $h^{2}$ will no longer be linear as $h^{2}$ becomes larger. However, the limiting slope as $\mathrm{h}^{2}$ approaches zero is still related to the "average" radius of gyration of the scattering particles.

The relationship is:

$$
S=\frac{1}{3} \bar{R}^{2}
$$

where: $S=$ limiting slope of Guinier plot as $h^{2}$ approaches zero

$$
\bar{R}=\begin{aligned}
& \text { "average" radius of gyration of the } \\
& \text { scattering particles }
\end{aligned}
$$

The method of averaging the radii of gyration for different sized particles will be discussed later. The task of relating an "average" radius of gyration to some measure of particle size requires first the assumption of a particle shape. The relationship between radii of gyration and 
measures of size for a number of regular geometric shapes have been worked out (7). Thus, the average size of the scattering particles can be at least approximately determined from their "average" radius of gyration by assuming a reasonable shape.

It was stated that $\bar{R}$ was related to the limiting slope of the Guinier plot as $h^{2}$ approaches zero. It is generally impossible to obtain scattered intensity values in the neighborhood of zero scattering angle because of the presence of the very intense primary X-ray beam. Also, interparticle interference may mask the true scattered intensity at very small angles when the system is not sufficiently dilute. Because of these difficulties it is necessary to have some experimental evidence that data has been obtained at sufficiently small angles to provide an accurate measure of the limiting slope when $h^{2}$ approaches zero.

Cement paste is a poor system upon which to apply Guinier's Law. It is far from any of the ideal situations in which Guinier's Law is most closely obeyed. Nevertheless, it was applied in a Iimited way in this research. The applicability in such an extreme case as cement paste will be discussed later. 


\section{EXPERIMENTAL PROCEDURES}

\section{Materials}

The principle material investigated in the course of this research was hardened cement paste prepared from a typical ASTM Type I portland cement. The cement analysis and characteristics are to be found in Appendix A. Additionally, several hardened pastes made from alite, a tricalcium silicate stabilized by impurities, were examined. The alite was obtained from the late Alex klein of the University of California at Berkeley and its analysis is also given in Appendix A.

Two non-cement materials were used to check the experimental procedure and results. One was an illite clay from Fithian, Illinois, and the other, an activated coconut charcoal kindly supplied by Peter Sereda of the National Research Council, Ottawa, Canada.

\section{Preparation of Cement and Alite Pastes}

All of the cement pastes were mixed with deionized water in a bench-top Hobart mixer of the type designated in ASTM Standard Method: C-305, "Mechanical Mixing of Hydraulic Cement Pastes and Mortars of Plastic Consistency". 
The paste was mixed for 15 minutes and then cast in polypropylene test tubes one inch in diameter and four inches 1ong. The fresh cement paste was placed in the tubes in three layers and each layer was rodded 25 times in a manner similar to common ASTM procedure for preparing concrete samples.

The tubes were then sealed with a rubber stopper and allowed to rest, inverted, for ten minutes. They were then placed in a 'stopper up' position for ten minutes, reinverted for ten minutes and finally returned to their normal, vertical position. This procedure was designed to provide a more uniform paste by nullifying the effect of any sedimentation before initial set.

The stoppered tubes were stored in a fog room for 24 hours and then the specimens were demolded. To facilitate removal of the hardened paste the tubes were placed briefly in hot water. This expanded the plastic and allowed the sample to slide out easily on inverting the test tube. Demolding was done directly into a jar which was already filled with water saturated with $\mathrm{Ca}(\mathrm{OH})_{2} \cdot$ The specimens continued to hydrate under limewater in the jars at room temperature until they had reached the desired age for testing.

\section{Preparation of $\mathrm{x}$-Ray Scattering Samples of Cement Pastes}

Upon reaching the desired degree of hydration, the hardened cement pastes were cut into short pieces and 
prepared for test. A central portion, approximately $1-1 / 4$ inches in length was removed from each cylinder of paste and the ends were discarded as they may have been of nonuniform density. The central portions were then cut into four small plugs about one fourth inch long. The cutting was done with a diamond bladed saw, with saturated lime water used as the coolant. At no time were the samples allowed to dry. Some of these plugs were put aside for future characterization tests on the paste.

The rest of the short plugs were then sliced to form disc-shaped scattering specimens. This slicing was done on a saw normally used for preparing rock thin sections. It was necessary that the discs be very thin for efficient $x-$ ray scattering; a discussion regarding the optimum thickness for $x$-ray scattering is presented in Appendix $B$. It was found that the thin section saw, when operated under optimal conditions, could produce a slice as thin as $250 \mathrm{\mu m}$. Since the optimum thickness with respect to $x$-ray scattering proved to be in the range of 500-700 $\mu \mathrm{m}$, such slices could be made without undue difficulty. The plugs were mounted for slicing with a pressure-sensitive cement to avoid the heating normally incident to the mounting of thin sections with Lakeside or other thermoplastic cements. The portion of the paste near the pressuresensitive mounting was discarded to avoid the possible effects of contamination. As before, the coolant used was 
saturated limewater and the sliced specimens were never allowed the slightest opportunity to dry. Figure 3 is a view of some of the plugs and slices

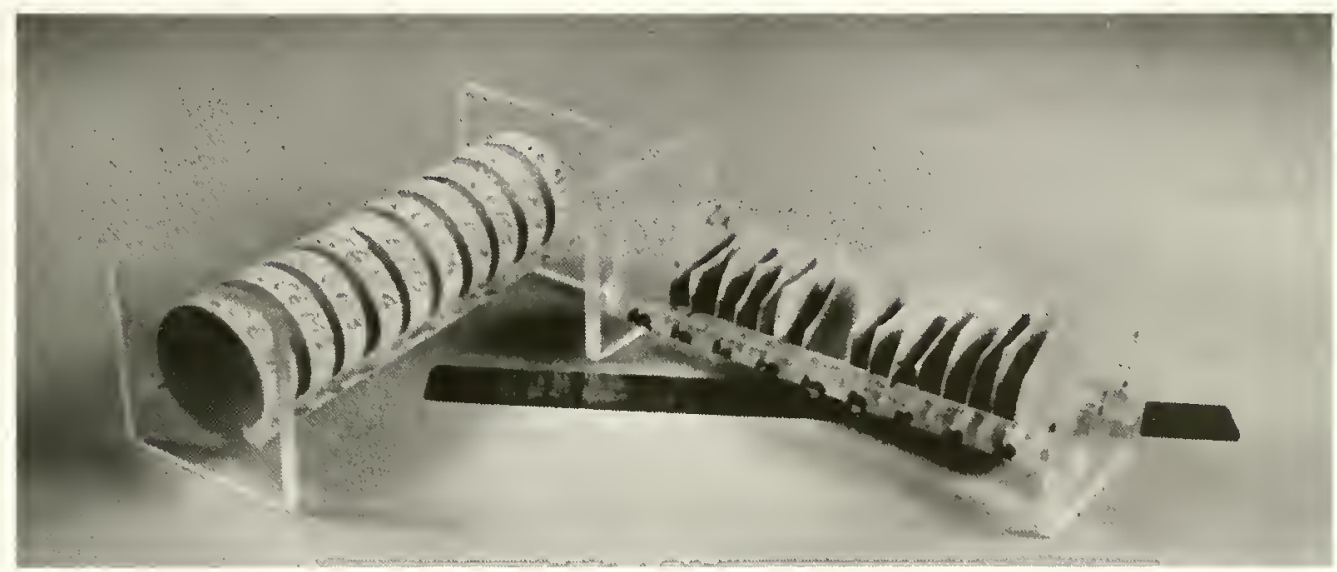

Figure 3

Cement Paste Plug and Slice Specimens in Drying Racks

\section{Drying of the Cement Paste Samples}

The cement paste samples were dried to one of six different states of dryness. Both the short plugs and the thin specimen slices were dried at the same time under exactly the same conditions. Special drying racks, as pictured in Figure 3, were used to keep each piece separated from its neighbors so as to facilitate the drying process. 
Two of the drying states were only of modest severity such as might actually be encountered by concrete in actual service. Both states were obtained by equilibration with water saturated with excess amounts of inorganic salts. The salts used were $\mathrm{Mg}\left(\mathrm{NO}_{3}\right)_{2}$, producing a relative humidity of $52 \%$, and LiCl producing a relative humidity of $12 \%$ (8).

The other drying states involved much more severe drying. Two were the familiar ' $P$ ' and ' $D$ ' drying conditions, traditional in cement research. To reach the ' $P$ ' dried state the sample is desiccated over a mixture of the diand tetra-hydrates of magnesium perchlorate which produces a partial pressure of water vapor of $8.0 \mu \mathrm{mHg}(9)$. 'D' drying involves equilibrating the sample with water ice while the latter is kept at $-78^{\circ} \mathrm{C}$, the sublimation temperature of solid $\mathrm{CO}_{2}$. This yields a partial pressure of water vapor of $0.5 \mu \mathrm{mHg}(10)$.

The two most severe conditions involved heating. In one case the samples were dried at $105^{\circ} \mathrm{C}$ in an oven under a blanket of carbion dioxide-free nitrogen to avoid carbonation. This process was carried out at a pressure of approximately one atmosphere. The most severe drying was performed in a vacuum oven, again at $105^{\circ} \mathrm{C}$, but this time the oven was continuously evacuated.

All of these drying procedures should have been continued until equilibrium with respect to weight loss was reached. The two oven drying procedures did reach 
equilibrium in 48 hours. However, for the various room temperature drying conditions, the samples continued to lose small amounts of water for extremely long times and true equilibrium may never be reached. Thus, an arbitrary operational definition of equilibrium was invoked. A sample was considered to have equilibrated when, in a 24 hour period, it lost less than $0.1 \%$ of the water it originally held. The one-quarter inch thick plugs were used to monitor the approach to equilibrium as the slices were too delicate to withstand the handing incident to repeated weighing. A typical sample required three or four months to reach the operational equilibrium. It is probable that the thin specimen slices, dried at the same time, were closer to true equilibrium than the plugs when the latter had reached the "0.1\% loss point".

\section{Special Treatments}

Some of the cement paste discs and plugs were given special treatments in lieu of the drying methods described above. The most important special treatment involved the resaturation of some specimens after they had been dried according to the previously outlined procedures. The samples were placed in a glass chamber and evacuated. Then, without breaking the vacuum, previously degassed, saturated limewater was admitted until the samples were completely covered. In trials it was found that water 
uptake had ceased after about one month of soaking in the chamber. However, the specimens on which $\mathrm{x}$-ray scattering was actually measured were left to soak for two months.

Samples in both plug and slice form were resaturated. The degree of resaturation was determined by measuring the saturated, surface-dry weight of the plugs only. The degree of resaturation was observed to be independent of the type of drying previously experienced by the samples, and, for the plug samples, averaged 98\%. The thin slice specimens were not handled because they were too fragile. Since they were very much thinner, it is thought that they might well have achieved close to $100 \%$ resaturation. This view is substantiated by the results of the $x$-ray scattering experiments that were later performed on them.

Two other special treatments involved heat. In one, pieces of the cement paste were sealed in a stainless steel bomb which was then heated to $105^{\circ} \mathrm{C}$, held at that temperature for 24 hours and returned to room temperature. Thus, the specimens were subjected to the same elevated temperature as used for oven drying but were never permitted to dry. Another variant heat treatment was a prolonged vacuum oven drying. Discs of the cement paste were dried in the vacuum oven exactly as stated previously but were kept in the vacuum oven for eight months instead of the two days required to reach equilibrium. Since carbonation of these pastes was more likely because of the prolonged time 
involved, to provide additional protection the samples were kept on a rack directly above a supply of an absorbent for carbon dioxide.

\section{Preparation of Samples Other Than Cement Pastes}

Specimens of illite clay and an activated coconut charcoal were used to check the X-ray scattering procedures. In neither case could these specimens be made to exactly the optimum thickness but both specimen types yielded reasonable intensities of scattered x-rays. The illite lacked mechanical cohesion and had to be approximately $50 \%$ thicker than optimum to be strong enough to handle. The charcoal had so small an X-ray absorption coefficient that the optimum thickness would have been too great to be accomodated in the X-ray machine and the thickness of the actual charcoal specimen used was about $50 \%$ of its optimum value.

The illite clay was first dispersed in deionized water, then dewatered to a thick, mud-like consistency by drawing the water out in a Buchner funnel. This mud was then spread into a Teflon mold to yield coin-shaped specimens of about the diameter and thickness of a U.S. quarter dollar. The clay and mold were then dried in an oven. The shrinkage of the clay caused it to pull away from the Teflon and the specimen was easily removable. The resulting specimens were solid discs of clay with enough strength to withstand careful handling. 
The charcoal could not be made self-supporting without the addition of some cementing agent. To avoid this contamination the specimens were packed into special holders which were mounted directly in the $\mathrm{x}$-ray machine. The holders were sections of one inch steel pipe about $3 / 8$ inch long, the ends of each were carefully faced to be parallel. A Mylar window, 0.001 inch thick, was cemented across one end of each holder. Then the charcoal was loaded into the holder with the aid of a vibrating table to help obtain a dense packing. The holder and charcoal were then oven dried and a second Mylar window was cemented across the open end of the holder. Thus a sealed plug was obtained which could be handled without disturbing the charcoal and through which $\mathrm{x}$-rays could pass.

\section{$\underline{X-R a y ~ A p p a r a t u s ~ a n d ~ M o d i f i c a t i o n s ~}$}

The low-angle scattering work in this research was done on a modified General Electric XRD-5 X-ray diffractometer equipped with vacuum tube electronics. A schematic diagram of the essential aspects of the scattering geometry is shown in Figure 4. The X-rays are first collimated into an extremely narrow beam by the beam slit collimator. They then pass through the sample and are scattered. Another set of narrow collimating slits is fixed to the detector, giving it a very narrow field of view. In operation, the detector is moved step-wise, and the intensity of the $\mathrm{x}-$ rays is sampled at successive angular positions. 


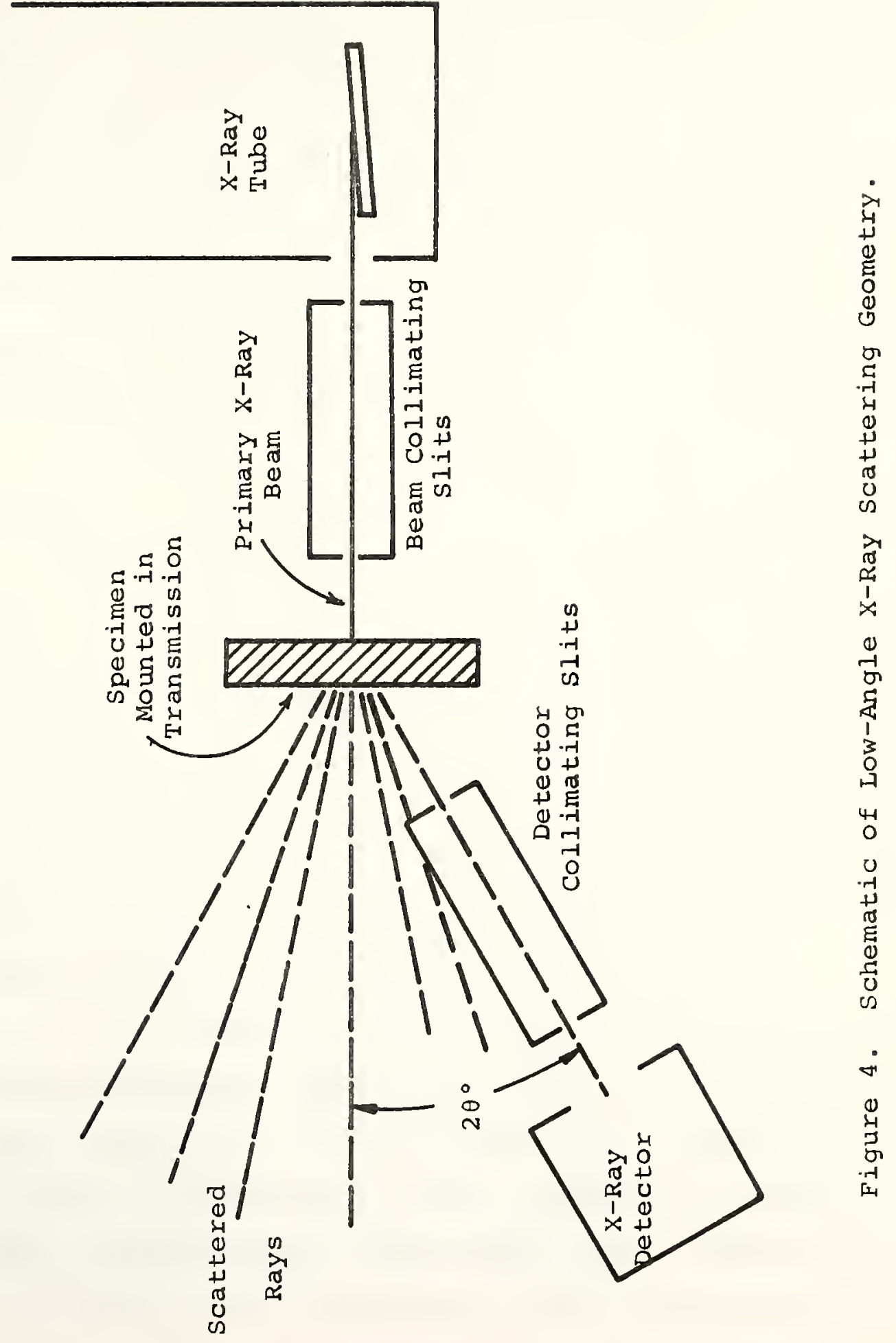


The diffractometer and its attendant accessories are shown in Figure 5. As discussed in Appendix B, the optimum thickness for a scattering sample is a function of the wave length of the incident radiation. To provide sufficiently penetrating radiation, an $\mathrm{x}$-ray tube with a molybdenum target was mounted on the diffractometer. It was operated at its maximum rating of two kilowatts and the tube was never turned off during an experiment to avoid the introduction of variations in $\mathrm{X}$-ray intensity that were found to occur on restarting the equipment.

The beam of $x$-rays that was used in a scattering experiment was much more narrowly collimated than is common in diffraction work. The narrow collimation was effected using tungsten knife edges placed parallel and very close to each other. The $\mathrm{x}$-rays were then required to pass between them. Two sets of such edges (the beam slits) were placed ahead of the samples and two more (the detector slits) between the sample and the detector. These slits, shown in Figure 6, were made especially for small-angle scattering work by the General Electric Company.

It was essential that these very narrow slits be aligned precisely, the alignment requirements for smallangle $\mathrm{X}$-ray scattering being much more stringent than for normal $x$-ray diffraction work. Often in the present study, shims were required to correct for slight imperfections in the machining of the parts of the diffractometer. 

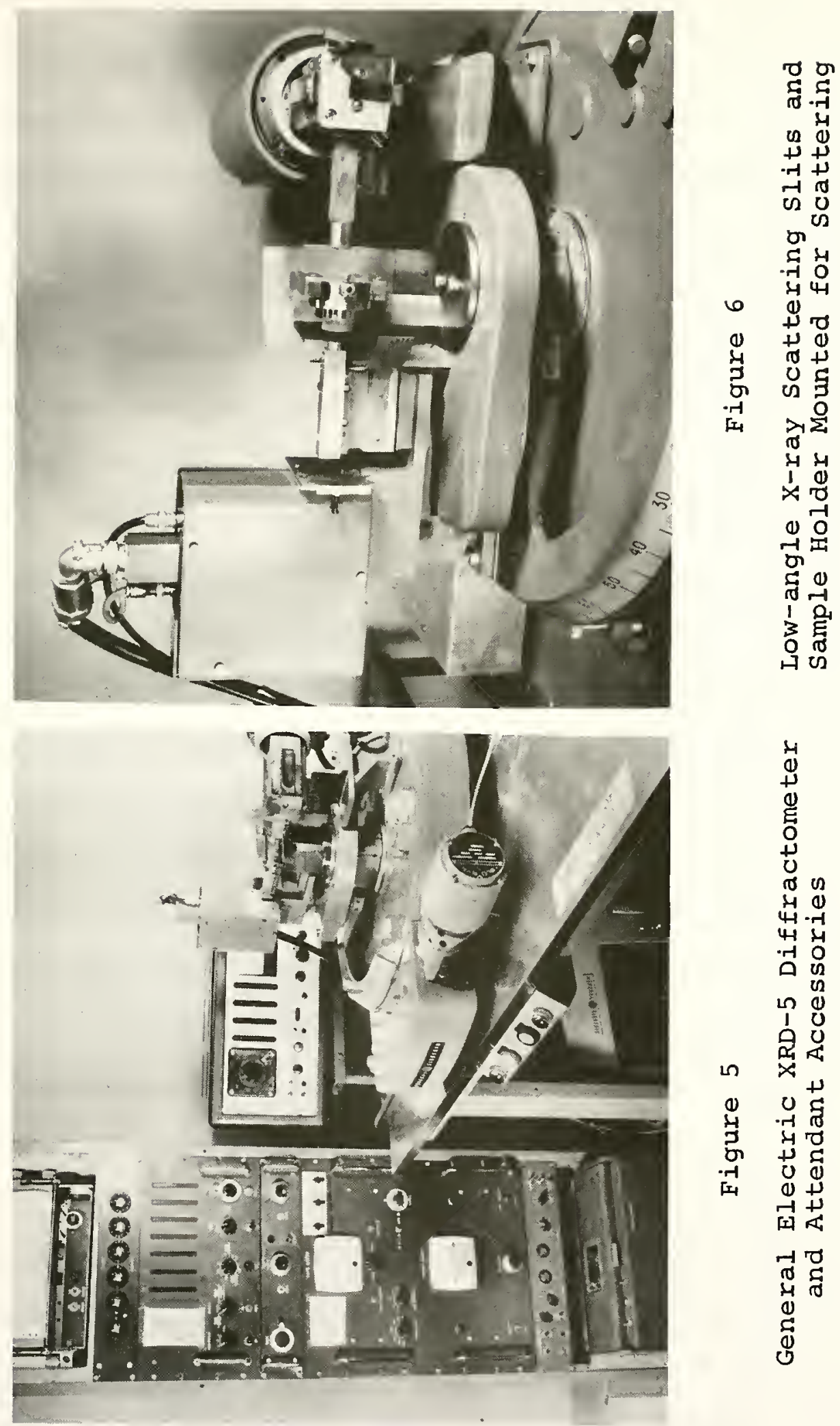
The beam slit produced a collimation with a spread of $0.05^{\circ}$ and the detector slit had a spread of $0.10^{\circ}$. The detector slit produced a broader sampling of the X-rays than desirable but its use was necessary for stability reasons. Very small lateral movements of the primary $\mathrm{x}$-ray beam resulted in its loss of alignment with the detector slit. Thus, the detector would 'see' a somewhat different part of the beam and this would register as an artificial change in intensity. By using a detector slit that was wider than the beam, the 'field of view' of the detector was sufficiently broadened so as to minimize the difficulty caused by these slight movements.

The GE XRD-5 diffractometer was modified in a number of ways. A rather large chamber was used to house the cement paste during the tests and this could not be fitted into the normal mount. A new sample mounting post was made and can be seen in Figure 6. In use, this mounting was placed in the holes provided on the XRD-5 for transmission work. That is, the plane of the sample support on the mount was perpendicular to the plane of the incident beam of $\mathrm{x}$-rays.

It is necessary to monochromatize the $x$-rays to analyze the scattering data. Only two methods of obtaining monochromatic radiation were readily applicable to the machine and these were tested and compared. One was the technique of balanced filters, also called Ross filters (11), which 
involved obtaining two complete sets of scattering data using. two different metal foil filters. The arithmetic difference of these sets was the desired monochromatic intensity. The other method involves electronic pulse height discrimination of the pulses being emitted by the scintillation detector used to detect the $x$-rays, the pulse height being a function of the $\mathrm{x}$-ray wave length. Discrimination is accomplished by properly setting a pulse height filtering circuit provided with the diffractometer electronics. The former method gives the better monochromatization but the latter technique requires that only one set of scattering data be obtained. Two separate scans of the sample introduced very large fluctuations in the measured intensities since all of the error made in each separate measurement was pooled when the difference of the two was obtained. After comparing results obtained with the two methods it was decided that the lesser selectivity of the discriminator was preferable to the inaccuracies of the intensity data of the balanced filter technique. Thus, all work reported here was done with a pulse height discriminator.

It is common to use a single metal foil filter, a $K \beta$ filter, with the pulse height discriminator. This filter is selected so as to absorb some of the $\mathrm{x}$-rays that have wave lengths shorter than the desired $K \alpha$. The normal General Electric filter holder supplied for the $\mathrm{K} B$ filter 
was exchanged for a specially designed mount which held the foil much closer to the detector. This was done to facilitate the measurement of parasitic scatter which will later be discussed in detail. The change of holder in no way altered the effect of the $\mathrm{k} \beta$ filter on the radiation.

The diffractometer required significant modifications to permit step scanning. The step scanner used a slo-syn stepping motor to position the goniometer, and associated electronics to control the motor. The minimum step size obtainable from the motor and controller was $0.0025^{\circ} 2 \theta$. It was also necessary to have a printer to record the intensities at each step.

The step scanner for the XRD-5 diffractometer is only capable of operating in the preset-time mode. That is, at each step, the machine can only record the number of x-rays counted over some period of time previously selected by the operator. The intensities that were measured in any one of the scattering experiments performed in this work varied over.four orders of magnitude. In such a circumstance the preset-time method of counting either yields data of varying accuracy over different ranges or is very wasteful of time. To obtain uniform accuracy and to do the experiments in a reasonable time, it was desirable to operate the step scanner in a preset-count mode. In the preset-count mode the detector counts a previously 
selected number of $\mathrm{x}$-rays and the time required for this is the variable which is obtained.

A considerable amount of electronic modification was necessary to convert the diffractometer to preset-count step scanning. The modified equipment operated as follows: pulses from the detector were fed into an auxiliary scaler (Radiation Instrument Development Laboratory; (R.I.D.I.); Model 49-54), which accumulated the x-ray counts, and was preset to the number of counts desired. The standard General Electric scaler, with which the XRD-5 was equipped, was used as a timer by feeding it with the 60 pulses per second coming from the alternating line current. When the R.I.D.I. scaler had reached its preset count, the G.E. scaler showed the elapsed time and this was printed. Then the stepping motor was activated, both scalers reset and the process repeated after the detector had been moved to and stopped at a new angle.

The last modification involved the method of containing the cement paste samples during a test. Depending on drying treatments, a particular sample might range in moisture content anywhere from saturated to exceedingly dry. In all cases, the moisture content had to be held constant during the test. A special specimen chamber was made which is shown disassembled in Figure 7 and assembled with a specimen in Figure 8. The chamber was equipped with a Mylar window at either end to allow the $\mathrm{x}$-rays access to 


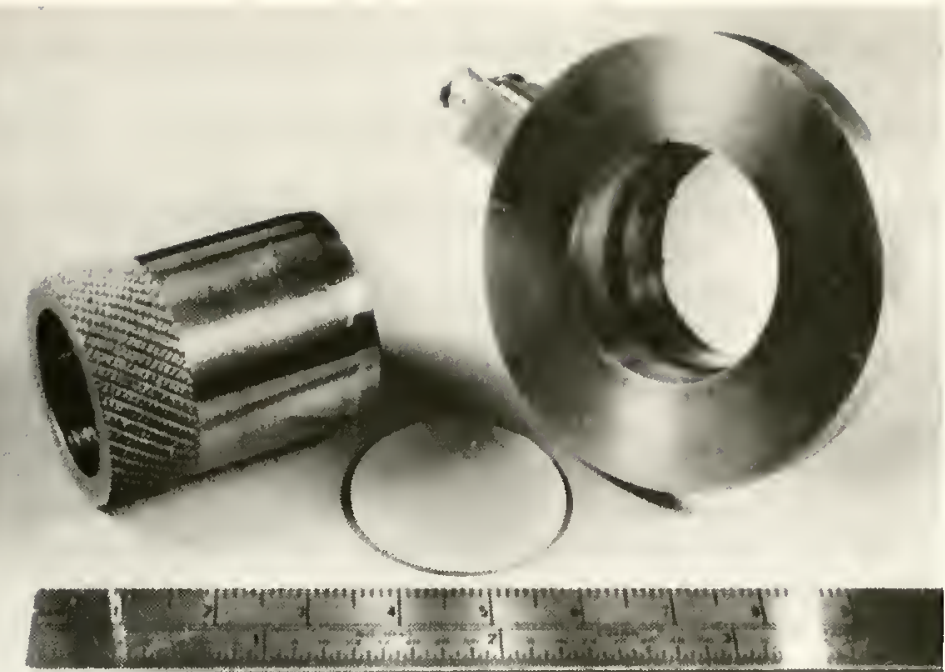

\section{Figure 7}

Disassembled Sample Holder and Cement Paste Slice Specimen

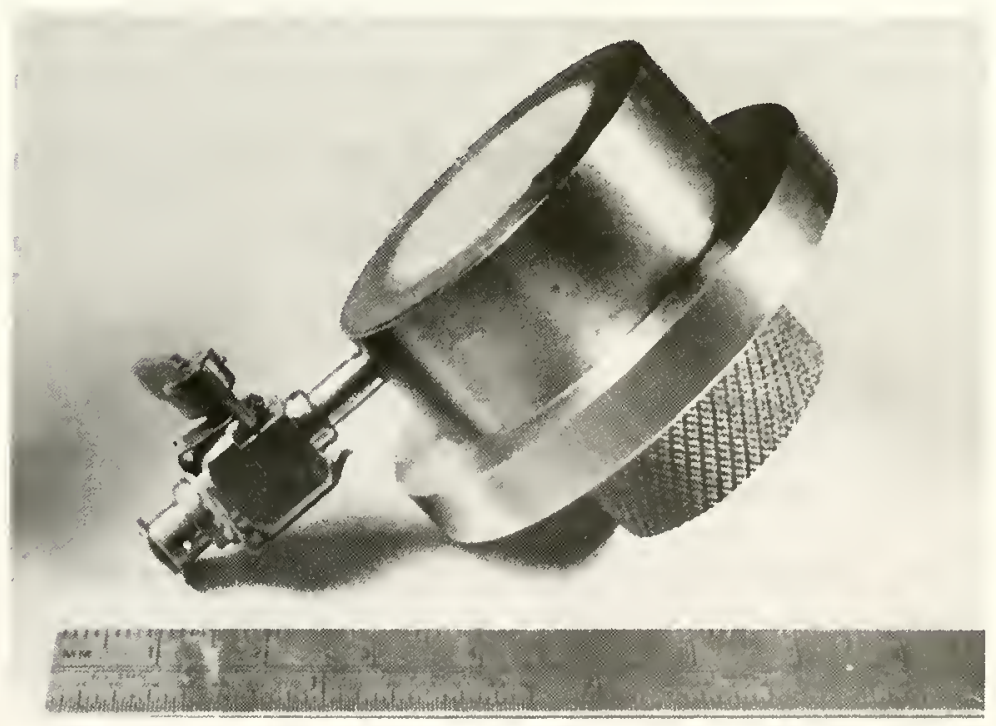

Figure 8

Assembled Sample Holder with Cement Paste Slice Specimen Installed 
the sample. One end could be slid in and out on an o-ring seal to conform to the thickness of any particular specimen. A small valve was added to allow the escape of air lor water) while the chamber was being closed. This valve was closed when the sliding end had been moved into contact with the sample. In this way, any specimen could be completely isolated from the ambient atmosphere in a chamber of minimum thickness in the direction of the direction of of the x-ray beam. This restriction on thickness is helpful as thick walls absorb more X-rays and accordingly reduce the intensity.

\section{X-Ray Intensity Measuring Strategy}

It can be demonstrated that the statistical error of an $\mathrm{X}$-ray intensity measurement is inversely proportional to the square root of the number of X-rays counted (12). Thus, the greater the number of counts obtained the less will be the error in the measured intensity. If 100 counts are registered, the relative standard error is $\pm 10 \%$, with 400 counts the relative standard error is $\pm 5 \%$ and with 10000 counts it is \pm 18 . It is evident that modest increases in accuracy necessitate huge increases in the number of $\mathrm{x}$-rays registered. There are only two ways on increasing this number: either the intensity of the $\mathrm{x}$-rays must be increased, or the time allotted to counting the $\mathrm{x}$-rays must be lengthened. In this research the $\mathrm{x}$-ray tube was operated for its maximum output and the specimen 
thicknesses were adjusted to give the maximum scattered intensity. Thus, the only remaining variable was the time spent counting each individual intensity. Selection of an optimum amount of time in this present work involved two distinct problems. The first was simply the length of time required to do the research. The work reported here involved 5400 hours of X-ray machine time, about 225 complete days. This time was needed for a comparatively modest suite of tests and had a direct bearing on the size of that suite. The second problem was due to the fact that the diffractometer exhibited long-term, random drifts in $x$-ray intensity. As the amount of time required for an individual experiment was increased, so also was the amount of drift experienced during the test and, so also its precision was decreased. As a result of the above factors the strategy used in measuring the $\mathrm{x}-\mathrm{ray}$ intensities was necessarily a trade-off between desired accuracy on one hand, and inherent machine instability and the number of individual experiments that could reasonably be included in the research program on the other.

In discussing the counting strategy it is useful to divide the low-angle region measured into three parts. The division is a natural one based on the particular counting problems encountered at different angles and the importance, relative to the accuracy of the surface area measured, of different segments of the scattering curve. 
Figure 9 shows a summary of the entire counting strategy.

The first segment of the curve is the very-low-angle region between $0^{\circ}$ and $0.15^{\circ} 2 \theta$. This region is very important for two reasons. First, it is here that Guinier's Law pertains and any chance of measuring an average pore size hinges on exceedingly accurate data in this range. Secondly, it proved impossible to make measurements within the direct beam of $\mathrm{x}$-rays because the intensity was too great. So, the data obtained at the very smallest possible angles had to be used to extrapolate the scattering curve back to $0^{\circ}$. Measurements in this range were made difficult by the fact that the intensity was very high. Intensities of 100,000 counts per second were not uncommon and the question of the dead time of the detection system became very important. The nature of this dead time and the correction for it are discussed fully in Appendix C.

With consideration for both the importance and difficulty of the measurements, the following strategy was adopted. No data could be taken at angles less than $0.05^{\circ} 2 \theta$ as this region was blanked out by the primary x-ray beam. Between $0.05^{\circ} 2 \theta$ and $0.08^{\circ} 2 \theta$ intensities were recorded every $0.0025^{\circ} 2 \theta$, at 13 positions in all. Between $0.085^{\circ} 2 \theta$ and $0.10^{\circ} 2 \theta$ intensities were recorded every $0.005^{\circ} 2 \theta$, four positions in all. Finally, intensities were recorded at $0.12^{\circ} 2 \theta$ and $0.15^{\circ} 2 \theta$. In the very-low-angle region the 


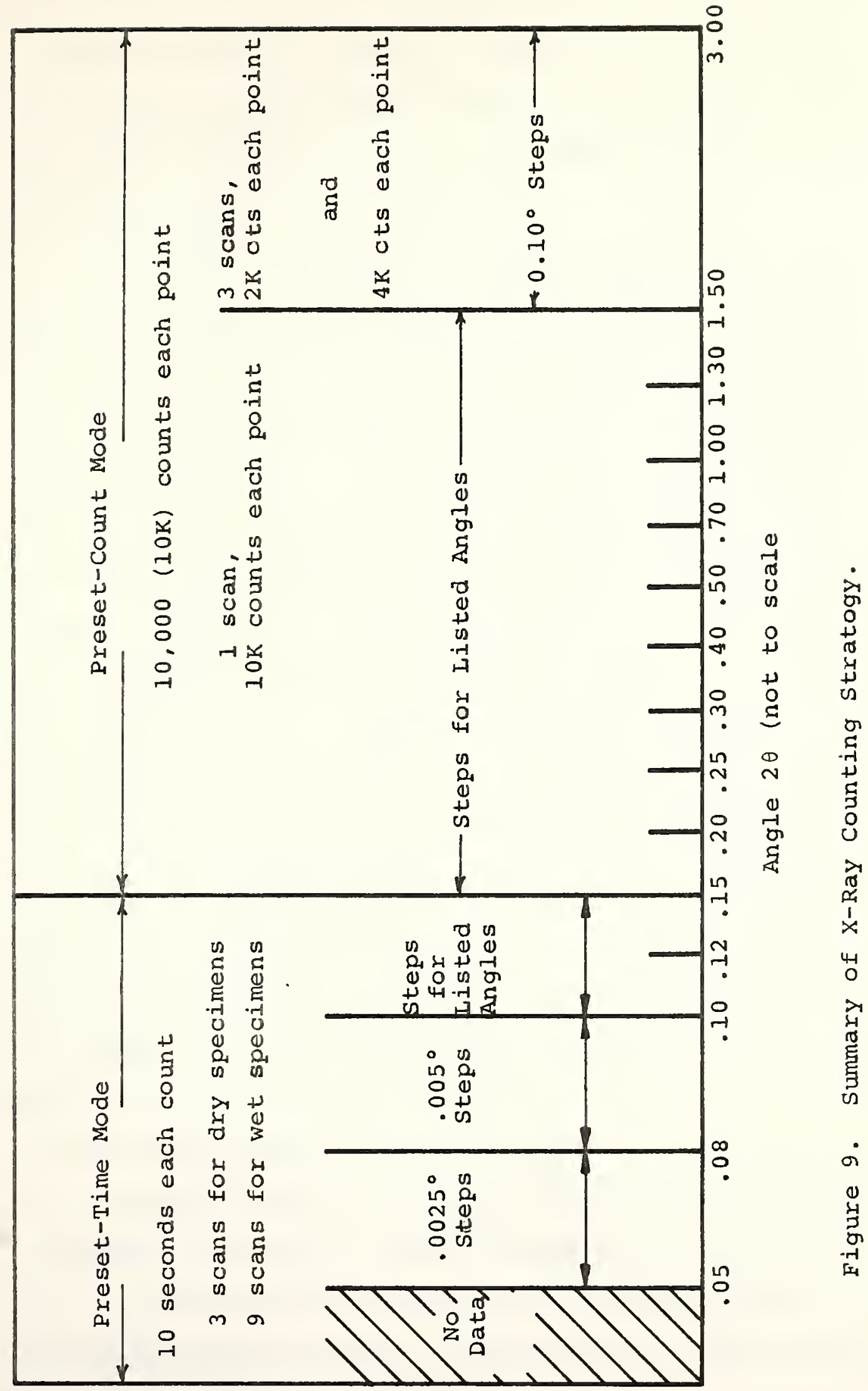


preset-count mode of operation would have involved very short time periods because of the very high intensities. Hence, in this region only, the equipment was operated at the preset-time of ten seconds.

All of the points in this region were scanned three times when nonsaturated samples were being tested. The average intensity of the three measurements at each point was used. This was necessary to damp out variations in any single measurement. It should be noted that even slight variations are greatly magnified by the nature of the deadtime correction equation. The saturated samples had a lesser difference in electron density across the solidpore interface and this decreased the intensity of the scattered radiation. Because of this, the relative importance of the very-low-angle region upon Porod's invariant was greater. So, the entire process of three scans was repeated three times on slightly different portions of the specimen. This improved the accuracy of this region by giving nine intensity measurements to average at each angle. The sample was moved after each set of three scans to damp out the slight intensity variations caused by inhomogeneities in the cement paste.

The next segment of the scattering curve, the easiest to measure, covered the region between $0.20^{\circ} 2 \theta$ and $1.30^{\circ}$ 20. In this region the scattered intensities were high enough so that the region could be scanned expeditiously. 
The relative importance of this region to the calculated specific surface was minimal. Thus, at least for the samples tested, this region was both easy to measure and not critically important.

A single intensity measurement was made at each angular position. The intensities in this region, although relatively high, were low enough to require the preset-count mode of operation. At each position 10,000 counts were accumulated. The angular positions that were chosen were: $0.20^{\circ}, 0.25^{\circ}, 0.30^{\circ}, 0.40^{\circ}, 0.50^{\circ}, 0.70^{\circ}, 1.00^{\circ}$ and $1.30^{\circ} 2 \theta$. The selection of these nonuniform steps was based on their effect upon Porod's invariant, a value which must be accurately evaluated to produce the specific surface measurement. They were selected so that, as nearly as possible, the area under the scattering curve between any two successive angular positions would be the same. In this way no single error in intensity measurement could unduly bias the measurement of the invariant. The third angular region lies between $1.60^{\circ} 2 \theta$ and $3.00^{\circ} 2 \theta$. This region is critically important to the result as it is in this tail of the scattering curve that the porod plot becomes asymptotic. Any error made in determining the value of the asymptote is directly reflected in the specific surface measurement. In this region the step size was held at a constant $0.10^{\circ} 2 \theta$. This gave 15 intensity measurements and tended to negate the 
effect of any one or two points that might have been erroneous. Data was not gathered at angles larger than $3.00^{\circ} 2 \theta$. Initially, points at larger angles were secured but the surface area results were no different than those obtained by stopping the test at $3.00^{\circ} 2 \theta$ and considerably more time was required to perform the extended measurements. In this region the intensities were low; typically they ranged between one and five counts per second. Thus, accumulating 10,000 counts at each point generally consumed between 10 and 12 hours for a single test. In such a long time the drifts in intensity of the diffractometer became important. A strategy of successively traversing the entire region, point by point, was often accompanied by enough drift to obliterate the asymptote. To damp out the effects of the drift the entire region was scanned four or five times. On each pass either 2000 or 4000 counts were accumulated at each point. Enough passes were made to total 10,000 counts at each angle. The counts for all the passes, at each point, were added and the resulting scattering curve was a composite of several scans across the region. In this way the effect of any drift was negated by spreading it across the entire angular region. Originally, five scans of 2000 counts were made. However, it was found that three scans of 2000 counts and one scan of 4000 counts produced just as satisfactory a result. 
This latter scheme was adopted as it permitted an easier testing schedule.

The relationship between accuracy and number of counts was the underlying principle of the strategy outlined above. Other factors aside, the principle that was followed was that 10,000 counts would be accumulated at every position. However, a counting time of less than ten seconds was never used. Errors in measuring the time could have been important for very short timing periods. So, a fixed time count of ten seconds was adopted whenever 10,000 counts could be accumulated in less than ten seconds. This kept the error in each intensity measurement to $\pm 1 \%$ or less.

\section{Parasitic Scatter}

The scattering curve that is used to calculate the specific surface of a sample must include only the intensity of scatter from the sample. Unfortunately, the $\mathrm{x}$-rays are also scattered by the collimating slits and the air along the path of the $\mathrm{x}$-rays. It was necessary to measure this parasitic scatter and to subtract it from the total observed scatter to obtain that scatter due solely to the sample.

Simply removing the sample from the machine and repeating the experiment without any sample would not yield a usable measure of the parasitic scatter. This was so because the absence of the sample would raise the measured 
intensity of the $\mathrm{X}$-rays, there being no sample to absorb some of them. What was required was a method of measuring the X-ray intensities attenuated by the sample's absorption, but not altered by its scattering power. That is, one wanted to repeat the experiment and have the sample merely absorb but not scatter X-rays.

This was accomplished by moving the sample from its normal position and replacing it in a position very close to the detector. In this position the sample still absorbed and scattered x-rays, but it was now so close to the detector that all of the scattered X-rays were recorded by the detector. Thus, as registered by the equipment, the sample seemed to be no longer scattering $x$-rays but merely absorbing them. Dr. H. Leopold of the University of Graz, Graz, Austria suggested this technique; a diagram demonstrating it is given in Figure 10.

The previously mentioned alteration to the $K \beta$ filter holder on the diffractometer was effected to allow the placement of the sample very close to the detector. After the scattering curve had been measured as previously discussed, a test was carried out with the sample moved to its parasitic scatter position. The sample was still contained in its Mylar envelope and care was taken to expose the same part of the specimen to the $\mathrm{x}$-ray beam, so as to maintain exactly the same absorption of $x$-rays for both positions. The parasitic scattering curve was 

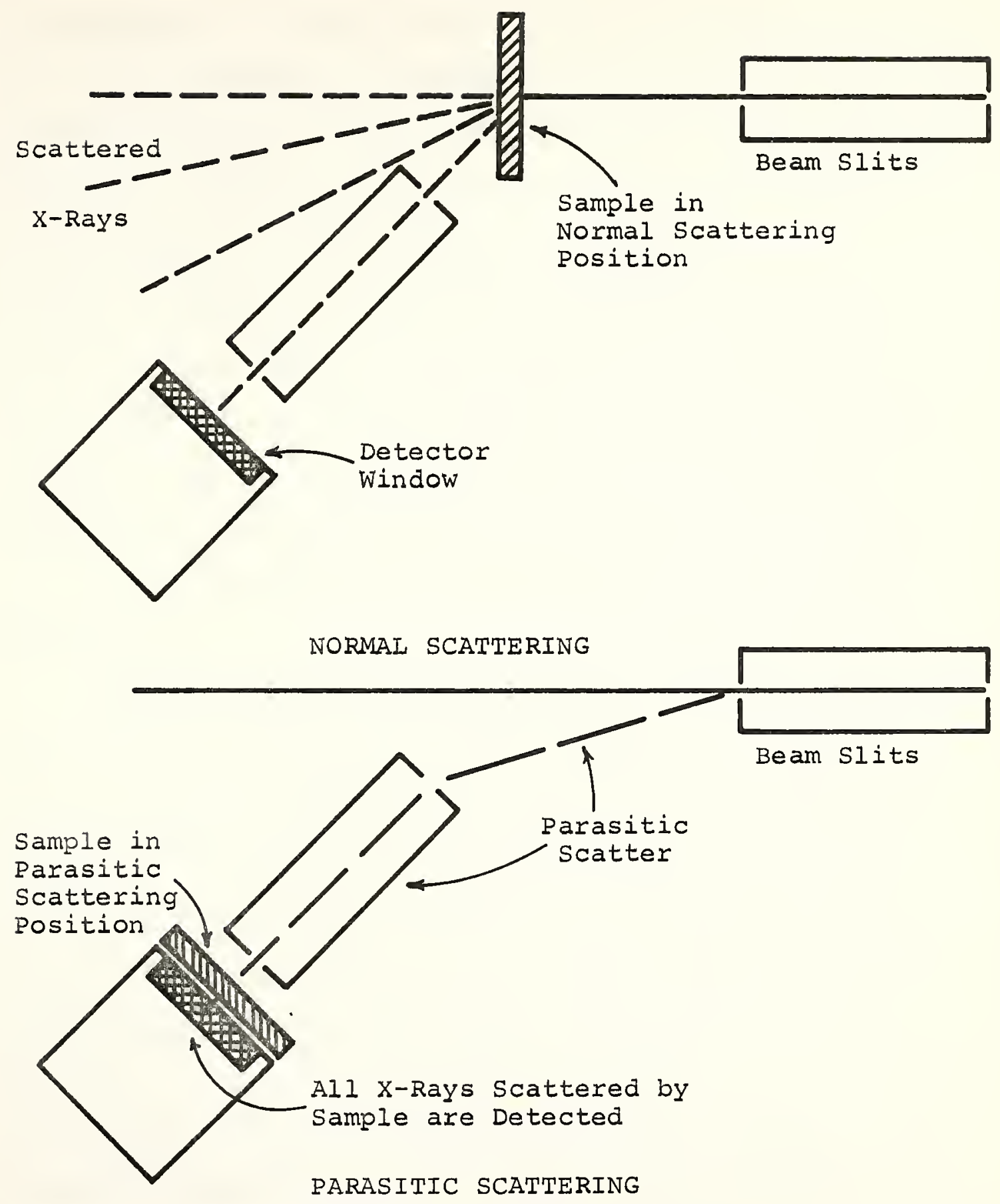

Figure 10. Technique for Parasitic Scatter Measurement. 
then measured and was found to be of significant intensity only over the angular range from $0^{\circ}$ to $0.15^{\circ} 2 \theta$. The parasitic scattering originated mostly from widely spaced scattering centers, and thus the intensity of the parasitic scatter at larger angles was exceedingly low. A number of tests were conducted in which the parasitic scatter was measured to much larger angles than $0.15^{\circ} 2 \theta$. The exceedingly small correction that resulted was judged not worth the additional 36 hours per test required to measure the complete parasitic scattering curve and the $0^{\circ}$ to $0.15^{\circ} 2 \theta$ range was adopted as standard for this measurement.

Exactly the same counting strategy was used to measure the parasitic scatter as was described for the angular range between $0^{\circ}$ and $0.15^{\circ} 2 \theta$. Thus, for dry samples the very-low-angle region was scanned a total of six times: three for total scatter and three for parasitic scatter. The measurement of the parasitic scatter was always made immediately following the total scatter very-low-angle measurement, to minimize inherent changes in the primary $\mathrm{X}$-ray beam intensity between the two sets of scans. For saturated specimens, a total of nine scans was made in the very-low-angle region. It was felt that machine drift might be noticeable during the time (about 45 minutes) required for nine scans. Thus, a modification to the counting strategy was made so that three "normal" scans 
alternated with three "parasitic" scans until nine of each were obtained. The order was: three "normal" and three "parasitic" scans for one location on the sample, then three "normal" and three "parasitic" scans for a second location and finally, three more "normal" and three "parasitic" scans for a third position on the sample.

\section{Sample Porosity}

It is necessary to know the porosity of a sample before its $x$-ray scattering curve can be converted to a specific surface. The amount of scatter is controlled, in the final analysis, by the probability that an $\mathrm{X}$-ray will traverse one or more pores in the sample. A value for the porosity hence is required in order to reduce the scattering data to a surface area measurement.

The porosity of a solid is defined as the ratio of the pore volume to the total bulk volume. Bulk volumes were measured for all samples by displacement in mercury. The pressure upon the mercury was adjusted so that it would not penetrate pores smaller than $100 \mu \mathrm{m}$ in diameter. Thus, the bulk volume obtained was actually the total, exterior volume of the sample less the volume of any pores with $100 \mu \mathrm{m}$ or larger connection to the exterior. Evidence (13) is available to show that such large pores are not to be expected in the materials examined and the mercury displacement technique registered the true bulk volume. 
The pore volumes of the illite clay and the charcoal were easy to obtain. Both materials possess an unambiguous solid density. This density could be used to calculate the volume of solid in the porous mass. The pore volume was then obtained by the difference between the bulk and solid volumes.

Unfortunately, the density of hydrated cement solids is difficult to evaluate without ambiguity. This is so because there is no clear-cut way of separating the water of hydration from some of the water held in the smallest pores. Because of this uncertainty an arbitrary definition of the pore volume was adopted. It was observed that the driest state from which all of the surface area could be recovered upon resaturation was the 'D' dried condition. Thus, it seemed that all of the water removed when a sample was ' $D$ ' dried might be coming solely from pores. So, for this work the volume of pores was defined as the volume of water removed from the sample when it was dried from the saturated surface-dry state to the ' $D$ ' dried state. This determination was done gravimetrically and a water density of $1 \mathrm{~g} / \mathrm{cc}$ was assumed to compute the volume. An alternate definition might be based upon the slightly less rigorous ' $P$ ' drying. This was also used in trials and specific surfaces were computed on both ' $P$ ' and ' $D$ ' dry bases. The ' $P$ ' dry basis gave areas which were only about $3 \%$ less than the ' $D$ ' dry basis because 
of the way in which the porosity enters into the surface area equation. ' $D$ ' drying was finally preferred as the basis since it was the most rigorous drying which exhibited complete area recovery upon resaturation.

The volume of water that is removed from a sample upon drying is actually representative of the volume of pores present in the saturated sample. As water empties from these pores the sample shrinks. It is likely that most of the shrinkage is the result of a lessening of pore volume rather than solid volume. Thus, in the dry state, the volume of pores is not exactly the volume of the water removed but is this volume diminished by the shrinkage. The linear shrinkage of each of the cement paste samples was determined as the discs dried to each of the drying states. This was done by measuring the saturated and the dried diameter of each scattering disc with a micrometer with a sensitivity of 0.0001 inch. This method is not the most accurate way of measuring the shrinkage of cement paste but it was felt to be adequate for the purposes of making a correction to the porosity. The cement was assumed to shrink isotropically and the volume shrinkage was calculated using the assumption that it was three times the linear shrinkage. This latter assumption is accurate for the small shrinkages considered here.

Several other factors must be considered before a calculation of the porosity is possible. Although the 
desired porosity is in terms of the ratio of one volume (pores) to another volume (bulk), in measuring these one must use different samples. The volumes must therefore be related to some consistent weight basis. Owing to the definition of "volume of pores" adopted, all values will be in terms of a volume of pores per gram ' $D$ ' dried. However, the bulk volumes were measured for each particular state of dryness and are expressed in terms of a volume per gram of cement paste in whatever state of dryness is being considered. If this state is not the ' $D$ ' dried state then the pore and bulk volumes must be put on the same weight basis before their ratio can be computed. The ignited weight was used to put the various numbers on the same weight basis. Some of the plugs of each paste at each condition of dryness were ignited at $1050^{\circ} \mathrm{C}$ according to generally accepted procedures (14). This allowed the calculation of the ratio of the weight of cement paste dried to any condition to its ignited weight, which is assumed to be the same as the weight of the cement originally present. Actually, any condition of dehydration to which all samples had been brought would have served just as well but the condition of ignition at $1050^{\circ} \mathrm{C}$ seemed a good choice as equilibrium was quickly attained at this temperature. The ratios determined in this way were used to place all volumes on a similar basis before calculation of the porosity. 
There remained one last difficulty. It would have been difficult to measure the bulk volume of the saturated specimens by mercury displacement because of the presence of the water. Consequently, this bulk volume was calculated from the bulk volume of a dried sample in the following way. First, the measured dry volume was corrected for shrinkage to adjust it from the dry state back to the saturated condition. At this point the result would be in terms of saturated volume per dry gram. Since the desired terms are saturated volume per saturated gram, the weight of water removed was added to the dry weight to estimate, finally, the volume and weight of the paste in its original saturated condition.

The following is a step-by-step sample calculation of the porosity. Consider the case of a mature, $w / c=0.4$ cement paste equilibrated at $12 \%$ relative humidity. The experimentally determined values that are needed are:

1. Mature, $w / c=0.4$ samples have a pore volume of 0.1770 cC per gram ' $D$ ' dried.

2. The $12 \%$ relative humidity sample had a linear shrinkage of $0.71 \%$.

3. The bulk volume of the sample by mercury displacement is $0.5543 \mathrm{cc}$ per gram dried at $12 \%$ relative humidity.

4. 1.2912 grams of cement paste dried at $12 \%$ relative humidity will weigh 1 gram when ignited at $1050^{\circ} \mathrm{C}$ and there are 1.2100 grams of ' $D$ ' dried cement paste per ignited gram. 
The volume of pores corrected for shrinkage is then:

$$
0.1770(1-3 \times 0.0071)=0.1732 \mathrm{cc} / \text { gram ' } \mathrm{D} \text { ' dried }
$$

The porosity is then:

$$
\frac{0.1732 \frac{C C}{g^{\prime} D^{\prime} \text { dried }} \times 1.2100 \frac{g^{\prime} D^{\prime} \text { dried }}{g^{i g n i t e d}}}{0.5543 \frac{C C}{912 \% \text { RH dried }} \times 1.2919 \frac{\mathrm{g} 128 \mathrm{RH} \text { dried }}{\mathrm{g} \text { ignited }}}=0.2928
$$

In the case of a saturated sample, the bulk volume would have first been calculated. The experimentally determined values that are needed are:

1. The bulk volume of a vacuum-oven dried, $w / c=0.4$ cement paste is $0.5750 \mathrm{cc}$ per gram vacuum-oven (VO) dried.

2. The sample had a linear shrinkage of 1.108 .

3. Also, the sample had a pore volume of $0.1770 \mathrm{cc}$. The original volume before shrinkage is:

$$
0.5750(1+3 \times 0.0110)=0.5940 \mathrm{cc} / \mathrm{g} \text { Vo dried }
$$

The bulk density on a saturated gram basis is then:

$$
\frac{0.5940 \mathrm{cc} / \mathrm{g} \text { Vo dried }}{(1+0.1770) \mathrm{g} \text { saturated } / \mathrm{g} \text { Vo dried }}=0.5047 \mathrm{cc} / \mathrm{g} \text { saturated }
$$

Table 1 is a compilation of the various required experimental parameters and calculated porosities for all of the cement pastes tested in the course of this research.

\section{Sorption Measurements}

A comparison was desired between some of the $\mathrm{x}-\mathrm{ray}$ surface area values and those obtained by conventional vapor sorption techniques. Hence, adsorption isotherms 


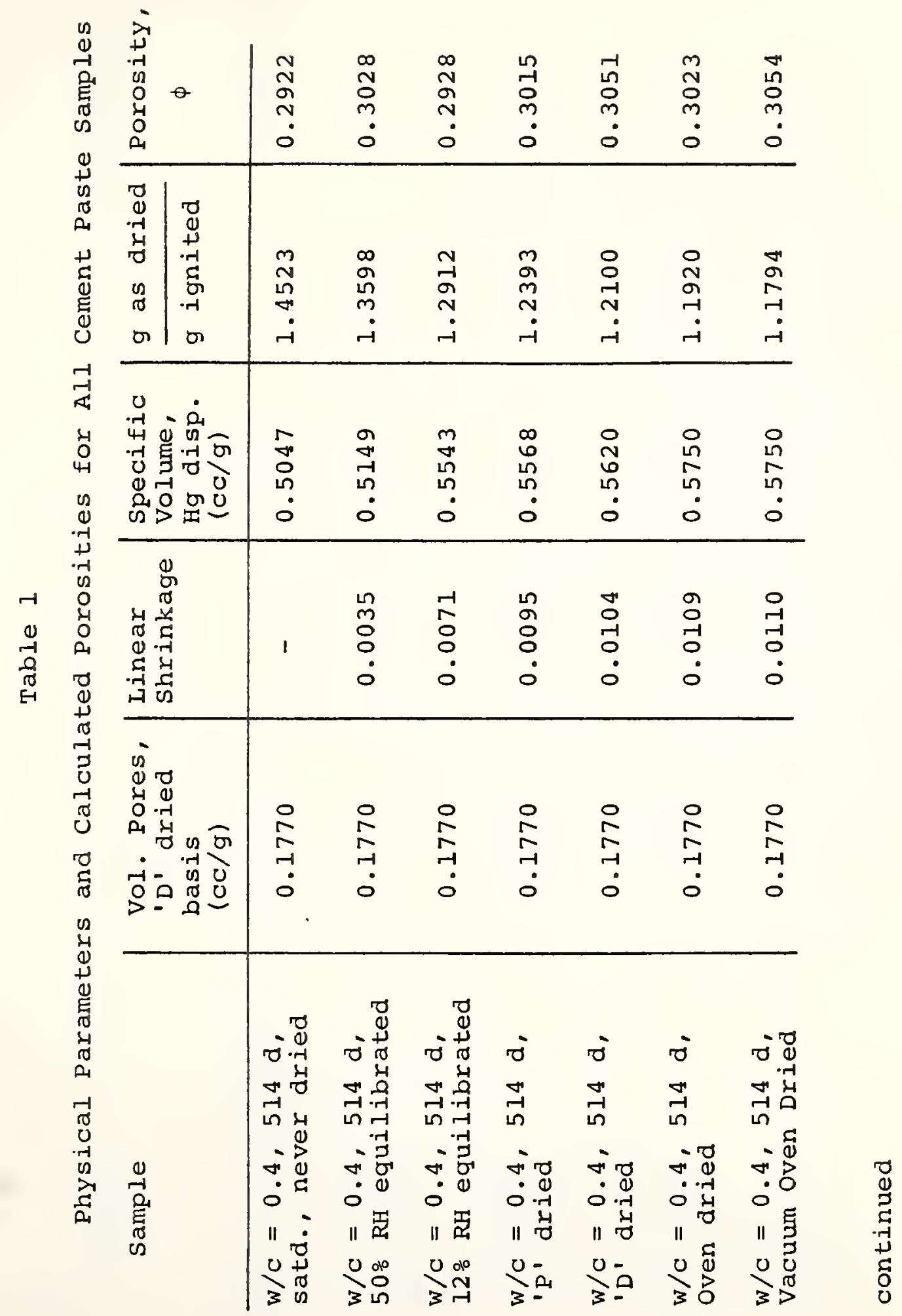




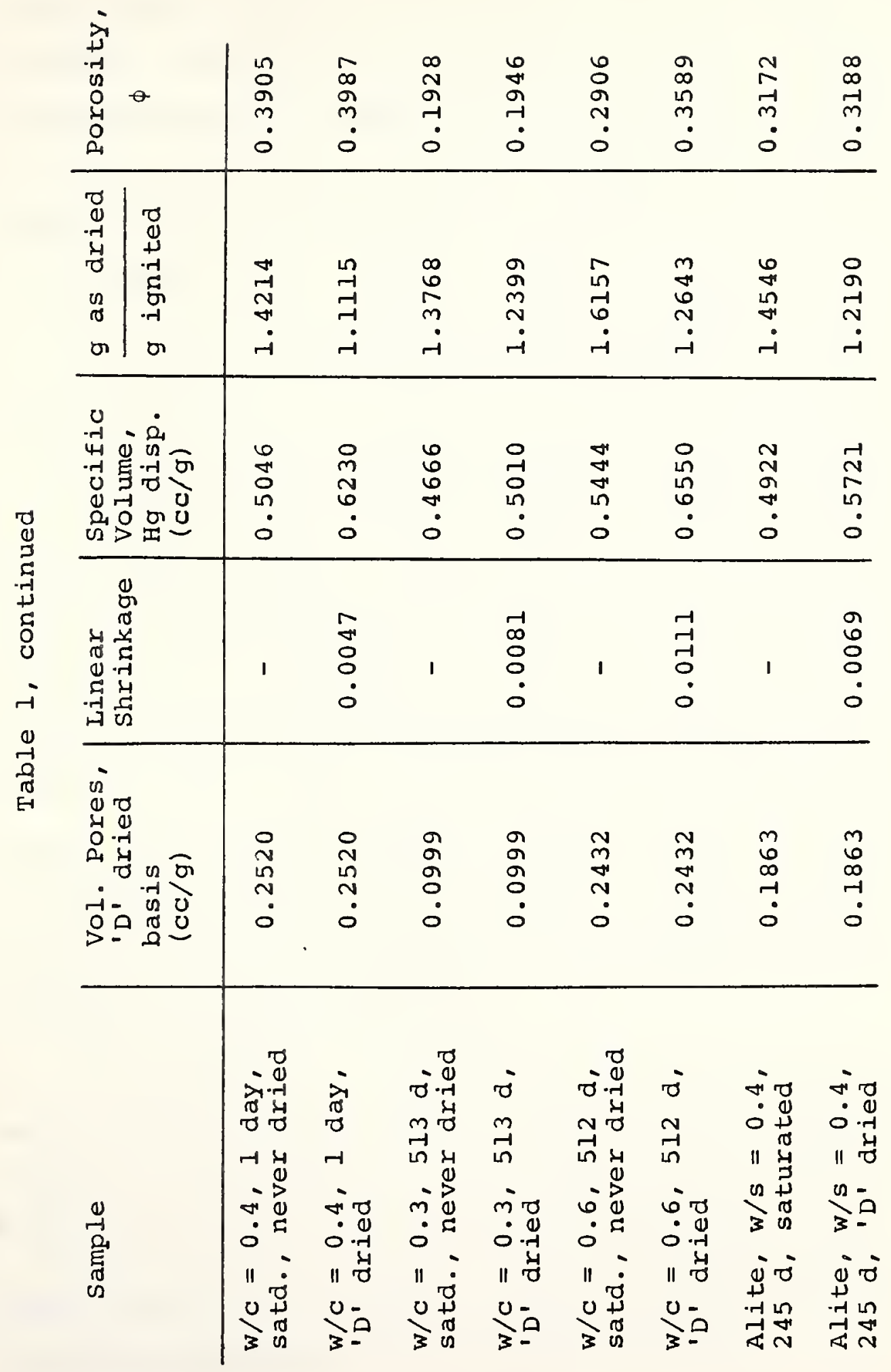


were measured for the illite, the charcoal and the driest cement paste samples. In all cases, the isotherms were analyzed with the Brunauer, Emmett and Teller theory (3). Two adsorbates were used: water vapor at $25^{\circ} \mathrm{C}$ and nitrogen at $-196^{\circ} \mathrm{C}$. The area covered by one water molecule was taken to be $10.6 \AA^{2}$ and that covered by a nitrogen molecule was assumed to be $16.2 \AA^{2}$.

The water vapor isotherms were measured gravimetrically using desiccators in which to control the vapor pressures. The cement paste samples were ground to a powder passing a No. 200 standard sieve. The illite and charcoal specimens were tested in their already powered state. In all cases, the specimens commenced the adsorption in the vacuum-oven dry state. The samples were housed in low-form glass weighing bottles, and about one gram of sample was placed in each bottle. Each type of sample was tested in triplicate. The relative humidities were controlled by solutions of glycerine and water as described in ASTM Recommended Practice: E-104, "Maintaining Constant Relative Humidity by Means of Aqueous Solutions".

The adsorption isotherms for the illite and charcoal were determined sequentially. That is, the samples were brought to equilibrium at the lowest relative humidity, then moved to the next higher relative humidity, reequilibrated and so on until they had passed through five equally spaced humidities between $5 \%$ and $35 \%$. 
Equilibration was found to be slow, about 30 days per point for the charcoal.

Equilibration between water vapor and cement paste is much slower. Previous work (15) has indicated that, if equilibrium can be reached, it requires many months at each point to achieve it. This work also indicated a sharp decrease in the rate of adsorption after about two days of exposure to the vapor. This was taken to be the point at which most of the physical adsorption was complete. The definition of equilibrium adopted for the sorption reported here was simply that each step would be considered essentially at equilibrium after being given two days to sorb vapor. A freshly dried cement sample was exposed to each relative humidity to avoid any 'carryover' of weight gain since true equilibrium was never reached at any point. Again, five relative humidities, equally spaced, were used between $5 \%$ and $35 \%$.

The above procedure and definition of equilibrium are not those usually employed for sorption on cement paste. Typically, a sample is moved sequentially through the series of relative humidities and usually more than two days of sorption is allowed at each point. When a single sample is used in this sequential manner, the adsorption at each point is slightly more than was measured in this work and, consequently, the surface area is slightly larger. 
The nitrogen vapor isotherms were determined volumetrically; an American Instrument Company instrument called a SorBET (Model 5-7300) was used. This device differs from conventional volumetric sorption apparatus in two ways; it uses a diaphram pump to circulate the vapor past the specimen and it uses a charge of helium gas mixed with the nitrogen. Both of these features promote a more rapid equilibration. All samples were prepared for nitrogen sorption in exactly the same way as they were prepared for water vapor sorption. 


\section{$X$-RAY SCATTERING DATA}

All of the X-ray scattering data was printed by the diffractometer in one of two forms: either as the number of seconds required to reach a preset number of counts, or as the counts registered during a preset interval of time. At any given angle there might have been several repeat measurements as outlined in the description of the counting strategy. The resulting raw data was, thus, a series of between 200 and 400 printed numbers which had to be combined and then converted to the common intensity basis of counts per second (cps).

About 22,000 such printed numbers were recorded for the scattering work reported here. A listing of these would be both exceedingly voluminous and also not directly applicable to graphing and calculation. Hence, each experiment has been reduced to a single listing of intensities versus angles. All of the scattering curves are given in this tabular form in Appendix D. The data in this appendix are three steps removed from the raw data. First, multiple values obtained on replicate scans have been reduced to a single value for a single angle. Secondly, the correction for the dead time of the counting circuit has been applied. 
This correction is discussed in Appendix $C$ and has been applied to measured intensities of 100 counts per second or greater. The correction is negligible at lesser intensities. Lastly, the very-low-angle parasitic scatter has been subtracted. Thus, the listed intensities are due solely to the scatter of the sample.

The very-low-angle data for some tests listed in Appendix $D$ are missing intensity values at a few angular positions. This is due to experimental error. The recorded intensities were very high at positions very close to the primary beam. However, most of this intensity was either due to the primary beam itself or to the parasitic scatter. occasionally, a parasitic scatter intensity would be greater than the corresponding intensity which included the sample scatter. This happened in spite of the procedures outlined previously and when the parasitic scatter was subtracted it left a negative intensity for the point. This result is not physically possible and is clearly the result of error in testing. 'Such values have been eliminated from the listings in Appendix D.

The raw data for two representative tests are also presented in Tables 2 and 3. A saturated and a dry cement paste test have been selected to illustrate the differences in the data brought on by the different counting strategies. The data are shown in a format which is very similar to that actually used in the notebooks and are given merely 
Table 2

Raw X-ray Scattering Data Direct from X-ray Machine $\mathrm{w} / \mathrm{C}=0.4,514$ days, ' $\mathrm{D}$ ' dried

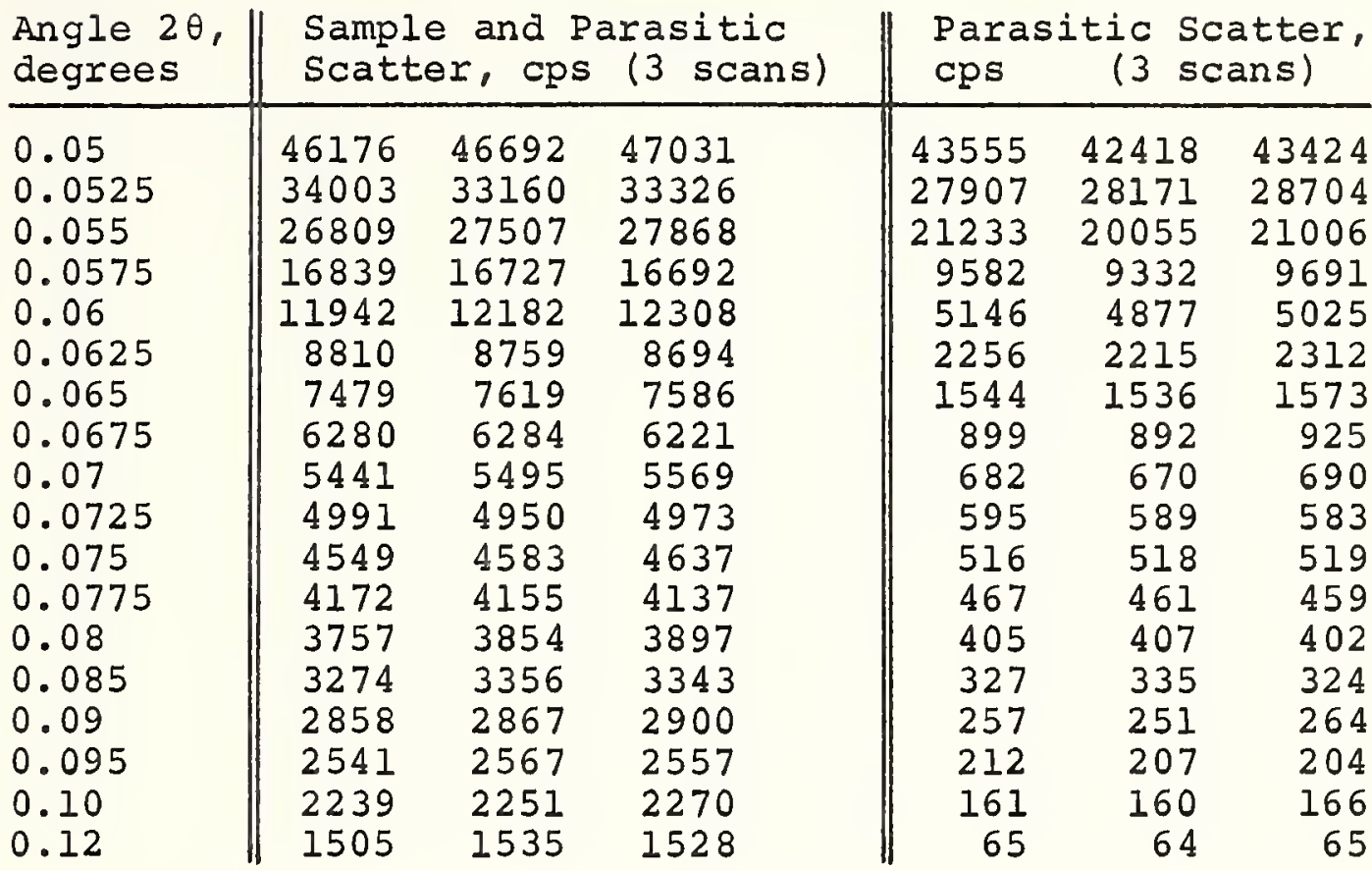

\begin{tabular}{|c|c|c|c|c|c|c|}
\hline $\begin{array}{l}\text { Angle } \\
2 \theta, \text { deg. }\end{array}$ & $\begin{array}{l}\text { Seconds } \\
\text { to get } \\
10 \mathrm{~K} \text { cts }\end{array}$ & $\begin{array}{l}\text { Angle } \\
2 \theta, \text { deg }\end{array}$ & $\begin{array}{l}\text { Seconds } \\
\text { to get } \\
4 \mathrm{~K} \text { cts }\end{array}$ & $\begin{array}{l}\text { Seconds } \\
\text { to get } \\
2 \mathrm{~K} \text { cts }\end{array}$ & $\begin{array}{l}\text { Seconds } \\
\text { to get } \\
2 \mathrm{~K} \text { cts }\end{array}$ & $\begin{array}{l}\text { Seconds } \\
\text { to get } \\
2 \mathrm{~K} \text { cts }\end{array}$ \\
\hline $\begin{array}{l}0.15 \\
0.20 \\
0.25 \\
0.30 \\
0.40 \\
0.50 \\
0.70 \\
1.00 \\
1.30\end{array}$ & $\begin{array}{r}10 \\
16 \\
22 \\
29 \\
46 \\
70 \\
142 \\
330 \\
619\end{array}$ & $\begin{array}{l}1.60 \\
1.70 \\
1.80 \\
1.90 \\
2.00 \\
2.10 \\
2.20 \\
2.30 \\
2.40 \\
2.50\end{array}$ & $\begin{array}{l}392 \\
440 \\
489 \\
560 \\
615 \\
668 \\
708 \\
797 \\
840 \\
891\end{array}$ & $\begin{array}{l}190 \\
210 \\
233 \\
275 \\
290 \\
320 \\
351 \\
374 \\
410 \\
445\end{array}$ & $\begin{array}{l}198 \\
224 \\
239 \\
283 \\
300 \\
326 \\
359 \\
378 \\
416 \\
457\end{array}$ & $\begin{array}{l}191 \\
225 \\
246 \\
283 \\
308 \\
341 \\
357 \\
386 \\
428 \\
450\end{array}$ \\
\hline $\begin{array}{c}\text { Parasit } \\
\text { at } 2 \theta= \\
\text { Seconds } \\
10 \mathrm{~K} \text { cour } \\
317\end{array}$ & $\begin{array}{l}\text { Scatter } \\
15^{\circ} \\
r^{2}=\end{array}$ & $\begin{array}{l}2.60 \\
2.70 \\
2.80 \\
2.90 \\
3.00\end{array}$ & $\begin{array}{r}969 \\
1014 \\
1065 \\
1097 \\
1150\end{array}$ & $\begin{array}{l}470 \\
500 \\
520 \\
550 \\
560\end{array}$ & $\begin{array}{l}472 \\
514 \\
530 \\
550 \\
576\end{array}$ & $\begin{array}{l}486 \\
539 \\
553 \\
587 \\
587\end{array}$ \\
\hline
\end{tabular}




\section{Table 3}

Raw X-ray Scattering Data Direct from X-ray Machine $\mathrm{w} / \mathrm{c}=0.4,514$ days, Saturated, Never aried

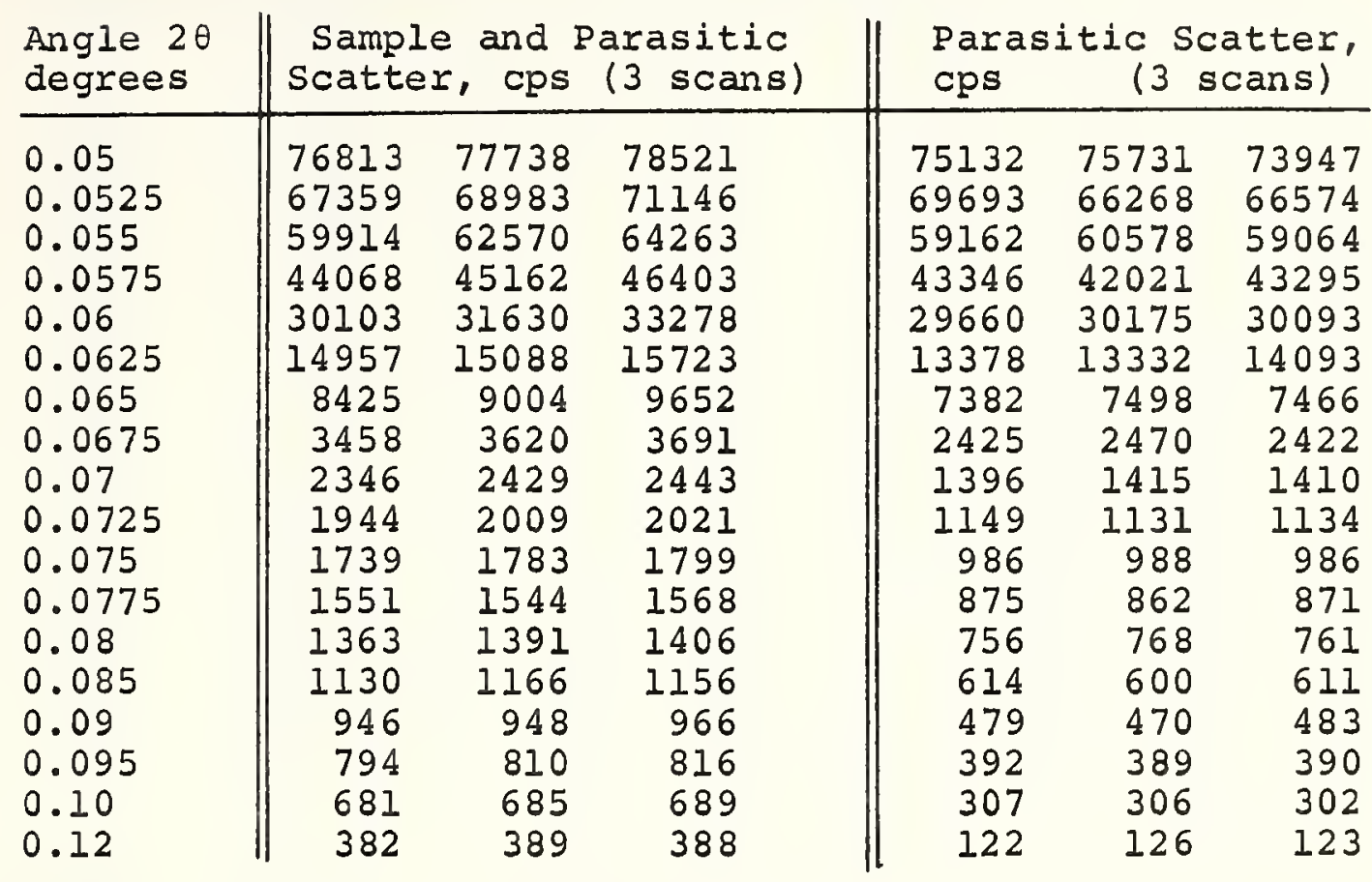

\begin{tabular}{l||rrr||rrr}
$\begin{array}{l}\text { Angle 2 } \\
\text { degrees }\end{array}$ & \multicolumn{2}{|c||}{$\begin{array}{c}\text { Sample and Parasitic } \\
\text { Scatter, cps }\end{array}$} & (3 scans) & \multicolumn{3}{|c}{ Parasitic Scatter, } \\
cps & (3 scans) \\
\hline 0.05 & 75453 & 75655 & 74160 & 76126 & 72939 & 74921 \\
0.0525 & 70244 & 69542 & 67850 & 70937 & 67187 & 69040 \\
0.055 & 62171 & 62060 & 59389 & 63927 & 60900 & 61495 \\
0.0575 & 46553 & 45784 & 45082 & 48339 & 46100 & 46424 \\
0.06 & 33867 & 33315 & 30665 & 34517 & 32995 & 33746 \\
0.0625 & 16285 & 16584 & 16460 & 17821 & 16492 & 17433 \\
0.065 & 9876 & 9753 & 8732 & 9459 & 9023 & 9259 \\
0.0675 & 3796 & 3824 & 3713 & 2879 & 2729 & 2824 \\
0.07 & 2442 & 2420 & 2380 & 1515 & 1484 & 1499 \\
0.0725 & 2001 & 2065 & 2010 & 1179 & 1169 & 1174 \\
0.075 & 1773 & 1779 & 1737 & 1030 & 1016 & 1019 \\
0.0775 & 1564 & 1556 & 1564 & 881 & 893 & 892 \\
0.08 & 1385 & 1370 & 1360 & 782 & 782 & 777 \\
0.085 & 1136 & 1172 & 1162 & 620 & 606 & 617 \\
0.09 & 954 & 956 & 974 & 487 & 478 & 491 \\
0.095 & 790 & 806 & 812 & 388 & 385 & 386 \\
0.10 & 679 & 683 & 687 & 305 & 304 & 300 \\
0.12 & 385 & 392 & 391 & 125 & 129 & 126
\end{tabular}


Table 3, continued

\begin{tabular}{|c|c|c|c|c|c|c|}
\hline $\begin{array}{l}\text { Angle } 2 \theta \\
\text { degrees }\end{array}$ & \multicolumn{3}{|c|}{$\begin{array}{l}\text { Sample and Parasitic } \\
\text { Scatter, cps (3 scans) }\end{array}$} & \multicolumn{3}{|c|}{$\begin{array}{l}\text { Parasitic scatter, } \\
\text { cps (3 scans) }\end{array}$} \\
\hline 0.05 & 72780 & 73946 & 73112 & 72564 & 73203 & 73667 \\
\hline 0.0525 & 67981 & 68352 & 68118 & 67276 & 69274 & 69971 \\
\hline 0.055 & 61596 & 61548 & 61421 & 61417 & 61199 & 62812 \\
\hline 0.0575 & 46368 & 47651 & 47552 & 46341 & 47988 & 47997 \\
\hline 0.06 & 34666 & 35121 & 34552 & 34118 & 33913 & 35123 \\
\hline 0.0625 & 17958 & 17599 & 19097 & 16338 & 16778 & 17705 \\
\hline 0.065 & 10413 & 10631 & 10122 & 9383 & 9240 & 9588 \\
\hline 0.0675 & 3788 & 3724 & 3793 & 2770 & 2643 & 2809 \\
\hline 0.07 & 2423 & 2420 & 2401 & 1484 & 1452 & 1503 \\
\hline 0.0725 & 1955 & 1974 & 1949 & 1167 & 1156 & 1172 \\
\hline 0.075 & 1734 & 1750 & 1733 & 1020 & 1014 & 1043 \\
\hline 0.0775 & 1516 & 1533 & 1518 & 858 & 886 & 894 \\
\hline 0.08 & 1374 & 1336 & 1368 & 776 & 788 & 793 \\
\hline 0.085 & 1124 & 1160 & 1150 & 608 & 594 & 605 \\
\hline 0.09 & 938 & 940 & 958 & 471 & 462 & 475 \\
\hline 0.095 & 798 & 814 & 820 & 396 & 393 & 394 \\
\hline 0.10 & 683 & 687 & 691 & 309 & 308 & 304 \\
\hline 0.12 & 379 & 386 & 385 & 119 & 123 & 120 \\
\hline
\end{tabular}

\begin{tabular}{|c|c|c|c|c|c|c|}
\hline $\begin{array}{l}\text { Angle } \\
2 \theta \text {, deg }\end{array}$ & $\begin{array}{l}\text { Seconds } \\
\text { to get } \\
10 \mathrm{~K} \text { cts }\end{array}$ & $\begin{array}{l}\text { Angle } \\
2 \theta \text {, deg }\end{array}$ & $\mid \begin{array}{ll}\text { Seconds } \\
\text { to } & \text { get } \\
4 \mathrm{~K} & \mathrm{cts}\end{array}$ & $\begin{array}{l}\text { Seconds } \\
\text { to get } \\
2 \mathrm{~K} \text { cts }\end{array}$ & $\begin{array}{l}\text { Seconds } \\
\text { to get } \\
2 \mathrm{~K} \text { cts }\end{array}$ & $\begin{array}{l}\text { Seconds } \\
\text { to get } \\
2 \mathrm{~K} \text { cts } \\
\end{array}$ \\
\hline $\begin{array}{l}0.15 \\
0.20 \\
0.25 \\
0.30 \\
0.40 \\
0.50 \\
0.70 \\
1.00 \\
1.30\end{array}$ & $\begin{array}{r}46 \\
78 \\
105 \\
129 \\
175 \\
224 \\
324 \\
491 \\
705\end{array}$ & \multirow{2}{*}{$\begin{array}{l}1.60 \\
1.70 \\
1.80 \\
1.90 \\
2.00 \\
2.10 \\
2.20 \\
2.30 \\
2.40 \\
2.50 \\
2.60 \\
2.70 \\
2.80 \\
2.90 \\
3.00\end{array}$} & \multirow{2}{*}{$\begin{array}{r}399 \\
424 \\
480 \\
520 \\
568 \\
612 \\
652 \\
717 \\
768 \\
837 \\
889 \\
940 \\
993 \\
1070 \\
1131\end{array}$} & \multirow{2}{*}{$\begin{array}{l}189 \\
207 \\
226 \\
241 \\
271 \\
283 \\
329 \\
343 \\
372 \\
399 \\
416 \\
458 \\
485 \\
525 \\
536\end{array}$} & \multirow{2}{*}{$\begin{array}{l}193 \\
212 \\
239 \\
255 \\
281 \\
307 \\
336 \\
340 \\
363 \\
400 \\
442 \\
452 \\
500 \\
531 \\
545\end{array}$} & \multirow{2}{*}{$\begin{array}{l}202 \\
217 \\
241 \\
251 \\
279 \\
304 \\
345 \\
359 \\
391 \\
417 \\
433 \\
460 \\
511 \\
531 \\
568\end{array}$} \\
\hline $\begin{array}{l}\text { Parasi } \\
\text { at } 2 \theta= \\
\text { Seconds } \\
\text { loK col } \\
31\end{array}$ & $\begin{array}{l}\text { Scatter } \\
.15^{\circ} \\
\text { or } \\
\mathrm{s}=\end{array}$ & & & & & \\
\hline
\end{tabular}


to provide an insight into the actual recording of the raw data. These two tests are also given in reduced form in Appendix $D$ along with all of the others. The raw data for the ' $D$ ' dry cement paste test will be used to illustrate the procedure used for the calculations. 


\section{X-RAY SCATTERING CORRECTIONS AND CALCULATIONS}

A single, complete $x$-ray scattering curve for a sample is required to calculate the specific surface of that sample using the Porod theory. At the conclusion of a test one has the sort of data illustrated in the previous section. In this section the procedure will be detailed for obtaining the required scattering curve and for calculating the specific surface from it. There are three steps in the task of reducing this data to a single specific surface measurement. First, multiple measurements due to replicate scans must be combined. This step produces two scattering curves which are the total scatter (sample and parasitic combined) and the parasitic scatter alone. Secondly, the parasitic scatter must be subtracted from the total scatter leaving a single scattering curve due solely to the specimen. This must then be corrected for aberrations due to such factors as dead time, interparticle interference and non-interfacial scatter. After these corrections there remains a single corrected scattering curve due solely to interfacial scatter. This single corrected scattering curve must then be used to obtain the necessary numbers for the calculation of the surface area. 
The process of combining multiple measurements is straightforward. At the larger angles there are a series of individual time values for each angle. The sum of these values is the total interval required to accumulate 10,000 counts. Hence, in the angular region between $1.60^{\circ} 2 \theta$ and $3.00^{\circ} 2 \theta$ the counting times at each angle are summed and the result divided into 10,000 to yield the intensity in counts per second at that angle. The same procedure is followed in the angular region from $0.15^{\circ} 2 \theta$ to $1.30^{\circ} 2 \theta$ but here there is no need for summing multiple values as this region was scanned in one pass.

The intensity values are already in terms of counts per second in the angular region from $0.05^{\circ} 2 \theta$ to $0.12^{\circ} 2 \theta$. Originally, each value was obtained during a ten second count. However, the diffractometer was so arranged that the total count was automatically divided by ten. Thus, the value, as printed, was already in terms of counts per second. There are three such values at each angle for a dry specimen and nine for the saturated ones. The combination process is merely calculating the average intensity value for each position.

An example of the combined scattering curves is given in Table 4. It is based upon the ' $D$ ' dry specimen example that was presented in the Data Section. Table 4 contains the data for two raw scattering curves, combined scatter and parasitic scatter. They must now be combined and corrected. 
Table 4

Total and Parasitic Scattering Curves after Combination of Multiple Scans

Cement Paste, $\mathrm{w} / \mathrm{c}=0.4$, Age $=514$ days, ' $\mathrm{D}$ ' dried

\begin{tabular}{l|c|c}
$\begin{array}{c}\text { Angle } 2 \theta \\
\text { (deg.) }\end{array}$ & $\begin{array}{c}\text { Total } \\
\text { scatter } \\
\text { (cps) }\end{array}$ & $\begin{array}{c}\text { Parasitic } \\
\text { Scatter } \\
\text { (cps) }\end{array}$ \\
\hline 0.05 & 53322 & 48794 \\
0.0525 & 36813 & 30586 \\
0.055 & 29574 & 21993 \\
0.0575 & 17543 & 9786 \\
0.06 & 12554 & 5085 \\
0.0625 & 8965 & 2275 \\
0.065 & 7715 & 1557 \\
0.0675 & 6369 & 908 \\
0.07 & 5584 & 682 \\
0.0725 & 5039 & 590 \\
0.075 & 4647 & 518 \\
0.0775 & 4202 & 463 \\
0.08 & 3876 & 405 \\
0.085 & 3354 & 329 \\
0.09 & 2897 & 258 \\
0.095 & 2573 & 208 \\
0.10 & 2267 & 162 \\
0.12 & 1528 & 65 \\
0.15 & 1035 & 3
\end{tabular}

0.20

645.16

454.55

350.88

215.83

142.52

70.59

30.30

16.16

10.30

9.10

8.29

7.15

6.61

6.04

5.57

5.17

4.78

4.46

4.17

3.95

3.75 
The first step is to correct the more intense values for the detector dead time. This correction is made as discussed in Appendix $C$ and is applied to any intensity greater than 100 counts per second, the correction being negligible of lesser intensities. Next, the set of data representing the parasitic scatter is subtracted from the set which represents combined parasitic and sample scatter. This subtraction is carried out, angle by angle, and the result is a single scattering curve due solely to the sample. Appendix D contains curves such as this for all of the tests carried out in this work. The particular test that forms the basis for the example in this section is Test E9.

In the following calculations and corrections it will be convenient to use a modified expression for the scattering angle. A number of modifications exist (16). They all involve the angle expressed per unit of $\mathrm{x}$-ray wave length. The one used in this work is termed " $h$ " and is defined as:

$$
h=\frac{4 \pi \sin \theta}{\lambda}
$$

The term $4 \pi$ is present simply to facilitate future calculations.

The next correction to be considered applies to the very-low-angle data. There are two difficulties in this region. First, no data could be obtained for the section between $0^{\circ}$ and $0.05^{\circ} 2 \theta$ but intensity values are needed 
here to completely define the scattering curve. Secondly, the measured scattered intensity at the very smallest angles is often seen to decrease rather than increase. This drop in intensity is in a sense artificial, and is brought on by the densely packed nature of the cement paste. The surface area of a collection of particles should be independent of the way in which they are packed. However, if they are packed closely, at small enough angles there will be inter-particle interference with the scatter. Thus, it will be necessary to correct for the interference brought on by the dense packing of particles in cement paste.

The method used to overcome both of these difficulties is based on Guinier's Law. As discussed, a plot of the logarithm of the scattered intensity versus the square of the scattering angle should become linear at small enough angles. The slope of this linear portion should be related to the average size of the scattering particles. To obtain this plot $\mathrm{h}^{2}$ is first calculated for each angle between $0.05^{\circ} 2 \theta$ and $0.12^{\circ} 2 \theta$. Then a semi-logarithmic plot is made of intensity versus $h^{2}$. Table 5 shows the calculated values and Figure $l 1$ is the Guinier plot for the example being considered here.

It is possible to extrapolate the linear portion of the Guinier plot to smaller angles only to the extent that Guinier's Law obtains. The applicability of Guinier's Law 
Table 5

Values for Guinier Plot

Cement Paste, $\mathrm{w} / \mathrm{c}=0.4$, Age $=514$ days, ' $\mathrm{D}$ ' dried

\begin{tabular}{l|c|c}
$\begin{array}{c}\text { Angle } 2 \theta \\
\text { (degrees) }\end{array}$ & $\begin{array}{c}h^{2} \\
\left(\AA^{-2}\right)\end{array}$ & $\begin{array}{c}\text { Scattered } \\
\text { Intensity (cps) }\end{array}$ \\
\hline 0.05 & $0.61 \times 10^{-4}$ & 4528 \\
0.0525 & $0.66 \times 10^{-4}$ & 6227 \\
0.055 & $0.72 \times 10^{-4}$ & 7581 \\
0.0575 & $0.80 \times 10^{-4}$ & 7757 \\
0.06 & $0.86 \times 10^{-4}$ & 7469 \\
0.0625 & $0.94 \times 10^{-4}$ & 6690 \\
0.065 & $1.02 \times 10^{-4}$ & 6158 \\
0.0675 & $1.10 \times 10^{-4}$ & 5459 \\
0.07 & $1.19 \times 10^{-4}$ & 4902 \\
0.0725 & $1.27 \times 10^{-4}$ & 4449 \\
0.075 & $1.35 \times 10^{-4}$ & 4129 \\
0.0775 & $1.44 \times 10^{-4}$ & 3739 \\
0.08 & $1.54 \times 10^{-4}$ & 3471 \\
0.085 & $1.74 \times 10^{-4}$ & 3025 \\
0.09 & $1.95 \times 10^{-4}$ & 2639 \\
0.095 & $2.17 \times 10^{-4}$ & 2365 \\
0.10 & $2.40 \times 10^{-4}$ & 2105 \\
0.12 & $3.46 \times 10^{-4}$ & 1463
\end{tabular}

will be discussed later. However, the slope of the plot does correspond reasonably well to the average pore size to be expected in the cement paste. Hence, it is felt that Guinier's Law obtains sufficiently well to justify the extrapolation.

Extrapolated intensities are then picked off of the plot in the extremely low angle region. These values are either added onto the scattering curve or used in lieu of those values that were affected by the inter-particle interference. Table 6 lists the extrapolated values for the example being used. 


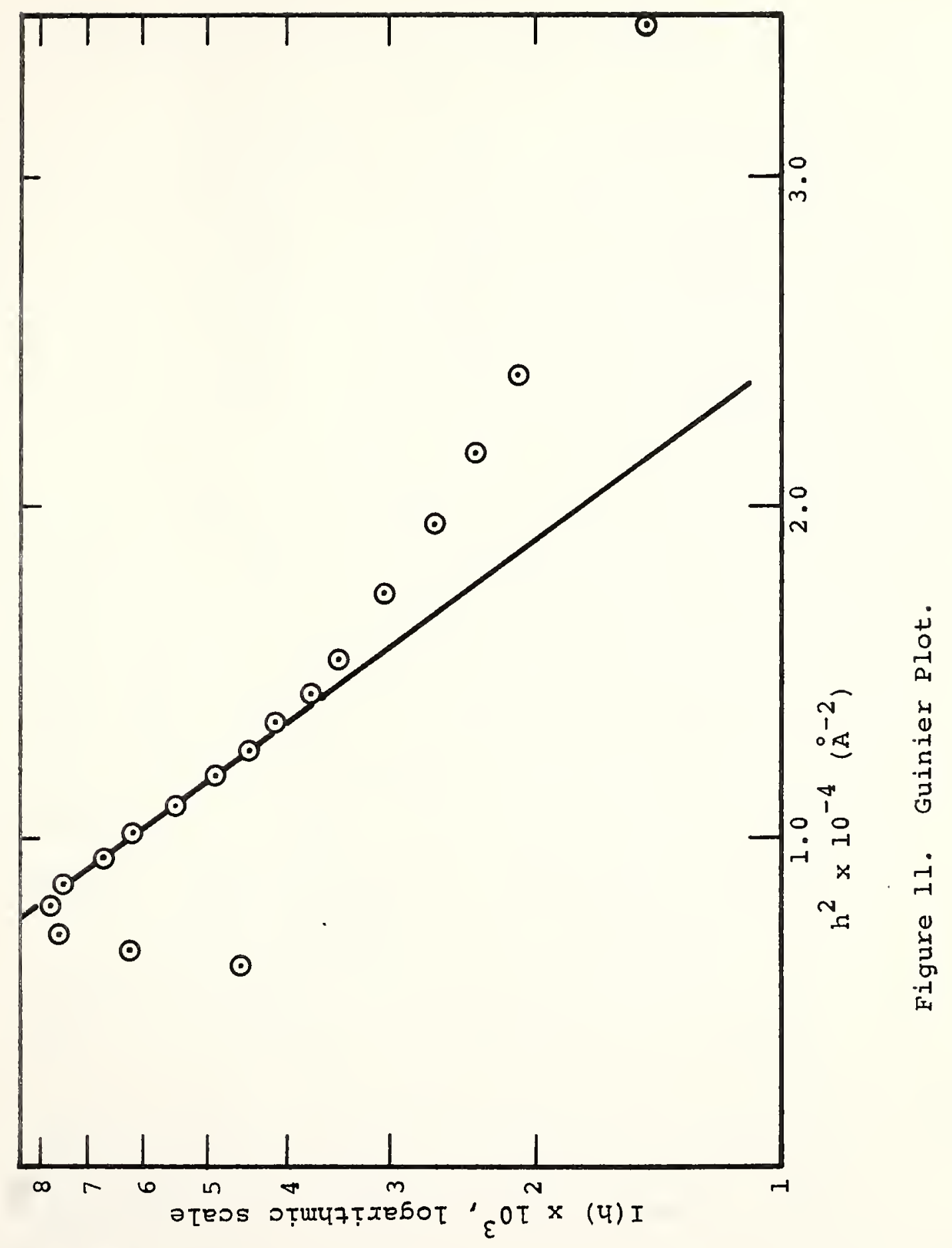


Table 6

Extrapolated Values from Guinier Plot Cement Paste, $w / c=0.4$, Age $=514$ days, ' $D$ ' dried

\begin{tabular}{l|l|l}
$\begin{array}{l}\text { Angle } 2 \theta \\
\text { (degrees) }\end{array}$ & $\begin{array}{c}\mathrm{h}^{2} \times 10^{-4} \\
\left(\AA^{-2}\right)\end{array}$ & $\begin{array}{l}\text { Extrapolated } \\
\text { Intensities (cps) }\end{array}$ \\
\hline 0.01 & 0.03 & 20400 \\
0.02 & 0.10 & 18800 \\
0.03 & 0.22 & 16200 \\
0.035 & 0.29 & 15000 \\
0.04 & 0.38 & 13400 \\
0.045 & 0.49 & 11600 \\
0.05 & 0.61 & 10000 \\
0.055 & 0.72 & 8700
\end{tabular}

It is next necessary to work with the high angle region or 'tail' of the scattering curve. Here again, there are two problems. One is that a measure of the area under the entire curve to infinity is required. However, at large angles, the intensity of scatter is extremely low. To obtain values at high angles, Porod's Law will be used to extrapolate the curve to very large angles without the need for making additional, time-consuming measurements. The second problem is that Porod's Law predicts a hroizontal asymptote when the scatter in the tail of the curve is due solely to the presence of interfaces. That is, the surface area is the extent of the interface between particles and pores and only scatter from this source will obey Porod's Law. However, in many samples, there are sources of electron density discontinuity other than interfaces. Two such sources are the presence of ions such as 
calcium and other ions found in pore water in cement paste and the existance of atomic vacancies and other irregularities in the structure of the solid particles. The second problem will be considered first.

The high-angle, non-interfacial scatter has been observed before, and a method for deducting its contribution to the scattering curve has been worked out $(17,18)$. The first step is to calculate $\mathrm{h}^{3}$ for each angle in the 'tail' region. Then the intensity corresponding to each $h^{3}$ is multiplied by that value of $h^{3}$. The results of such a calculation are shown in Table 7 for the example being used. Next a plot is made of $h^{3} I(h)$ versus $h^{3}$ (see Figure 12). This plot would attain a horizontal asymptote as predicted by Porod's Law if the scatter was due only to interfaces.

The plot of Figure 12 indicates a linear but sloping shape at the larger angles. This may be thought of as a linearly increasing non-interfacial scatter superimposed upon a horizontal asymptote. A straight line is fitted, by the method of least squares, to the linear part of the curve to aid in subtracting off the unwanted scatter. The slope of the line is then multiplied by each value of $h^{3}$ to obtain the amount by which $h^{3} I(h)$ must be reduced. For each value of $h^{3}$ the correction is made and then the corrected value of $h^{3} I(h)$ is divided by $h^{3}$ to obtain the corrected intensity, $I(h)$. This process need not be 
Table 7

Calculations for Initial Porod Plot Cement Paste, $\mathrm{w} / \mathrm{C}=0.4$, Age $=514$ days, ' $\mathrm{D}$ ' dried

\begin{tabular}{l|c|c|c}
$\begin{array}{c}\text { Angle } 2 \theta \\
\text { (degrees) }\end{array}$ & $\begin{array}{c}\mathrm{h}^{3} \times 10^{-2} \\
\left(\mathrm{~A}^{-3}\right)\end{array}$ & $\begin{array}{c}\text { Scattered } \\
\text { Intensity, } \\
\text { I(h).(cps) }\end{array}$ & $\begin{array}{r}\mathrm{h}^{3} I(\mathrm{~h}) \\
\mathrm{x} 10^{-2}\end{array}$ \\
\hline 0.50 & 0.0466 & 142.52 & 6.64 \\
0.70 & 0.1278 & 70.59 & 9.02 \\
1.00 & 0.3726 & 30.30 & 11.29 \\
1.30 & 0.8186 & 16.16 & 13.23 \\
1.60 & 1.5260 & 10.30 & 15.72 \\
1.70 & 1.8306 & 9.10 & 16.66 \\
1.80 & 2.1729 & 8.29 & 18.01 \\
1.90 & 2.5555 & 7.15 & 18.27 \\
2.00 & 2.9808 & 6.61 & 19.70 \\
2.10 & 3.4506 & 6.04 & 20.84 \\
2.20 & 3.9673 & 5.57 & 23.10 \\
2.30 & 4.5331 & 5.17 & 24.62 \\
2.40 & 5.1508 & 4.78 & 25.96 \\
2.50 & 5.8217 & 4.46 & 27.31 \\
2.60 & 6.5485 & 4.17 & 29.00 \\
2.70 & 7.3339 & 3.95 & 30.67 \\
2.80 & 8.1792 & 3.75 & 32.62 \\
2.90 & 9.0870 & 3.59 & 35.01 \\
3.00 & 10.0597 & 3.48 &
\end{tabular}




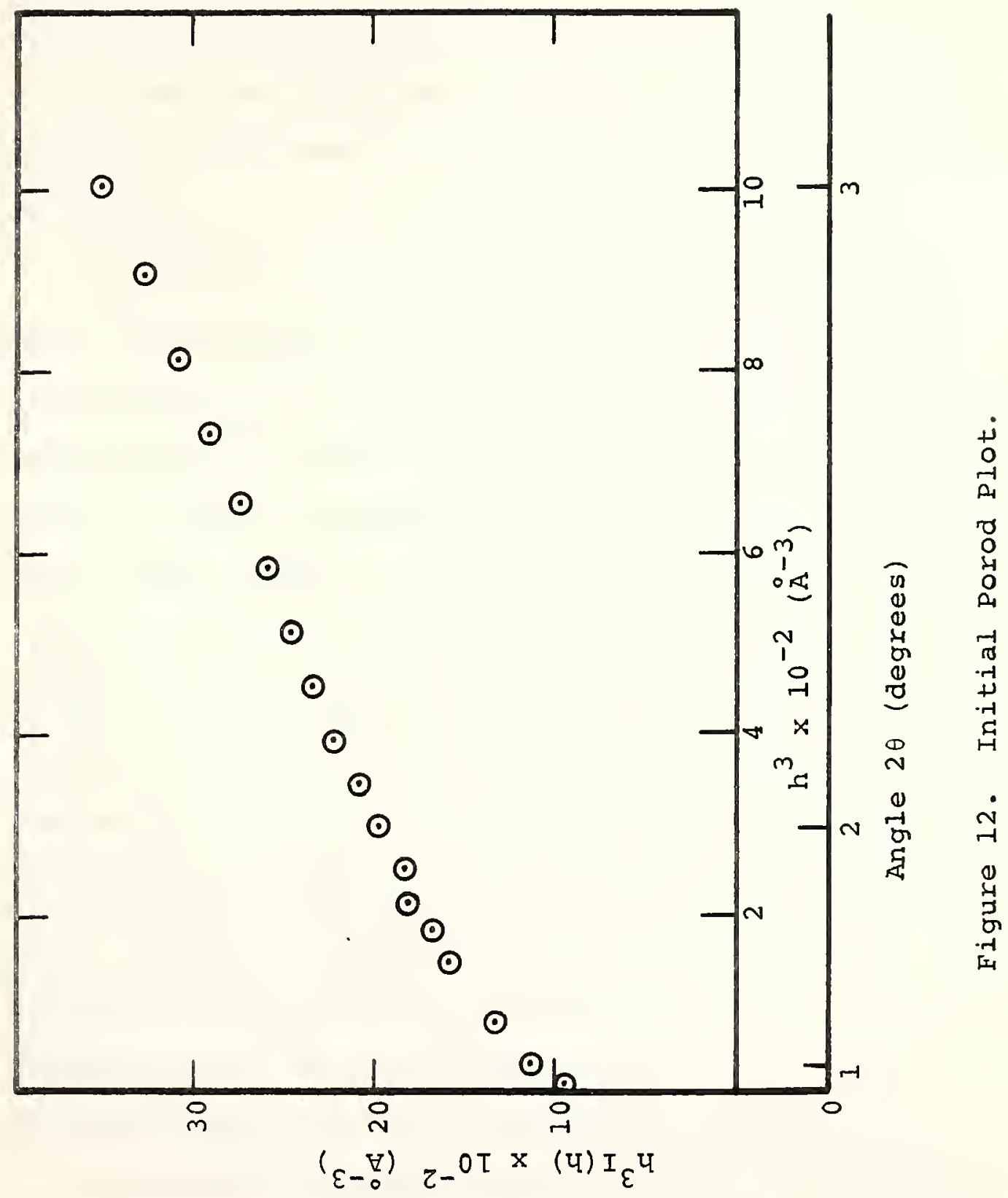


carried back to angles of less than about $0.50^{\circ} 2 \theta$ (approximately equal to $h^{3}=0.05$ ) as the correction becomes very small. Table 8 illustrates the process of making the correction. Figure 13 is a plot of $h^{3} I(h)$ versus $h^{3}$ after the intensities have been corrected for non-interfacial scatter. It is seen to now attain the expected horizontal asymptote.

The other difficulty with this scattering region, the first problem mentioned previously, is that the very low intensities at very high angles $\left(2 \theta\right.$ greater than $\left.3^{\circ}\right)$ make measurements in this region impractical. Fortunately, the value of Porod's asymptote can be used to extrapolate the data. The limiting value of $h^{3} I(h)$ can be obtained from Figure 13. Then a series of very large angles can be converted to their respective $h^{3}$ values. Each $h^{3}$ is then divided into the limiting value of $h^{3} I(h)$ to obtain the desired intensity at a series of very large angles. This process is carried on until the extrapolated intensity falls to a value of about 0.01 counts per second. Further extrapolation would not contribute noticeably to further calculations. For the example under consideration, Table 9 demonstrates this very-large-angle extrapolation. The above processes have resulted in a corrected scattering curve over the entire angular range of interest. Table 10 lists the entire set of intensities. 
Table 8

Non-Interfacial scatter Corrections to Porod Plot Cement Paste, $w / C=0.4$, Age $=514$ days, ' $D$ ' dried

\begin{tabular}{|c|c|c|c|c|c|}
\hline $\begin{array}{l}\text { Angle } 2 \\
\text { (degrees) }\end{array}$ & $\begin{array}{l}h^{3} \\
\times 10^{-2} \\
\left(\AA^{-3}\right)\end{array}$ & $\begin{array}{l}\text { Initial } \\
\text { Scattered } \\
\text { Intensity, } \\
\text { I(h) (cps) }\end{array}$ & $\mid \begin{array}{l}h^{3} I(h) \\
\times 10^{-2}\end{array}$ & $\begin{array}{l}\text { Corrected } \\
h^{3} I(h) \\
\times 10^{-2}\end{array}$ & $\begin{array}{l}\text { Corrected } \\
\text { Scattered } \\
\text { Intensity } \\
\text { i (h) (cps) }\end{array}$ \\
\hline $\begin{array}{l}0.50 \\
0.70 \\
1.00 \\
1.30 \\
1.60 \\
1.70 \\
1.80 \\
1.90 \\
2.00 \\
2.10 \\
2.20 \\
2.30 \\
2.40 \\
2.50 \\
2.60 \\
2.70 \\
2.80 \\
2.90 \\
3.00\end{array}$ & $\begin{array}{r}0.0466 \\
0.1278 \\
0.3726 \\
0.8186 \\
1.5260 \\
1.8306 \\
2.1729 \\
2.5555 \\
2.9808 \\
3.4506 \\
3.9673 \\
4.5331 \\
5.1508 \\
5.8217 \\
6.5485 \\
7.3339 \\
8.1792 \\
9.0870 \\
10.0597\end{array}$ & $\begin{array}{r}142.52 \\
70.59 \\
30.30 \\
16.16 \\
10.30 \\
9.10 \\
8.29 \\
7.15 \\
6.61 \\
6.04 \\
5.57 \\
5.17 \\
4.78 \\
4.46 \\
4.17 \\
3.95 \\
3.75 \\
3.59 \\
3.48\end{array}$ & $\begin{array}{r}6.64 \\
9.02 \\
11.29 \\
13.23 \\
15.72 \\
16.66 \\
18.01 \\
18.27 \\
19.70 \\
20.84 \\
22.10 \\
23.44 \\
24.62 \\
25.96 \\
27.31 \\
29.00 \\
30.67 \\
32.62 \\
35.01\end{array}$ & $\begin{array}{r}6.54 \\
8.75 \\
10.49 \\
11.47 \\
12.44 \\
12.72 \\
13.34 \\
12.78 \\
13.29 \\
13.42 \\
13.57 \\
13.69 \\
13.55 \\
13.44 \\
13.23 \\
13.23 \\
13.08 \\
13.08 \\
13.38\end{array}$ & $\begin{array}{r}140.34 \\
68.47 \\
28.15 \\
14.01 \\
8.15 \\
6.95 \\
6.14 \\
5.00 \\
4.46 \\
3.89 \\
3.42 \\
3.02 \\
2.63 \\
2.31 \\
2.02 \\
1.80 \\
1.60 \\
1.44 \\
1.33\end{array}$ \\
\hline
\end{tabular}

Slope of Iine $=2.15 \times 10^{-2} h^{3} I(h) / h^{3}$ 


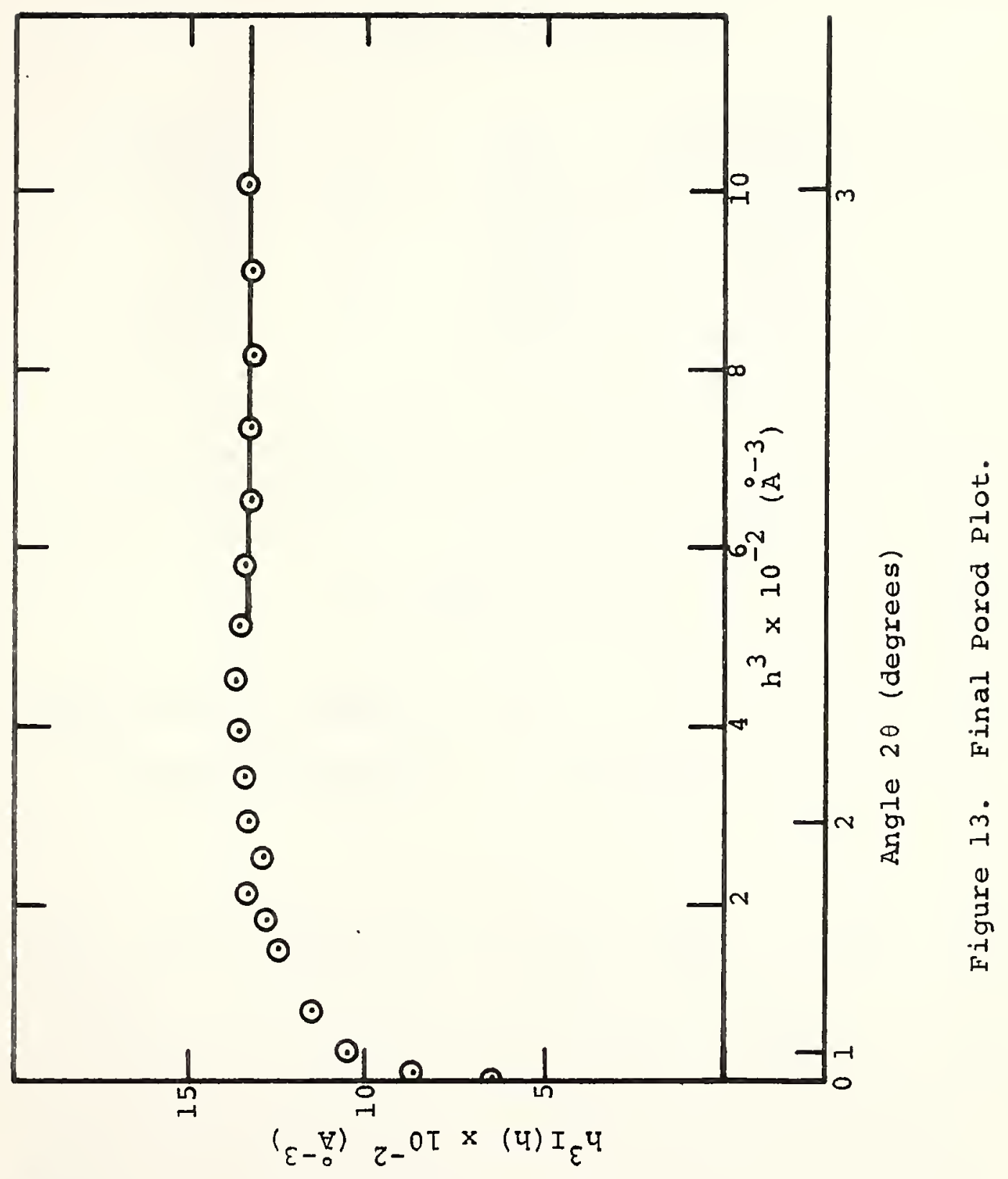


Table 9

Very-Large-Angle Extrapolation of Porod's Invariant Cement Paste, $W / c=0.4, A g e=514$ days, ' $D$ ' dried

$$
\begin{aligned}
& \text { limit } h^{3} I(h)=0.1336 \\
& h^{3} \rightarrow \infty
\end{aligned}
$$

\begin{tabular}{c|c|c}
$\begin{array}{c}\text { Angle 2 } \theta \\
\text { (degrees) }\end{array}$ & $\begin{array}{c}\mathrm{h}^{3} \\
0 \\
\left(\mathrm{~A}^{-3}\right)\end{array}$ & $\begin{array}{c}\text { Extrapolated } \\
\text { Intensity, I (h), (cps) }\end{array}$ \\
\hline 3.55 & 0.1664 & 0.80 \\
4.52 & 0.3430 & 0.39 \\
6.45 & 1.0000 & 0.13 \\
9.68 & 3.3750 & 0.04 \\
12.90 & 8.0000 & 0.02 \\
16.13 & 15.6250 & 0.01
\end{tabular}

It will be recalled that the term $k$, which is required to calculate the specific surface, is:

$$
\begin{aligned}
K= & \operatorname{limit} h^{3} I(h) \\
& h^{3} \rightarrow \infty
\end{aligned}
$$

This value is already at hand.

Porod's invariant, $Q$, is defined as:

$$
Q=0^{j^{\infty}} h I(h) d h
$$

Thus, what is required is the area under a graph of $h I(h)$ versus $h$. In this work, the area is obtained by numerical integration using the trapezoid rule. The entire range of $h$ values is divided into a number of small segments. The curve of $h I(h)$ is assumed to be linear within any one segment and the area of each segment is calculated as though it were a trapezoid. The sum of all of these areas 
Table 10

Complete, corrected Iisting of scattered Intensities Cement Paste, $\mathrm{W} / \mathrm{C}=0.4$, Age $=514$ days, ' $\mathrm{D}$ ' Dried

\begin{tabular}{|c|c|c|c|}
\hline $\begin{array}{l}\text { Angle } 2 \theta \\
\text { (degrees) }\end{array}$ & $\begin{array}{l}\text { Intensity } \\
\text { (cps) }\end{array}$ & $\begin{array}{l}\text { Angle } 2 \theta \\
\text { (degrees) }\end{array}$ & $\begin{array}{c}\text { Intensity } \\
\text { (cps) }\end{array}$ \\
\hline $\begin{array}{l}0.01 \\
0.02 \\
0.03 \\
0.035 \\
0.04 \\
0.045 \\
0.05 \\
0.055 \\
0.0575 \\
0.06 \\
0.0625 \\
0.065 \\
0.0675 \\
0.07 \\
0.0725 \\
0.075 \\
0.0775 \\
0.08 \\
0.085 \\
0.09 \\
0.095 \\
0.10 \\
0.12 \\
0.15 \\
0.20 \\
0.25\end{array}$ & $\begin{array}{l}20,400 \\
18,800 \\
16,200 \\
15,000 \\
13,400 \\
11,600 \\
10,000 \\
8,700 \\
7,757 \\
7,469 \\
6,690 \\
6,158 \\
5.459 \\
4,902 \\
4,449 \\
4,129 \\
3,739 \\
3,471 \\
3,025 \\
2,639 \\
2,365 \\
2,105 \\
1,463 \\
1,017 \\
645.2 \\
454.6\end{array}$ & $\begin{array}{r}0.30 \\
0.40 \\
0.50 \\
0.70 \\
1.00 \\
1.30 \\
1.60 \\
1.70 \\
1.80 \\
1.90 \\
2.00 \\
2.10 \\
2.20 \\
2.30 \\
2.40 \\
2.50 \\
2.60 \\
2.70 \\
2.80 \\
2.90 \\
3.00 \\
3.55 \\
4.52 \\
6.45 \\
9.68 \\
12.90 \\
16.13\end{array}$ & $\begin{array}{r}350.9 \\
215.8 \\
140.3 \\
68.47 \\
28.15 \\
14.01 \\
8.15 \\
6.95 \\
6.14 \\
5.00 \\
4.46 \\
3.89 \\
3.42 \\
3.02 \\
2.63 \\
2.31 \\
2.02 \\
1.80 \\
1.60 \\
1.44 \\
1.33 \\
0.80 \\
0.39 \\
0.13 \\
0.04 \\
0.02 \\
0.01\end{array}$ \\
\hline
\end{tabular}


is then very nearly equal to the area under the curve. Table 11 illustrates this calculation process.

A portion of the complete scattering curve, under which this integration is being performed, was obtained by extrapolation. Thus, in contrast to the value of $\mathrm{K}$ which is based solely on experimentally measured data, a part of the value of $Q$ is based upon extrapolation. In the example at hand, approximately 208 of $Q$ is due to the very-low and very-large-angle extrapolations; this percentage is fairly typical for all tests reported here.

All the terms required to calculate the specific surface are now available. The equation is:

$$
S_{W}=\frac{4 K \phi(1-\phi)}{Q \rho}
$$

For the example, $K=13.36 \times 10^{-2} \AA^{-3}$ and $Q=3.1977 \AA^{-2}$. From the preceeding section on experimental techniques, Table 1 gives the porosity, $\phi$, as 0.3051 and the bulk density, $\rho$, as $1.7794 \mathrm{~g} / \mathrm{cc}$. Hence, the specific surface is:

$$
\begin{gathered}
S_{W}=\frac{4 \times 13.36 \times 10^{-2} \AA_{A}^{-3} \times 0.3051 \times(1-0.3051) \times 10^{8} \AA^{2}}{3.1977 \AA^{\circ} \times 1.7794 \mathrm{~g} / \mathrm{cc} \times 10^{4} \mathrm{cc}} \\
S_{W}=199 \frac{\mathrm{m}^{2}}{\mathrm{~g} \mathrm{D}^{1} \mathrm{dry}}
\end{gathered}
$$

If the value is desired on a basis of area per gram of ignited cement, it remains only to multiply the surface 
Table 11

Calculation of Porod's Invariant Cement Paste, $\mathrm{w} / \mathrm{c}=0.4$, Age $=514$ days, ' $\mathrm{D}$ ' dried

\begin{tabular}{|c|c|c|c|c|c|c|}
\hline $\begin{array}{l}\text { Angle } 2 \theta \\
\text { (deg.) }\end{array}$ & $\begin{array}{l}\text { Corrected } \\
\text { Scattered } \\
\text { Intensity, } \\
\text { I(h) (cps) }\end{array}$ & $\left(\begin{array}{c}h \\
\AA^{-1}\end{array}\right)$ & $\begin{array}{l}\text { hI (h)at } \\
\text { smaller } \\
\text { value of } \\
\text { h }\end{array}$ & $\begin{array}{l}h I(h) \text { at } \\
\text { larger } \\
\text { value of } \\
h\end{array}$ & $\begin{array}{l}\text { Change } \\
\text { in h } \\
\text { over } \\
\text { segment }\end{array}$ & \begin{tabular}{|l} 
area \\
of \\
segment
\end{tabular} \\
\hline 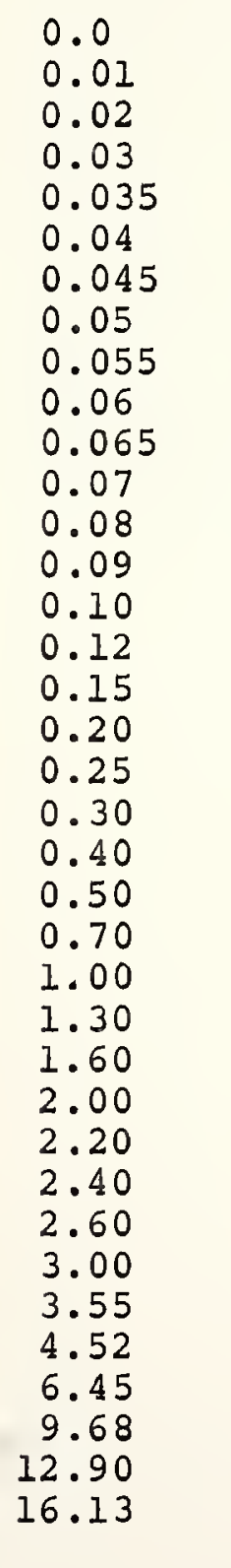 & $\begin{array}{c}- \\
20400 \\
18800 \\
16200 \\
15000 \\
13400 \\
11600 \\
10000 \\
8700 \\
7469 \\
6158 \\
4902 \\
3471 \\
2639 \\
2105 \\
1463 \\
1017 \\
645.2 \\
454.6 \\
350.9 \\
215.8 \\
140.3 \\
68.47 \\
28.15 \\
14.01 \\
8.15 \\
4.46 \\
3.42 \\
2.63 \\
2.03 \\
1.33 \\
0.80 \\
0.39 \\
0.13 \\
0.04 \\
0.02 \\
0.01\end{array}$ & $\begin{array}{l}0.0 \\
0.0016 \\
0.0031 \\
0.0047 \\
0.0054 \\
0.0062 \\
0.0070 \\
0.0078 \\
0.0085 \\
0.0093 \\
0.0101 \\
0.0109 \\
0.0124 \\
0.0140 \\
0.0155 \\
0.0186 \\
0.0233 \\
0.0310 \\
0.0388 \\
0.0465 \\
0.0620 \\
0.0775 \\
0.1085 \\
0.1550 \\
0.2015 \\
0.2480 \\
0.3101 \\
0.3411 \\
0.3721 \\
0.4031 \\
0.4651 \\
0.5500 \\
0.7000 \\
1.0000 \\
1.5000 \\
2.000 \\
2.5000\end{array}$ & $\begin{array}{c}0.0 \\
32.64 \\
58.28 \\
76.14 \\
81.00 \\
83.08 \\
81.20 \\
78.00 \\
73.95 \\
69.46 \\
62.20 \\
53.43 \\
43.04 \\
36.95 \\
32.63 \\
27.21 \\
23.70 \\
20.00 \\
17.64 \\
16.32 \\
13.38 \\
10.88 \\
7.43 \\
4.36 \\
2.82 \\
2.02 \\
1.38 \\
1.17 \\
0.98 \\
0.82 \\
0.62 \\
0.44 \\
0.27 \\
0.13 \\
0.06 \\
0.04 \\
0.03\end{array}$ & $\begin{array}{l}32.64 \\
58.28 \\
76.14 \\
81.00 \\
83.08 \\
81.20 \\
78.00 \\
73.95 \\
69.46 \\
62.20 \\
53.43 \\
43.04 \\
36.95 \\
32.63 \\
27.21 \\
23.70 \\
20.00 \\
17.64 \\
16.32 \\
13.38 \\
10.88 \\
7.43 \\
4.36 \\
2.82 \\
2.02 \\
1.38 \\
1.17 \\
0.98 \\
0.82 \\
0.62 \\
0.44 \\
0.27 \\
0.13 \\
0.06 \\
0.04 \\
0.03 \\
- \\
0 \\
=\end{array}$ & $\begin{array}{l}0.0016 \\
0.0015 \\
0.0016 \\
0.0007 \\
0.0008 \\
0.0008 \\
0.0008 \\
0.0007 \\
0.0008 \\
0.0008 \\
0.0008 \\
0.0015 \\
0.0016 \\
0.0015 \\
0.0031 \\
0.0047 \\
0.0077 \\
0.0078 \\
0.0077 \\
0.0155 \\
0.0155 \\
0.0310 \\
0.0465 \\
0.0465 \\
0.0465 \\
0.0621 \\
0.0310 \\
0.0310 \\
0.0310 \\
0.0621 \\
0.0849 \\
0.1500 \\
0.3000 \\
0.5000 \\
0.5000 \\
0.5000 \\
- \\
0.0 \\
0.0\end{array}$ & $\begin{array}{l}0.0261 \\
0.0682 \\
0.1075 \\
0.0550 \\
0.0656 \\
0.0657 \\
0.0637 \\
0.0532 \\
0.0574 \\
0.0527 \\
0.0463 \\
0.0724 \\
0.0640 \\
0.0522 \\
0.0928 \\
0.1196 \\
0.1682 \\
0.1468 \\
0.1307 \\
0.2302 \\
0.1880 \\
0.2838 \\
0.2741 \\
0.1669 \\
0.1125 \\
0.1056 \\
0.0395 \\
0.0333 \\
0.0279 \\
0.0447 \\
0.0450 \\
0.0533 \\
0.0600 \\
0.0475 \\
0.0250 \\
0.0175 \\
- \\
3.1977\end{array}$ \\
\hline
\end{tabular}


area by the appropriate ratio from the loss on ignition data. Thus:

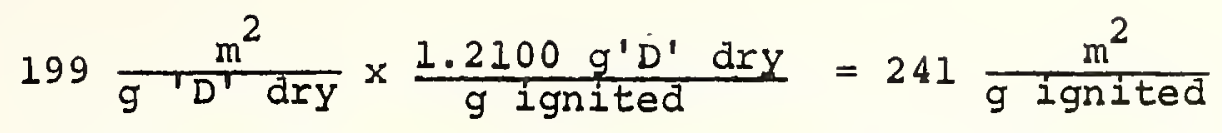

The above process is straightforward once the corrected scattering curve is at hand. The corrections involved, in summary, each of the following: overcoming experimental problems such as dead time and parasitic scatter; adjusting intensities to reflect scatter from interfaces only; and extending the range of values to permit a calculation of the area under the complete scattering curve. 
RESULTS

\section{Illite and Activated Charcoal}

The specific surface of illite clay and of activated charcoal were measured by vapor adsorption using nitrogen and water vapor as adsorbates as well as by low-angle $x$-ray scattering. The values obtained from each of the individual experimental trials are given in Table 12 along with the average surface area for each method. The agreement between the vapor sorption and the $\mathrm{x}$-ray scattering areas is not as close as might be hoped, but the results do show that approximately the same specific surfaces are measured by each method. Certain details of the experiments will be discussed later and may account for the spread in values.

\section{Tests on Mature, $w / c=0.4$ Cement Pastes}

The main thrust of this research was a thorough investigation of the surface area of a mature, $w / c=0.4$ cement paste under a variety of wet and dry conditions. Table 13 lists the surface area of a series of progressively drier cement pastes. Individual surface area values obtained from each experiment are listed, along with averages for each state of dryness. All surface areas are given as 
Table 12

Specific Surface of Illite $\mathrm{Clay}$ and Activated Charcoal $\left(\mathrm{m}^{2} / \mathrm{g}\right)$

\begin{tabular}{c|c|c|c} 
& \begin{tabular}{l|l}
$\mathrm{N}_{2}$ \\
Sorption \\
Tests
\end{tabular} & $\begin{array}{l}\mathrm{H}_{2} \mathrm{O} \\
\text { Sorption } \\
\text { Tests }\end{array}$ & $\begin{array}{l}\text { X-Ray } \\
\text { Scattering } \\
\text { Tests }\end{array}$ \\
\hline Illite Clay & 88 & 85 & 80 \\
Average: & 83 & 82 & 83 \\
77 & 87 & 71 \\
& 83 & 85 & 78 \\
\hline Activated Charcoal & 1045 & 1380 & 1147 \\
& 1016 & 1456 & 1075 \\
& 1035 & 1334 & 1089 \\
& & & 1065 \\
& & & 1187 \\
Average: & 1032 & 1390 & 1130
\end{tabular}

square meters per gram of cement paste ignited at $1050^{\circ} \mathrm{C}$.

The table shows a progressive decrease in surface area as the cement paste is dried, except that the measured surface area of specimens equilibrated at $12 \%$ relative humidity appears to be an aberration with respect to the general trend.

Table 14 delineates the surface areas of dried and resaturated cement pastes. In this table, as in ones to follow, previously itemized results are repeated for ease in comparing with other values. The results in this table indicate that virtually all of the surface area lost upon drying is regained upon resaturation. Samples which were 
Table 13

Results of Drying Cement Paste $\mathrm{w} / \mathrm{c}=0.4,514$ days old, $86 \%$ hydrated

\begin{tabular}{|c|c|c|}
\hline Condition & $\begin{array}{l}\text { Surface Area, } \\
\text { individual } \\
\text { tests } \\
\text { (m²/ignited g) }\end{array}$ & $\begin{array}{l}\text { Average } \\
\text { Surface } \\
\text { Area } \\
\left(\mathrm{m}^{2} / \text { ignited g) }\right.\end{array}$ \\
\hline Saturated, surface dry & $\begin{array}{l}682 \\
747 \\
696\end{array}$ & 708 \\
\hline $\begin{array}{l}\text { Equilibrated with } 50 \% \\
\text { relative humidity }\end{array}$ & $\begin{array}{l}331 \\
335 \\
324\end{array}$ & 330 \\
\hline $\begin{array}{l}\text { Equilibrated with } 12 \% \\
\text { relative humidity }\end{array}$ & $\begin{array}{l}180 \\
203 \\
184\end{array}$ & 189 \\
\hline 'P' Dried & $\begin{array}{l}288 \\
261 \\
268\end{array}$ & 272 \\
\hline 'D' Dried & $\begin{array}{l}240 \\
218 \\
214\end{array}$ & 224 \\
\hline $\begin{array}{l}\text { Oven Dried, } 105^{\circ} \mathrm{C} \text {, } \\
\text { no vacuum }\end{array}$ & $\begin{array}{l}168 \\
177 \\
195\end{array}$ & 180 \\
\hline Vacuum Oven Dried, $105^{\circ} \mathrm{C}$ & $\begin{array}{l}138 \\
132 \\
145\end{array}$ & 138 \\
\hline
\end{tabular}


Table 14

Results of Resaturating Cement Paste $\mathrm{w} / \mathrm{c}=0.4,514$ days old, 868 hydrated

\begin{tabular}{l|c|c} 
Condition & $\begin{array}{c}\text { Surface Area } \\
\text { Individual } \\
\text { Test } \\
\left(\mathrm{m}^{2} / \text { ignited g) }\right.\end{array}$ & $\begin{array}{c}\text { Average } \\
\text { Surface } \\
\text { Area } \\
\left(\mathrm{m}^{2} / \text { ignited g) }\right.\end{array}$ \\
\hline Saturated, surface dry & 682 & \\
747 & 708 \\
'P' Dried and & 696 & 697 \\
Resaturated & 700 & \\
'D' Dried and & 674 & 707 \\
Resaturated & 701 & \\
Oven Dried, 105 & \\
Vacuum and Resaturated & 664 & 651 \\
Vacuum Oven Dried, 105 & 602 & \\
and Resaturated & 688 & 655 \\
& 655 & \\
& 629 &
\end{tabular}

Table 15

Results of Heating Cement Paste $\mathrm{w} / \mathrm{c}=0.4,514$ days old, 868 hydrated

\begin{tabular}{|c|c|c|}
\hline Condition & $\begin{array}{l}\text { Surface Area } \\
\text { Individual } \\
\text { Tests } \\
\left(\mathrm{m}^{2} / \text { ignited g) }\right.\end{array}$ & $\begin{array}{l}\text { Average } \\
\text { Surface } \\
\text { Area } \\
\text { ( } \mathrm{m}^{2} / \text { ignited g) }\end{array}$ \\
\hline Saturated, surface dry & $\begin{array}{l}682 \\
747 \\
696\end{array}$ & 708 \\
\hline $\begin{array}{l}\text { Saturated and Heated in } \\
\text { Limewater at } 105^{\circ} \mathrm{C} \text { for } \\
24 \text { hours }\end{array}$ & $\begin{array}{l}402 \\
461 \\
335\end{array}$ & 399 \\
\hline Vacuum Oven Dried, $105^{\circ} \mathrm{C}$ & $\begin{array}{l}138 \\
132 \\
145\end{array}$ & 138 \\
\hline $\begin{array}{l}\text { Vacuum Oven Dried, } 105^{\circ} \mathrm{C} \\
\text { for } 240 \text { days }\end{array}$ & $\begin{array}{l}125 \\
109 \\
133\end{array}$ & 122 \\
\hline
\end{tabular}


dried without heat, ('P' and ' $D$ ' drying), recover all of their surface; those that were heated to $105^{\circ} \mathrm{C}$ for 48 hours show an irreversible loss of about $88^{\circ}$ of their original surface area.

The effects of the special heat treatments are given in Table 15. Cement paste that is heated to $105^{\circ} \mathrm{C}$ for 24 hours shows a decrease in surface area of about $40 \%$ from the saturated but never heated value. Vacuum oven drying produces a large decrease in surface area, and very prolonged vacuum oven drying causes a further decrease of about $10 \%$.

Two other variations were tried on $\mathrm{w} / \mathrm{c}=0.4$ cement pastes and Table 16 lists these results. Cement paste hydrated for one day has a considerably lower surface area, wet or dry, than mature cement paste. However, there does not appear to be an exactly proportional relationship between the degree of hydration and the surface area, i.e. the mature sample is 2.2 times as hydrated as the one day specimen but has 2.4 times as much surface area when wet. When ' $D$ ' dried, the 514 day sample has only 1.5 times as much surface as the one day sample. The relatively mature alite paste is seen to have very nearly the same surface area as the mature portland cement paste.

Table 17 lists the surface areas of cement pastes of varying water to cement ratios. The trend for both wet and dry samples is that, for almost the same age, the 


\section{Table 16}

Surface Area of Other $\mathrm{w} / \mathrm{s}=0.4$ Cement Pastes

\begin{tabular}{|c|c|c|}
\hline Condition & $\begin{array}{l}\text { Surface Area, } \\
\text { individual } \\
\text { tests } \\
\left(\mathrm{m}^{2} / \text { ignited g) }\right.\end{array}$ & $\begin{array}{l}\text { Average } \\
\text { Surface } \\
\text { Area } \\
\left(\mathrm{m}^{2} / \text { ignited } \mathrm{g}\right)\end{array}$ \\
\hline $\begin{array}{l}\text { Cement Paste, } w / c=0.4, \\
514 \text { days, } 86 \% \text { hydrated, } \\
\text { saturated, surface dry }\end{array}$ & $\begin{array}{l}682 \\
747 \\
696\end{array}$ & 708 \\
\hline $\begin{array}{l}\text { Cement Paste, } w / c=0.4 \text {, } \\
514 \text { days, } 86 \% \text { hydrated, } \\
\text { 'D' dried. }\end{array}$ & $\begin{array}{l}240 \\
218 \\
214\end{array}$ & $\begin{array}{l}224 \\
224\end{array}$ \\
\hline $\begin{array}{l}\text { Cement paste, } w / c=0.4, \\
1 \text { day, } 39 \% \text { hydrated, } \\
\text { saturated, surface dry }\end{array}$ & $\begin{array}{l}262 \\
296 \\
320\end{array}$ & 293 \\
\hline $\begin{array}{l}\text { Cement Paste, } w / c=0.4 \text {, } \\
\text { I day, } 39 \% \text { hydrated, } \\
\text { ' } D \text { ' dried }\end{array}$ & $\begin{array}{l}152 \\
105 \\
146\end{array}$ & 134 \\
\hline $\begin{array}{l}\text { Alite Paste, } w / s=0.4, \\
245 \text { days, saturated, } \\
\text { surface dry }\end{array}$ & $\begin{array}{l}745 \\
766 \\
695\end{array}$ & 735 \\
\hline $\begin{array}{l}\text { Alite Paste, } w / s=0.4 \text {, } \\
245 \text { days, ' } D \text { ' dried }\end{array}$ & $\begin{array}{l}258 \\
258 \\
247\end{array}$ & 254 \\
\hline
\end{tabular}


Table 17

Surface Area of Different $w / C$ Cement Pastes

\begin{tabular}{|c|c|c|}
\hline Condition & $\begin{array}{l}\text { Surface Area, } \\
\text { individual } \\
\text { tests } \\
\text { (mgnited g) }\end{array}$ & $\begin{array}{l}\text { Average } \\
\text { Surface } \\
\text { Area } \\
\left(\mathrm{m}^{2} / \text { ignited } \mathrm{g}\right)\end{array}$ \\
\hline $\begin{array}{l}\text { w/c }=0.3,513 \text { days, } \\
78 \% \text { hydrated, } \\
\text { saturated, surface dry }\end{array}$ & $\begin{array}{l}540 \\
533 \\
506\end{array}$ & 527 \\
\hline $\begin{array}{l}w / c=0.3,513 \text { days, } \\
78 \% \text { hydrated, ' } D \text { ' dried }\end{array}$ & $\begin{array}{l}158 \\
156 \\
162\end{array}$ & 159 \\
\hline $\begin{array}{l}\text { w/c }=0.4,514 \text { days, } \\
86 \% \text { hydrated, } \\
\text { saturated, surface dry }\end{array}$ & $\begin{array}{l}682 \\
747 \\
696\end{array}$ & 708 \\
\hline $\begin{array}{l}w / c=0.4,514 \text { days, } \\
868 \text { hydrated, 'D' dried }\end{array}$ & $\begin{array}{l}240 \\
218 \\
214\end{array}$ & 224 \\
\hline $\begin{array}{l}\text { w/c }=0.6,512 \text { days, } \\
918 \text { hydrated, } \\
\text { saturated, surface dry }\end{array}$ & $\begin{array}{l}880 \\
801 \\
664\end{array}$ & 782 \\
\hline $\begin{array}{l}w / c=0.6,512 \text { days, } \\
91 \% \text { hydrated, ' } D \text { ' dried }\end{array}$ & $\begin{array}{l}300 \\
316 \\
245 \\
276\end{array}$ & 284 \\
\hline
\end{tabular}


greater the water to cement ratio, the greater is the degree of hydration and, so, the greater is the surface area. Again, there is not an exactly proportional relationship between the degree of hydration and the surface area. 


\section{DISCUSSION}

It is clear from the level of agreement obtained between the surface areas measured for the illite clay and the activated charcoal samples by $\mathrm{x}$-ray scattering and those measured on the same samples by sorption that the X-ray surface area measurements yield appropriate and correct surface areas for non-cementitious materials. Detailed discussion of this portion of the work and other matters of interpretation will be deferred until after the discussion of the results of the cement paste studies.

\section{Cement Paste Microstructure}

Vapor Sorption and X-Ray Surface Area Comparisons The question of the validity of $\mathrm{N}_{2}$ versus $\mathrm{H}_{2} \mathrm{O}$ vapor sorption specific surfaces for cement paste was the initial impetus for this work, and the x-ray scattering results shed considerable light on the debate. As pointed out in the introduction, nitrogen vapor adsorption measurements yield values of $10-50 \mathrm{~m}^{2} / \mathrm{g}$ for the surface area of dried cement paste. It is clear that even for the most rigorously dried cement paste, which has the lowest surface area by $\mathrm{x}$-ray measurements, the nitrogen values are far too low. 
The $\mathrm{x}$-ray scattering data indicates that most of the surface area that exists is not being recorded by nitrogen. There are a number of reasons why this may be so. First, nitrogen molecules may be too large to penetrate the fine pores where a considerable portion of the surface lies. Adaitionally or alternatively, some of the surface area may be completely sealed off and thus unavailable for sorption; $\mathrm{x}$-rays can of course penetrate "closed" pores and register their surface. Another possibility concerns kinetics. Sorption experiments with nitrogen are typically performed at $-196^{\circ} \mathrm{C}$. There is evidence that at this low temperature the energy of the $\mathrm{N}_{2}$ molecule may be insufficient to overcome some activation energy barrier, so that it requires an exceedingly long time to reach equilibrium during sorption. Thus, what appears to be a sorption equilibrium may not actually be so. Whatever the cause, it appears that nitrogen measures only a small portion of the surface area of dried cement paste.

Water vapor sorption typically gives specific surfaces of 150-250 $\mathrm{m}^{2} / \mathrm{g}$ for dried cement paste. This is at least in approximate agreement with the $x$-ray scattering values. However, according to the indirect evidence advanced by Feldman (2), water in the vapor phase is able to reenter a dried cement paste, presumably going into interlayer space. The present research clearly demonstrates that exposure to water in the liquid phase drastically increases 
the measured surface areas of dried samples, by a factor of the order of three or four. Thus, there is reason to believe that, in addition to registering the existing surface area of a dried cement paste, water vapor may also increase the extent of that surface during the adsorption measurement. Thus, it may be fortuitous that water vapor adsorption gives results in approximate agreement with X-ray scattering results. To assist in deciding the issue, x-ray scattering experiments would need to be carried out upon samples which were dried and then exposed to specific relative humidities within the B.E.T. range. This work has not been done and the question of water vapor's ability to correctly measure the specific surface remains open, at least in the opinion of the author.

\section{Effect of Drying Saturated Cement Paste}

Perhaps the single most important result of the present study is that wet and dry cement pastes have very different surface areas. Virtually all prior microstructural research on cement paste has been performed on dry specimens. However, the hydrated portland cement paste that acts as a binder in concrete is generally saturated or at least has a high moisture content. The present results thus imply that the cement paste in concrete structures does not have the same microstructure as the cement paste usually studied in laboratories. Techniques that involve drying alter the microstructure of saturated or wet cement 
paste in at least this one important detail. The surface area of dried cement paste should certainly not be used as a parameter for a model of saturated or "normal" cement paste. Other characterizations of cement paste after drying should be regarded as provisional unless and until it has been established that the drying process has not, in itself, changed the parameters in question.

\section{Surface Area of Saturated Cement Paste}

Table 13 indicates that the $w / c=0.4$ specimens of portland cement paste, hydrated for 514 days, have a surface area, when saturated, of $708 \mathrm{~m}^{2} / \mathrm{g}$ of ignited cement paste. This value converts to about $585 \mathrm{~m}^{2} / \mathrm{g}$ of equivalent ' $D$ ' dried cement paste. The cement paste in question is only partially hydrated, about $86 \%$ to be specific. If one makes the reasonable assumption that the remaining components of the unhydrated cement have essentially zero surface area, then the above figures can be used to estimate surface area values for fully hydrated cement paste. The values would be: $825 \mathrm{~m}^{2} / \mathrm{g}$ of ignited, fully hydrated cement paste and $680 \mathrm{~m}^{2} / \mathrm{g}$ of ' $\mathrm{D}$ ' dried, fully hydrated cement paste.

The hydrated cement paste contains hydrates other than those of calcium silicate, especially hydrated lime, $\mathrm{Ca}(\mathrm{OH})_{2}$. In a mature cement paste similar to those studied here, made with the same portland cement, the weight percent of $\mathrm{Ca}(\mathrm{OH})_{2}$ was found to be about $22 \%$. Much of the 
lime appearing in photomicrographs of cement paste is in large, bulky crystals which probably have a negligible surface area. If one assumes that all of the lime has a zero surface area, the specific surface values may be "corrected" for the presence of the lime. After subtracting off the lime and adjusting for the degree of hydration, surface areas are: $1055 \mathrm{~m}^{2} / \mathrm{g}$ of ignited, hydrated cement exclusive of lime and $870 \mathrm{~m}^{2} / \mathrm{g}$ of ' $\mathrm{D}$ ' dried, hydrated cement exclusive of lime. While there are other constituents present in minor amounts, these values may reasonably be taken as being estimates of the surface area of the calcium silicate hydrate gel itself.

There is no experimental evidence that all of the lime has a negligible surface area. If even a small fraction of the lime present is finely divided, then the above assumption is in error and the adjusted values of specific surface for the calcium silicate hydrate gel are erroneously large.

Brunauer has calculated ( 1 ) that a theoretical surface area for single layered calcium silicate hydrate gel is $755 \mathrm{~m}^{2} / \mathrm{g}$. Expressed on an ignited weight basis this value is about $910 \mathrm{~m}^{2} / \mathrm{g}$. Theoretical estimates of the surface area of single layers of montmorillonite clay yield about $780 \mathrm{~m}^{2} / \mathrm{g}$ (19). Such a value would be about $850 \mathrm{~m}^{2}$ when expressed on the basis of a gram of clay ignited at $1050^{\circ} \mathrm{C}$. Thus, the adjusted, measured values for the calcium 
silicate hydrate gel in cement paste are of the order of 15-20\% higher than the theoretical values for singlelayered calcium silicate hydrate gel and montmorillonite systems.

This modest concordance between the $\mathrm{X}$-ray estimates for the surface area of calcium silicate hydrate gel in the saturated state and theoretically calculated surface areas for hypothetical individual layered systems is interesting. The fact that the $\mathrm{x}$-ray estimates are slightly larger could be explained by the imperfect assumption that the lime present has zero surface, or by assuming that the individual layers may be relatively small in areal extent, or have holes in them. The latter two possibilities would allow the edges of the unit-layer thick particles to make contributions to the total theoretically calculated surface area, thus increasing the figures previously cited.

The results of this research do not prove nor disprove the idea that interlayer spaces exist in the calcium silicate hydrate gel within cement paste. They do indicate that the theoretically predicted surface area of such a system is about the same as the experimentally measured and subsequently adjusted surface area of hydrated cement paste. However, other microstructural models, such as the one recently proposed by Grudemo (20), might be developed to explain the large surface area. 
Effect of Progressive Drying of Cement Paste

Table 13 indicates that progressively more severe drying, resulting in the removal of more and more water, is accompanied by an attendant reduction in surface area. This could be explained as the progressive removal of interlayer water and the collapse of interlayer spaces. The nature of the decrease in area suggests that, if this is an interlayer system, all of the interlayer water is not equally easily removed; as the severity of the drying is increased, it may be that water which is increasingly hard to remove is pulled out and the interlayer spaces in which it lay then collapse. Certainly the fact that vacuum oven drying produces a smaller surface area than does oven drying at atmospheric pressure indicates that some of the water is exceedingly tightly bound. Finally, it is important to note that, of the original saturated surface area, approximately $20 \%$ lies in pores other than those that collapse or are removed by drying, and that even vacuum oven aried cement paste retains a large surface area.

The cement paste specimens conditioned at $12 \%$ relative humidity are an exception to the observed trend of decreasing surface area with decreasing moisture content. This exception is thought to be the result of the failure of the sample to meet the assumptions of Porod's theory. Porod assumed a two-phase scattering system. As long as 
the surface bounds pores that are either saturated or empty, this assumption is met by the cement paste. Even when the sample is conditioned to $50 \%$ relative humidity (equivalent Kelvin equation pore diameter of $30 \AA$ ) the bulk of the surface area must bound smaller, still saturated micropores. On the other hand, when the sample is dried to the condition of, say, 'D' drying, the bulk of the remaining area must bound empty pores. However, at $12 \%$ relative humidity the situation may be that a portion of the surface area bounds empty pores, and an approximately similar portion may bound saturated micropores. This situation is not amenable to evaluation with Porod's theory. The value for the 128 relative humidity thus may likely be spurious.

Effect of Resaturation of Cement Paste Table 14 lists the surface area of cement paste specimens that have been dried and then resaturated. It will be recalled that the resaturation was performed upon samples that were first evacuated, and is thus more efficient than simply soaking the cement paste in water. In all cases more than 908 of the surface area is recovered. It is thus indicated that, if interlayer spaces do exist, water is able to reopen the collapsed interlayer structure. When the specimen is dried without heating, all of the collapsed space can be reopened. This indicates that, as 
regards surface area, the effect of any room temperature drying is completely reversible.

Recently Smith et al. (21) have been able to detect a basal spacing diffraction peak in an artifically prepared calcium silicate hydrate, CSH(I). They found a decrease in the basal spacing upon severe drying from about $12.5 \AA$ to about $9.8 \AA$, and found that resaturation did not reexpand the basal spacing. This indicates a supposedly irreversible collapse of interlayer space for the material that they tested.

The calcium silicate hydrate gel in the cement paste in the present research is not the same material as the artifically prepared CSH(I) of Smith et al. Its calcium oxide to silica ratio is probably more than 2 (22) as compared to 1.07 in the material evaluated by these workers. The cement paste specimens studied in the present research never produced a basal spacing diffraction peak in any state of dryness. One might argue that it is possible that the greater disorder of the cement paste causes a less perfect collapse of interlayer space and, hence, permits water to reenter the interlayers. Nevertheless, the data of Smith et. al. do not prove the existence of interlayers in the calcium silicate hydrate gel in cement paste and they certainly do not prove that a single layer of water exists and is expelled permanently upon drying. Quite the opposite must obtain if interlayer spaces are present, 
since the lost surface area in cement paste is recoverable upon resaturation.

\section{Effect of Heating Cement Paste}

The results for heated and then resaturated cement paste, given in Table 14, are of interest. The vacuum oven drying process is more severe than oven drying at atmospheric pressure; it removes more water and it yields a lower surface area. However, after resaturation, samples dried both ways display the same surface area. The small portion of the original, saturated surface area which is irreversibiy lost appears to be attributable to the factor common to both, the heating at $105^{\circ} \mathrm{C}$ for 48 hours. This result lead to a series of tests involving heat treatments under several different conditions. The results of this series are given in Table 15.

It is evident that heat facilitates some sort of permanent change which may be akin to sintering. The term 'sintering' is used loosely here to denote some sort of heat-assisted process of crystal growth or of fusing particles together. The results of prolonged heating in a vacuum suggest that, even when dry, the cement paste particles are subject to change and concomitant additional loss in surface area. Lankard (23) has reported the same effect. The results of heating while maintaining saturation suggest that the 'sintering' process is greatly augmented by the presence of water. Perhaps the water acts 
as a medium for the facile transfer of material. It is known that steam curing of fresh cement paste produces a coarser grained, lower surface area hydration product than does curing at room temperature. Apparently this effect can be also brought about in already hydrated cement paste. The marked effect of the presence of water at elevated temperatures suggests that perhaps the irreversible loss in surface area experienced by the cement paste in 48 hours of drying may occur while the specimen is hot but not yet dry.

Surface Area of Alite Paste

The results obtained upon the alite pastes shown in Table 16 indicate that alite and portland cement paste display substantially the same surface area. As one might expect, the alite has a slightly larger surface area, both wet and dry, than does the cement paste. Alite hydrates faster than other constituents in portland cement and it is reasonable that a pure alite paste should achieve a larger surface area in less time.

\section{Effect of Degree of Hydration}

The effect of altering the water to cement ratio is shown in Table 17. Since the main thrust of this research was a study of a single $\mathrm{w} / \mathrm{c}=0.4$ cement paste, only a small amount of data was obtained on mature cement pastes hydrated at different water to cement ratios. One result 
seen from the table is that, for the same age, a larger water to cement ratio yielas a cement paste with a larger surface area. This is to be expected as the samples with larger water to cement ratios have hydrated to a greater extent.

The data in Table 16 permit one observation on an effect of degree of hydration at a single water to cement ratio. The table lists values for a one-day old, $w / c$ $=0.4$ sample which is only $39 \%$ hydrated. This sample displays a considerably lower surface area than the more mature, $86 \%$ hydrated cement paste of the same water to cement ratio. It is seen that, upon ' $D$ ' drying, the oneday cement paste loses about 54 \% of its saturated surface area. Table 16 shows that a similar but older paste, $86 \%$ hydrated, loses about $68 \%$ of its surface area in the same drying treatment. This may point to differences in the hydration product at different stages of hydration. One might suppose that, at later stages of hydration, more of the presumed collapsible, interlayer-rich hydration product is being layed down, so that the more hydrated paste has proportionately more surface area to lose upon arying. However, results on more samples would be required to verify this inference. 
General Matter of Interpretation of $\mathrm{X}$-Ray Scattering Results

Reproducibility of X-Ray scattering Measurements

Examination of the individual surface area results suggests that the repeatability of replicate surface area measurements upon ostensibly duplicate specimens is not as good as might be desired. A discussion of factors relating to this problem can be framed with respect to the fact that Low-angle $x$-ray scattering requires exceedingly accurate measurements of small scattered intensities. Unfortunately, the equipment used in this research was not specifically designed for low-angle scattering and its attendant stringent accuracy requirements. Data sufficiently accurate to be useful was obtained only by a continuous effort to maintain the equipment in its most stable and accurate conaition. This equipment problem limits the inherent reproducibility of the results.

Under these conditions the repeatability is to some extent dependent on the level of scattered intensity produced by the sample. Any factor that tends to lower the scattered intensity tends to reduce the repeatability of the replicate measurements. One such factor was the condition of saturation of the specimens. The scattered intensity is proportional to the difference in electron density across the solid-pore interface. This difference is relatively small when the pores are filled with water, tinus reducing the scattered intensity as compared with 
dried specimens. A second factor is the specific surface of the sample itself; larger surface areas produce more intense scatter and thus permit better precision. While to some extent the effects of these two factors are opposed to each other as saturated specimens had larger surface areas, in the present measurements the greatest spread in values of replicate tests is seen to be with those specimens that either had a small surface area or were saturated. These indications do not, of course, preclude the possibilicy that real differences between replicates may have been present due to inhomogeneities in the pastes.

Comparison of Sorption and x-ray Scattering Results on Illite Clay and Activated Charcoal

The tests on illite clay and activated charcoal were carried out to verify that the experimental technique was being properly applied. They did this to a satisfactory degree, despite the spread of the individual values. Part of the spread was undoubtedly due to sample variation. Periect low-angle scattering specimens were hard to prepare for both materials. Homogeneity was difficult to achieve in the "mua" from which the illite specimens were cast, and it was hard to obtain specimens of uniform thickness; the charcoal particles tended to shift in their sample holder in spite of careful preparation and handling and this also caused some inhomogeneity. 
The illite clay results reveal close agreement between the surface areas obtained by the different techniques of measurement, but the x-ray data are about 5\% lower than the adsorption values. X-rays usually register a larger surface area than sorption measurements, as the $x$-rays can record the surface in isolated pores that are physically unavailable to adsorbing vapors. However, some authors (for example Shurov et. al. (24) and Kahovec et. al. (25)), have reported results in which the sorption values exceeded the $\mathrm{x}$-ray scattering values.

The activated charcoal results for $\mathrm{N}_{2}$ adsorption and $\mathrm{X}$-ray scattering tests are more typical in that the $\mathrm{x}$-rays register about $10 \%$ more surface than the nitrogen. But water vapor measurements yield values of the order of $20 \%$ higher than X-ray measurements. Nevertheless, the agreement is perhaps as good as might be expected for this system.

Brumberger (26) has published a short compilation taken from the existing literature of such comparisons between sorption and $\mathrm{x}$-ray scattering. The data from the literature generally indicate poorer agreement than that obtained in this research. Table 18 lists Brumberger's compilation. 
Table 18

Comparison of Specific Surfaces Measured by X-ray Scattering and Vapor Sorption Techniques (26)

\begin{tabular}{|c|c|c|}
\hline \multirow[b]{2}{*}{ Substance } & \multicolumn{2}{|c|}{ Specific Surface, $\mathrm{m}^{2} / \mathrm{g}$} \\
\hline & $x-r a y$ & Sorption \\
\hline $\mathrm{Al}_{2} \mathrm{O}_{3}$ & 255 & 210 \\
\hline $\mathrm{Al}_{2} \mathrm{O}_{3}$ & 506 & 399 \\
\hline $\mathrm{Al}_{2} \mathrm{O}_{3}$ & 145 & 116 \\
\hline $\mathrm{Al}_{2} \mathrm{O}_{3}-\mathrm{SiO}_{2}$ & 396 & 254 \\
\hline $\mathrm{SiO}_{2}$ & 206 & 310 \\
\hline
\end{tabular}

Interpretation of Guinier's Law

It is possible to obtain an "average" pore size from a measurement of the radius of gyration which is obtained from the scattering data by using Guinier's Law. As already discussed, the accuracy of such a calculation is dependent upon a knowledge of the steepest slope of the Guinier plot at small angles. Figure 11, a typical plot for this research, indicates that data at angles less than about $0.06^{\circ} 2 \theta$ are masked by interparticle interference and the primary $\mathrm{X}$-ray beam. Hence, values calculated from the data in this work may contain a component of exror due to lack of valid data at sufficiently small angles.

The measured "average" radius of gyration given by Guinier's law is not a simple arithmetic average of the radii of gyration of the individual pores. It is peculiar 
in that it is exceedingly biased to the large end of the size distribution of pores. Specifically it is (6):

$$
\overline{\mathrm{R}}^{2}=\frac{\sum_{i} \mathrm{n}_{i} R_{i}^{8}}{\sum_{i} n_{i} R_{i}^{6}}
$$

where: $\bar{R}=$ "average" radius of gyration of a collection of pores or particles

$\mathrm{R}=$ radius of gyration of the ith class of pores or particles

$\mathrm{n}_{i}=\begin{aligned} & \text { fraction of pores or particles in the } i t h \\ & \text { class. }\end{aligned}$

The fact that the "average" involves the ratio of the 8 th power of $R$ to the 6 th power of $R$ means that, with a pore size distribution as broad as that of cement paste, the "average" is dominated by the largest pores and the exceedingly small pores have virtually no impact upon its value.

In this research a spherical model was assumed to convert the measured radius of gyration to an average pore of a particular geometrical shape. Probably no pores in normal cement paste are actually spherical. Certainly, if there are interlayer spaces these depart very much from sphericity. However, the extreme bias of the "average" means that the smallest pores, i.e. any interlayer spaces, are simply not a factor. The largest pores may well be approximately equant and a spherical pore model may be a reasonable assumption for purposes of 
calculating an approximate "average" pore size from the radius of gyration.

It should be understood that the "average" pore size value obtained represents only a crude characterization of the pore system. An example of this is seen in the insensitivity of the "average" to changes in specific surface. It is reasonable to assume that the average pore size should change when the surface area changes. Table 19 lists the "average" pore sizes calculated from the radii of gyration for the cement pastes tested in this research. The figures cited range from $311 \AA$ to $487 \AA$. It is seen that the value does not change significantly, even though the surface area changes very much from sample to sample. The reason for this insensitivity is the large-pore bias. Virtually all of the surface area lies in the finest pores and changes in these are not reflected in the "average" size as computed with Guinier's Law. For the mature pastes, the "average" size ranges only from about $310 \AA$ to $350 \AA$, except for the single value of $455 \AA$ which may be considered aberrant.

The use of Guinier's Law in this work was not intended to produce an appropriate measure of the average pore size, but rather it was used to extrapolate the verylow-angle intensities to $0^{\circ} 2 \theta$. It was stated previously that the accuracy of this extrapolation depends upon some assurance that points have been measured at sufficiently 
Table 19

"Average" Guinier Law Pore Size of Cement Pastes Sample "Average" Pore Diameter, ( $(\AA)$

$w / c=0.4$ cement paste, $86 \%$ hydrated Saturated, surface dry

$w / c=0.4$ cement paste, $86 \%$ hydrated Equilibrated with $50 \%$ relative humidity $\mathrm{w} / \mathrm{c}=0.4$ cement paste, 868 hydrated, Equilibrated with $12 \%$ relative humidity

$w / c=0.4$ cement paste, $86 \%$ hydrated, ' $P$ ' dried

$\mathrm{w} / \mathrm{c}=0.4$ cement paste, $86 \%$ hydrated, ' $D$ ' dried

$\mathrm{w} / \mathrm{c}=0.4$ cement paste, $86 \%$ hydrated, Oven dried, $105^{\circ} \mathrm{C}$, no vacuum

$\mathrm{w} / \mathrm{c}=0.4$ cement paste, $86 \circ$ hydrated, Vacuum Oven dried, $105^{\circ} \mathrm{C}$

321

$\mathrm{w} / \mathrm{c}=0.4$ cement paste, $86 \%$ hydrated,

' $P$ ' dried and resaturated

$\mathrm{w} / \mathrm{c}=0.4$ cement paste, $86 \%$ hydrated, ' $D$ ' dried and resaturated

$\mathrm{w} / \mathrm{c}=0.4$ cement paste, $86 \%$ hydrated, oven dried and resaturated

$\mathrm{w} / \mathrm{c}=0.4$ cement paste, $86 \%$ hydrated, Vacuum oven dried and resaturated

$\mathrm{w} / \mathrm{c}=0.4$ cement paste, $86 \%$ hydrated, saturated and heated in lime water

$\mathrm{w} / \mathrm{c}=0.4$ cement paste, $86 \%$ hydrated, vacuum oven dried for 240 days

$\mathrm{w} / \mathrm{c}=0.4$ cement paste, $39 \%$ hydrated, saturated, surface dry

$\mathrm{w} / \mathrm{c}=0.4$ cement paste, $39 \%$ hydrated,

' $D$ ' dried

$\mathrm{w} / \mathrm{c}=0.3$ cement paste, $78 \%$ hydrated, Saturated, surface dry

$w / c=0.3$ cement paste, $78 \%$ hydrated, ' $D$ ' dried

$\mathrm{w} / \mathrm{c}=0.6$ cement paste, $91 \%$ hydrated, Saturated, surface dry

$\mathrm{w} / \mathrm{c}=0.6$ cement paste, $91 \%$ hydrated, 
small angles to accurately define the limiting slope of the Guinier plot. Some assurance can be gained from comparison of X-ray "average" pore sizes with mercury intrusion pore size data. Mercury intrusion porosimetry is capable of giving a volume average pore size for a porous material, that is, one can find the pore size which divides the total experimentally determined pore volume distribution into halves. For a mature cement paste, $w / c=0.4$, this mean pore diameter is about $100 \AA$ (13). This value is in at least order of magnitude agreement with the Guinier "average" which is so strongly biased toward big pores. This partial agreement suggests that the extrapolation based upon Guinier's Law is not greatly in error. Further, since the extrapolation is only used to complete the calculation of Porod's invariant, Q, small errors in the extrapolation will not effect the calculated surface area very much.

Sensitivity of Porod Method to Small Surface Separations One other general consideration needs to be mentioned. This is the question of how close two surfaces can be to each other before the pores between them will cease to scatter with sufficient intensity to be recorded as interfacial area. Obviously, if two flat surfaces are pressed completely together, any electron density difference across the interface will be very small and the interface will 
cease to be an effective scatterer of $x$-rays compared to a solid-pore interface.

In the course of this research, some $x$-ray scattering tests were performed on saturated montmorillonite clay specimens. These specimens have a definite layered structure and gave a Bragg diffraction peak indicating about a $19 \AA$ basal spacing. This spacing corresponds to an interlayer separation of about $9 \AA$. The presence of the diffraction peak precluded precise measurement of the surface area. However, theoreticaliy calculated areas for such dispersed clays give values of $700-800 \mathrm{~m}^{2} / \mathrm{g}$. Approximate estimates of the $\mathrm{x}$-ray scattering surface area, secured by working around the interference of the basal peak, were of this same order of magnitude. Hence, it is believed that the method of low-angle $\mathrm{x}$-ray scattering is sensitive to interfacial separations of at least $9 \AA$. Baro (27) has estimated that the sensitivity may extend down to $5 \AA$ separations. However, there is no experimental evidence of the exact minimum separation to which the $x-$ ray scattering method used in this research is sensitive. All that can be stated is that it is less than approximately $9 \stackrel{\circ}{\AA}$. 


\section{CONCLUSIONS}

1. Low-angle $\mathrm{x}$-ray scattering provides a suitable means for measuring the surface area of cement paste and is an important technique for the study of saturated cement paste. 2. Nitrogen vapor adsorption fails to measure most of the surface area that $\mathrm{x}$-ray scattering indicates is present in portland cement paste.

3. Water vapor adsorption yields a measure of the surface area of dried cement paste that is in approximate agreement with $\mathrm{X}$-ray scattering values for dried cement paste. 4. The surface area of saturated cement paste is very large, about $700 \mathrm{~m}^{2} / \mathrm{g}$ (ignited weight basis) for mature $\mathrm{w} / \mathrm{c}=0.4$ samples, and is in approximate agreement with the estimates of surface area for some theoretical systems of unit-layer thick particles.

5. The surface area of cement paste decreases progressively when the cement paste is dried from the saturated state to the dry state.

6. Measured surface areas of dry cement paste cannot be considered to characterize the microstructure of wet, or "normal" cement paste as it exists in concrete structures. 
7. The decrease in surface area upon drying is completely reversible upon resaturation if the drying operation had been carried out without heat.

8. Heating causes an irreversible decrease in the surface area of both saturated and dried cement paste. The decrease in surface area caused by heat is greatly augmented by the presence of pore water.

9. For the same water to solids ratio, the surface area of mature alite paste is nearly the same as that of portland cement paste. 
LIST OF REFERENCES 


\section{LIST OF REFERENCES}

1. Brunauer, S., Odler, I., and Yudenfreund, M., Highway Research Record 328, National Research Council, Washington, D. C., 1970, p. 89.

2. Feldman, R. F., Highway Research Record 370 , National Research Council, Washington, D. C., 1971, p. 8.

3. Brunauer, S., Emmett, P. H., Teller, E., Journal of American Chemical Society, 60, 309, (1938).

4. Porod, G., Kolloid Zeitschrift, 124, 83, (1951).

5. Debye, P., Anderson, H. R., and Brumberger, H., Journal of Applied Physics, 28, 679, (1957).

6. Guinier, A., and Fournet, G., "Small-Angle Scattering of X-Rays," John Wiley, New York, 1955, Chapter 4.

7. Alexander, L. E., "X-Ray Diffraction Methods in Polymer Science," Wiley-Interscience, New York, 1969, p. 301 .

8. Wexler, A., and Hasegawa, S., Journal of Research of National Bureau of Standards, 53, 19, (May 1954).

9. Copeland, L. E., and Bragg, R. H., Journal of Physical Chemistry, 58, 1075, (1954).

10. "Handbook of Chemistry and Physics," R. C. Weast, Ed., 48 th edition, Chemical Rubber, Cleveland, Ohio, 1967, p. D-109.

11. Cullity, B. D., "Elements of X-Ray Diffraction," Addison-Wesley, Reading, Mass., 1967, p. 211.

12. Alexander, I. E., "X-Ray Diffraction Methods in Polymer Science," Wiley-Interscience, New York, 1969, p. 67.

13. Winslow, D. N., and Diamond, S., Journal of Materials, $\underline{5}, 564,(1970)$. 
14. Powers, T. C., ASTM Bulletin 158, 1949, p. 68.

15. Winslow, D. N., MSCE Thesis, Purdue University, Lafayette, Indiana, 1969.

16. Alexander, L. E., "X-Ray Diffraction Methods in Polymer Science," Wiley-Interscience, New York, 1969, p. 283.

17. Schiller, $C_{.}$, and Mering, J., Comptes Rendus, Series B, 264, p. 247, (1967).

18. Ruland, W., Journal of Applied Cyrstallography, 4 p. 70, $(1971)$.

19. Diamond, S. and Kinter, E. B., Proceedings of 5 th National Conference on Clays and Clay Minerals, National Research Council, Washington, D. C., p. 334, (1958).

20. Grudemo, A., R.I.L.E.M. Colloquium on Composite Materials, Toulouse, France, November 1972.

21. Smith, R. H., Bayliss, P., Gamble, B. R., and Mills, R. H., Cement and Concrete Research, 2, 559, (1972).

22. Diamond, S., Cement and Concrete Research, 2,617 , (1972).

23. Lankard, D., Cement and Concrete Research, 2, 195 , (1972).

24. Shurov, A. F., Sorochkin, M. A., and Plavnik, G. M., Kolloidnyi Zhurnal, 32, 454, (1970).

25. Kahovec, L., Porod, G., and Ruck, H., Kolloid Zeitschrift, 16, 133, (1953).

26. Brumberger, H., "X-Ray and Electron Methods of Analysis," H. Van Olphen, Ed., Plenum Press, New York, 1968, p. 76 .

27. Baro, R., Journal Chimie Physique, 57, 1029, (1960).

28. Klug, H. P., and Alexander, L. E., "X-Ray Diffraction Procedures," John Wiley, New York, 1954, p. 205.

29. Cohen, J. B., "Diffraction Methods in Materials Science," Macmillan, New York, 1966, p. 294. 
APPENDICES 
APPENDIX A 
Table 20

Laboratory Report of Purdue Lab Cement No. 317

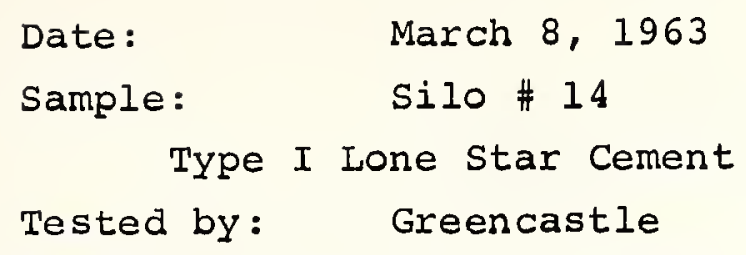

\begin{tabular}{|c|c|c|c|}
\hline \multicolumn{2}{|l|}{ CHEMICAL ANALYSIS: } & \multicolumn{2}{|l|}{ PHYSICAL TESTS: } \\
\hline $\mathrm{SiO}_{2}$ & 21.76 & Normal Consistency & 25.0 \\
\hline $\mathrm{Al}_{2} \mathrm{O}_{3}$ & 5.41 & Expansion & .203 \\
\hline $\mathrm{Fe}_{2} \mathrm{O}_{3}$ & 1.97 & Gilmore: Initial & $3: 15$ \\
\hline $\mathrm{CaO}$ & 65.30 & Gilmore: Final & $5: 05$ \\
\hline $\mathrm{MgO}$ & 1.11 & Vicat & 135 \\
\hline $\mathrm{SO}_{3}$ & 2.43 & \# 325 & 95.9 \\
\hline $\begin{array}{l}\text { Loss } \\
\text { Total } \\
\text { Free Lime } \\
\text { Insol. Res. } \\
\text { Factor } \\
\text { Ratio } \\
\text { A/F }\end{array}$ & $\begin{array}{r}1.78 \\
99.66 \\
0.72 \\
0.27 \\
2.41 \\
2.75\end{array}$ & $\begin{array}{l}\text { Wagner } \\
\text { Blaine } \\
\% \text { Water--Cubes } \\
\text { Flow } \\
\text { Air Entrained - } \frac{}{\%} \\
24 \text { Hr. Temp. }{ }^{\circ} \text {. } \\
\text { Relative Humidity } \\
\text { False Set P.M. }\end{array}$ & $\begin{array}{l}1810 \\
3380 \\
480 \\
108 \\
8.5 \\
70 \\
91 \\
96.88\end{array}$ \\
\hline \multicolumn{2}{|c|}{ COMPOUND COMPOSITION: } & \multicolumn{2}{|c|}{ TENSILE STRENGTH: $1-3$ SAND: } \\
\hline $\mathrm{C}_{3} \mathrm{~s}$ & 51.20 & 1 Day & 220 \\
\hline$C_{3} A \quad\left(C_{2} F\right)$ & 11.00 & 3 Days & 330 \\
\hline $\mathrm{C}_{4} \mathrm{AF}$ & 5.99 & 7 Days & 420 \\
\hline $\mathrm{CaSO}_{4}$ & 4.13 & 28 Days & 510 \\
\hline $\mathrm{Na}_{2} \mathrm{O}^{2}$ & 0.08 & COMPRESSIVE STRENGTH 2 & CUBES: \\
\hline $\mathrm{K}_{2} \mathrm{O}$ & 0.46 & I Day & 1470 \\
\hline Total Alkalies & 0.38 & 3 Days & 2880 \\
\hline & & 7 Days & 4370 \\
\hline & & 28 Days & 5680 \\
\hline
\end{tabular}


Table 21

Analysis of Alite cement

source: Alexander Klein,

university of California at Berkeley

Constituents, as weight percents

\begin{tabular}{ll|ll}
\hline $\mathrm{SiO}_{2}$ & 25.1 & $\mathrm{Al}_{2} \mathrm{O}_{3}$ & 1.1 \\
$\mathrm{CaO}$ & 71.4 & $\mathrm{MgO}$ & 1.5 \\
& & $\mathrm{Fe}_{2} \mathrm{O}_{3}$ & 0.9
\end{tabular}

Free CaO:

2.38

Fineness, Blaine: 
APPENDIX B 


\begin{abstract}
Appendix B
Optimum Thickness for X-Ray scattering Samples
\end{abstract}

An $\mathrm{X}$-ray scattering sample of any thickness will scatter $\mathrm{x}$-rays; however, both very thin and very thick samples will yield exceedingly low scattered intensities. The intensity of scattered $x$-rays will be at a maximum for some thickness between these extremes. It is important to use samples of a thickness that produces this maximum intensity since lower intensities both lengthen the time required to perform an experiment and reduce the accuracy of it. The optimum thickness can be calculated (28) in the following way:

Consider a sample of thickness $t$, with a $x$-ray linear absorption coefficient $\mu$, positioned normal to an incident $x$-ray beam of intensity $I_{0}{ }^{\cdot}$ The intensity of scatter from a small element of thickness $d x$ will be proportional to both $I_{0}$ and $d x$. In addition, the intensity will be diminished by the passage of the x-rays through the entire sample, for a distance of approximately $t$. (It should be noted that the distance of travel is approximately $t$ only for the case of scatter at small angles.) The increment of the scattered intensity, dI, from the small element dx 
can be written as:

$$
d I=k I_{0} e^{-\mu t} d x
$$

And the total intensity, I, from all the $d x$ elements along a line through the sample is then:

$$
I=s^{t} d I=k I_{0} t e^{-\mu t}
$$

Expression B-2 demonstrates that the intensity increases linearly and decreases exponantially with the thickness. This result could be qualitatively anticipated by considering that a thicker specimen provides, simultaneously, more matter to both scatter and to absorb x-rays. The thickness yielding the maximum intensity is obtained by setting the differential of expression $B-2$ equal to zero and solving it for $t$. The result is:

$$
t_{\text {opt }}=\frac{1}{\mu}
$$

The linear absorption coefficient, $\mu$, is a function, among other things, of the wave length of the incident radiation. Shorter, more penetrating, wavelengths have a smaller coefficient and permit a larger optimum thickness. It was for this reason that a molybdenum target was used as the source of radiation in this work, in lieu of the more conventional copper target. It proved impossible to make mechanically stable cement slices of the thickness that were optimum for $\mathrm{Cu} \mathrm{K} \alpha$; the more energetic Mo $\mathrm{K} \alpha$ made 
possible a thickness which could be reasonably sliced and handled. The absorption coefficient, and hence the optimum thickness, is also a function of the nature of the sample. Thus, the chemical composition and porosity of the specimen both have an influence upon the appropriate thickness. It would be possible, in principle, to calculate the best thickness for a sample of cement paste. However, the complexity of the material makes this a difficult and somewhat uncertain procedure. Hence, in this research the optimum thickness was determined experimentally.

Samples of cement pastes at all three w/c ratios used, $0.3,0.4$ and 0.6 , were examined in both the saturated and dry states. A series of slices of different thicknesses was prepared for each type, and the scattered intensity was measured for each in first the wet, and later in the dry condition. The optimum thickness was then obtained by simply preparing a graph of intensity versus thickness for each series of slices. The w/c ratio was found to have the greatest single effect upon the result since the porosity was greatly effected by changes in this parameter. Other factors, such as the degree of saturation and hydration, had a comparatively minor effect upon the optimum thickness. Hence, the $\mathrm{w} / \mathrm{c}$ ratio was the only variable taken into consideration when cutting the specimens for the scattering work reported here. Table 22 lists the experimentally determined optimum thicknesses. 
Table 22

Optimum Thickness of Cement Paste Samples for $\mathrm{X}$-Ray Scattering with Mo Ka Radiation

\begin{tabular}{l|c|c|c}
$\mathrm{w} / \mathrm{c}$ & 0.3 & 0.4 & 0.6 \\
\hline$t_{\text {opt }}$ & $500 \mu \mathrm{m}$ & $600 \mu \mathrm{m}$ & $700 \mu \mathrm{m}$
\end{tabular}

It is useful to observe that expression $B-2$ is not symmetrical about the optimum thickness. Figure 14 demonstrates this graphically. The intensity drops off much more quickly on the thin side of optimum than it does on the thick side. Consider, for example, the situation for thicknesses of $\frac{1}{2} \mu$ and $1 \frac{1}{2} \mu$. The intensity is seen to be about 108 greater for the sample that is $50 \%$ too thick than it is for the one that is 508 too thin. Obviously, it is better to err on the thick rather than the thin side of optimum when cutting a sample. Fortuitously, thicker specimens are also stronger and are handled more easily. So, specimens were never cut thinner than the values given in Table 22 . 


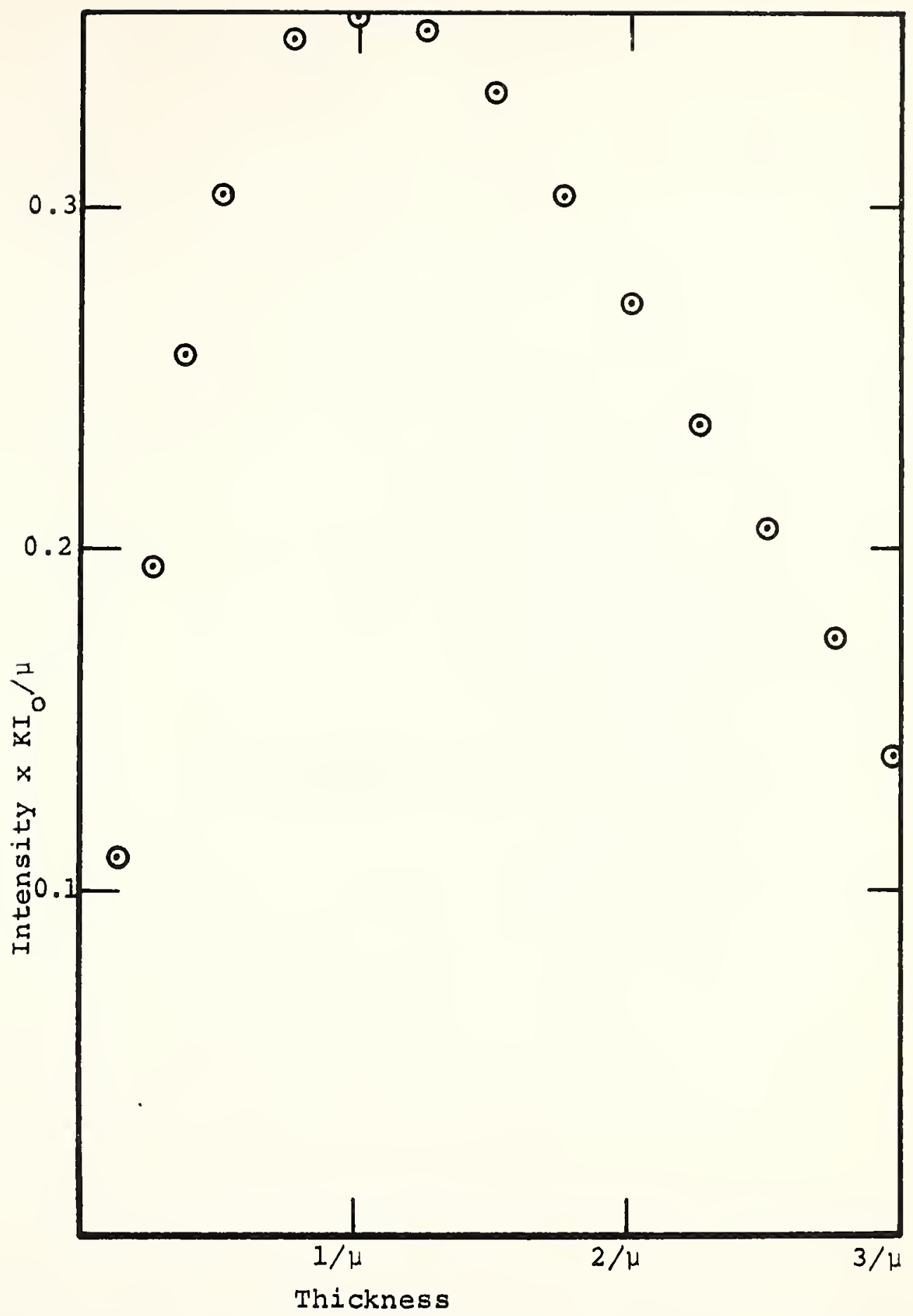

Figure 14. Scattered Intensity vs. Specimen Thickness. 
APPENDIX C 


\begin{abstract}
Appendix C
Counting Circuit Dead Time and Correction For It
\end{abstract}

When an X-ray photon strikes a detector a chain of events is initiated in the x-ray counting circuitry. The detector transforms the $\mathrm{X}$-ray photon into a small electrical pulse which is amplified, accepted or rejected by the pulse height selector and, if accepted, finally recorded by the scaler. The counting circuitry is able to perform this process on only one $x$-ray photon at a time. Thus, for the duration of this process, usually several micro-seconds, no other incident $\mathrm{X}-\mathrm{r}$ ay photons can be recorded. The length of time during which the circuit is disabled is called the dead time.

A circuit's dead time would be of little concern if the $\mathrm{X}$-ray photons arrived at the detector at regular time intervals. Then, as long as the interval was greater than the dead time, all the x-rays would be recorded. A detector could handle, under such a situation, intensities as high as 300,000 to 500,000 counts per second without any loss. The difficulty is that $x$-ray photons arrive at the detector at completely random intervals. Any $x$-ray photon that is spaced closer than the dead time to its predecessor 
will pass unnoticed by the counting circuit. There is, of course, a chance of this happening at any level of incident intensity. However, as the general intensity level increases, so also will the number of too closely spaced $\mathrm{x}$-ray photons. Thus, at high intensities the number of $\mathrm{X}$-ray photons that are missed by the counter can become important. An expression is required that will permit a correction for these missed X-ray photons.

Let: $N_{t}=$ true number of $\mathrm{X}$-ray photons incident upon a detector in one second

$\mathrm{N}_{0}=$ observed number of $\mathrm{X}-\mathrm{ray}$ photons recorded by the counting circuit in one second

$\tau$ = dead time of the counting circuit

If the observed intensity is $N_{0}$ counts per second then the circuit is dead for $N_{0} \tau$ of that second. Thus, the fraction of a second during which it missed other $\mathrm{X}$-ray photons is $\mathrm{N}_{0} \tau / \mathrm{l}$. The number of $\mathrm{x}$-rays that are missed is $\mathrm{N}_{t}-\mathrm{N}_{0}$ and the fraction of $x$-ray photons missed is $\left(N_{t}-N_{0}\right) / N_{t}$ Equating the fraction of time the detector missed $\mathrm{x}$-ray photons to the fraction of photons missed yields:

$$
\frac{N_{0} \tau}{I}=\frac{N_{t}-N_{0}}{N_{t}}
$$

and solving this for the true $x$-ray count gives:

$$
N_{t}=\frac{N_{0}}{1-N_{0}{ }^{\tau}}
$$

With this expression and a known dead time it is possible to convert observed intensities to true, incident intensities. 
A number of techniques have been put forward to measure the dead time of a given detector circuit. In all of them it is necessary that the entire counting circuit be set up exactly as it would be in actual use. This is so because all components contribute to the dead time and the adjustment of any one component may alter the overall dead time. The method that was selected is that described by Cohen (29) and seemed to offer both accuracy and simplicity. The method requires two intensity measurements: one attenuated by a piece of metal foil in the $x$-ray beam and one with nothing in the path of the $x$-rays. Let the subscripts 1 and 2 refer, respectively, to measurements with the foil in (1), and out (2) of the beam. The basic dead time expression is:

$$
N_{t}=\frac{N_{0}}{I-N_{0} T}
$$

Or, for cases 1 and 2:

$$
\mathrm{N}_{1 t}=\frac{\mathrm{N}_{10}}{1 \cdot-\mathrm{N}_{10} \tau} \text { and } \mathrm{N}_{2 t}=\frac{\mathrm{N}_{10}}{1-\mathrm{N}_{20} \tau}
$$

The ratio of $\mathrm{N}_{1 t}$ to $\mathrm{N}_{2 t}$ is then:

$$
\frac{N_{1 t}}{N_{2 t}}=\frac{N_{10}\left(1-N_{20} \tau\right)}{N_{20}\left(1-N_{10} \tau\right)}
$$

Let: $\quad R_{t}=\frac{\mathrm{N}_{1 t}}{\mathrm{~N}_{2 t}}$ and $\mathrm{R}_{0}=\frac{\mathrm{N}_{10}}{\mathrm{~N}_{20}}$ 
Substituting these into the preceeding relation gives:

$$
R_{t}=R_{0} \frac{\left(1-N_{20} \tau\right)}{\left(1-N_{10} \tau\right)}
$$

Rearranging and solving for $R_{O}$ yields:

$$
R_{0}=R_{t}+N_{10} \tau\left(1-R_{t}\right)
$$

This is a linear equation between $R_{0}$ and $N_{10}$ with a slope of $\tau\left(I-R_{t}\right)$ and an intercept of $R_{t}$.

A series of pairs of intensities, $\mathrm{N}_{10}$ and $\mathrm{N}_{20}$, are required to use this expression. The following technique provided the pairs of data. The counting circuitry was set up as it would be for the scattering work. The XRD-5 diffractometer was arranged for normal diffraction and positioned at an intense diffraction peak from a single crystal of calcite, $\mathrm{CaCO}_{3}$. The beam and detector slits used were very narrow to produce a peak with a minimum of width.

In this way an intense, nearly monochromatic source of radiation was produced. The goniometer was positioned near the base of the peak and measured intensities corresponding to $\mathrm{N}_{20}$ and $\mathrm{N}_{10}$ recorded. The detector was then moved so that it responded to a slightly more intense part of the peak and a second pair of $\mathrm{N}_{20}$ and $\mathrm{N}_{10}$ were recorded. This process was repeated until a number, in this case 22, of sets of values of $\mathrm{N}_{2}$ and $\mathrm{N}_{10}$ were recorded. It was 
necessary to make a special holder for the attenuating foil so that every $\mathrm{N}_{10}$ was attenuated by exactly the same portion of the foil. The need for a narrow diffraction peak can now be understood. The entire molybdenum $x$-ray spectrum is emitted from the $x$-ray tube and is diffracted by the crystal. Thus, the wave lengths of the radiation from different $2 \theta$ angles will differ slightly and will have slightly differing penetrating powers. Thus, the attenuating effect of the foil will not be constant if the range of $2 \theta$ is too great.

The results of this experiment are graphed in Figure 15. The range of variation in $\mathrm{R}_{0}, \mathrm{~N}_{10} / \mathrm{N}_{20}$, is not great. Hence, the measurements of $\mathrm{N}_{10}$ and $\mathrm{N}_{20}$ must be exceedingly accurate. The preset count mode of operation was used and each intensity represented the accumulation of one million counts. A straight line was fitted through the points by the method of least squares and the slope and intercept were computed. With these the dead time was found to be:

$$
\tau=2.69 \times 10^{-6} \text { seconds }
$$

In this research the above dead time was used to adjust all observed intensities in excess of 100 counts per second. The importance of the correction is related to the level of observed intensity as can be seen from Table 23. Obviously, the correction is not necessary for an intensity of 100 counts per second. However, it was 


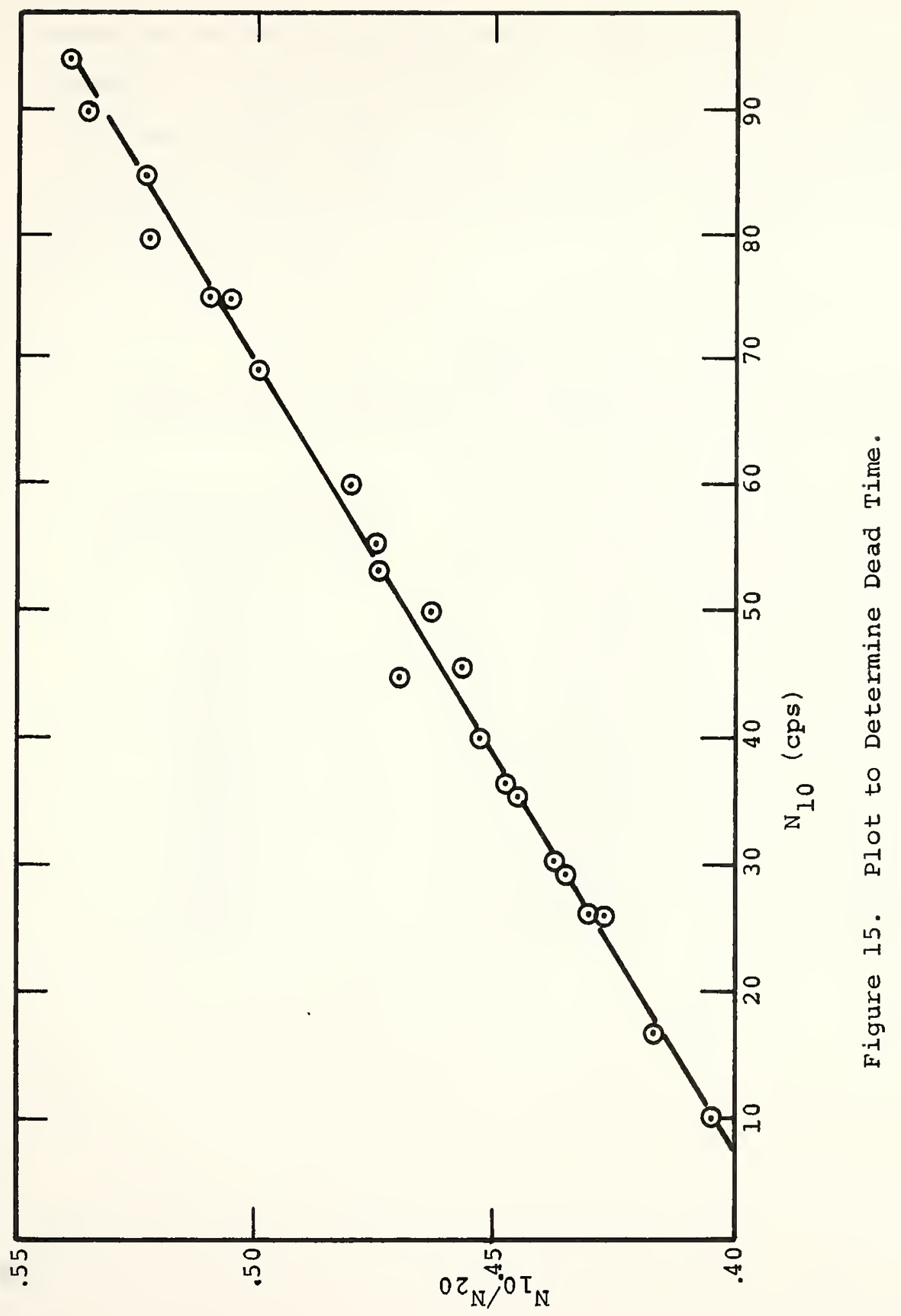


selected as the arbitrary cut-off point as a conservative measure. Ignoring the correction at much higher intensities can lead to large errors. For example, an uncorrected, observed intensity of 60,000 counts per second will be in error by about 208 .

\section{Table 23}

Observed and Dead Time Corrected X-ray Intensities,

$$
\tau=2.69 \times 10^{-6}
$$

\begin{tabular}{c|c|l}
$\begin{array}{c}\text { Observed Intensity, } \\
\mathrm{N}_{0}(\mathrm{cps})\end{array}$ & $\begin{array}{c}\text { True Intensity, } \\
\mathrm{N}_{t} \text { (cps) }\end{array}$ & $\mathrm{N}_{t} / \mathrm{N}_{\mathrm{O}}$ \\
\hline 100 & 100.03 & 1.0003 \\
500 & 500.65 & 1.0013 \\
1000 & 1002.69 & 1.0027 \\
5000 & 5068.16 & 1.0136 \\
10000 & 10276.43 & 1.0276 \\
20000 & 21137.18 & 1.0569 \\
30000 & 32633.52 & 1.0878 \\
40000 & 44822.94 & 1.1206 \\
50000 & 57770.07 & 1.1554 \\
60000 & 71547.81 & 1.1925 \\
70000 & 86238.75 & 1.2320 \\
80000 & 101936.79 & 1.2742 \\
90000 & 118749.17 & 1.3194 \\
100000 & 136798.90 & 1.3680
\end{tabular}


APPENDIX D 
Table 24

Index to x-ray Scattering Data Listed in Table 25

\begin{tabular}{|c|c|c|}
\hline Sample & $\begin{array}{l}\text { Test } \\
\text { Number }\end{array}$ & Page \\
\hline Illite Clay & $\begin{array}{l}\text { Illite II } \\
\text { Illite III } \\
\text { Illite IV } \\
\text { Illite V }\end{array}$ & $\begin{array}{l}133 \\
133 \\
133 \\
133\end{array}$ \\
\hline Charcoal, activated coconut & $\begin{array}{ll}\text { Charcoal } & \text { I } \\
\text { Charcoal } & \text { II } \\
\text { Charcoal } & \text { III } \\
\text { Charcoal } & \text { IV } \\
\text { Charcoal } & \text { V } \\
\text { Charcoal } & \text { VI } \\
\text { Charcoal } & \text { VIII } \\
\text { Charcoal } & \text { IX }\end{array}$ & $\begin{array}{l}134 \\
134 \\
134 \\
134 \\
134 \\
134 \\
135 \\
135\end{array}$ \\
\hline $\begin{array}{l}\text { Cement Paste, } w / c=0.4,514 \text { days, } \\
\text { saturated and never dried }\end{array}$ & $\begin{array}{l}\text { A4ND1 } \\
\text { A4ND2 } \\
\text { A4ND4 }\end{array}$ & $\begin{array}{l}135 \\
135 \\
135\end{array}$ \\
\hline $\begin{array}{l}\text { Cement Paste, } w / c=0.4,514 \text { days, } \\
\text { equilibrated with } 50 \% \mathrm{RH}\end{array}$ & $\begin{array}{l}\text { M11 } \\
\text { M14 } \\
\text { M15 }\end{array}$ & $\begin{array}{l}136 \\
136 \\
136\end{array}$ \\
\hline $\begin{array}{l}\text { Cement Paste, w/c }=0.4,514 \text { days, } \\
\text { equilibrated with } 12 \% \mathrm{RH}\end{array}$ & $\begin{array}{l}\mathrm{K} 3 \\
\mathrm{~K} 4 \\
\mathrm{~K} 6\end{array}$ & $\begin{array}{l}136 \\
136 \\
137\end{array}$ \\
\hline $\begin{array}{l}\text { Cement Paste, } w / C=0.4,514 \text { days, } \\
\text { 'P' dried }\end{array}$ & $\begin{array}{l}\mathrm{H} 4 \\
\mathrm{H} 5 \\
\mathrm{H} 6\end{array}$ & $\begin{array}{l}137 \\
137 \\
137\end{array}$ \\
\hline $\begin{array}{l}\text { Cement Paste, } w / c=0.4,514 \text { days, } \\
\text { ' } D \text { ' dried }\end{array}$ & $\begin{array}{l}\text { E6 } \\
\text { E8 } \\
\text { E9 }\end{array}$ & $\begin{array}{l}137 \\
138 \\
138\end{array}$ \\
\hline $\begin{array}{l}\text { Cement Paste, } w / \mathrm{c}=0.4,514 \text { days, } \\
\text { oven dried at } 105^{\circ} \mathrm{C}\end{array}$ & $\begin{array}{l}\text { S2 } \\
\text { S9 } \\
\text { S10 }\end{array}$ & $\begin{array}{l}138 \\
138 \\
138\end{array}$ \\
\hline $\begin{array}{l}\text { Cement Paste, } w / c=0.4,514 \text { days, } \\
\text { vacuum oven dried at } 105^{\circ} \mathrm{C}\end{array}$ & $\begin{array}{l}\text { B6 } \\
\text { B7 } \\
\text { B9 }\end{array}$ & $\begin{array}{l}139 \\
139 \\
139\end{array}$ \\
\hline $\begin{array}{l}\text { Cement Paste, } w / c=0.4,514 \text { days, } \\
\text { vacuum oven dried and resaturated }\end{array}$ & $\begin{array}{l}\text { RB3 } \\
\text { RB5 } \\
\text { RB } 8\end{array}$ & $\begin{array}{l}139 \\
139 \\
140\end{array}$ \\
\hline
\end{tabular}


Table 24, continued

\begin{tabular}{|c|c|c|}
\hline Sample & $\begin{array}{l}\text { Test } \\
\text { Number }\end{array}$ & Page \\
\hline $\begin{array}{l}\text { Cement Paste, } w / c=0.4,514 \text { days, } \\
\text { oven dried and resaturated }\end{array}$ & $\begin{array}{l}\text { RS4 } \\
\text { RS } 7 \\
\text { RS13 }\end{array}$ & $\begin{array}{l}140 \\
140 \\
140\end{array}$ \\
\hline $\begin{array}{l}\text { Cement Paste, } w / c=0.4,514 \text { days, } \\
\text { ' } \mathrm{D} \text { ' dried and resaturated }\end{array}$ & $\begin{array}{l}\mathrm{RE2} \\
\mathrm{RE3} \\
\mathrm{RE4}\end{array}$ & $\begin{array}{l}140 \\
141 \\
141\end{array}$ \\
\hline $\begin{array}{l}\text { Cement Paste, } w / c=0.4,514 \text { days, } \\
\text { 'P' dried and resaturated }\end{array}$ & $\begin{array}{l}\text { RH } 7 \\
\text { RH } 8\end{array}$ & $\begin{array}{l}141 \\
141\end{array}$ \\
\hline $\begin{array}{l}\text { Cement Paste, } w / c=0.4,514 \text { days, } \\
\text { never dried but heated under water }\end{array}$ & $\begin{array}{l}\mathrm{HL1} \\
\mathrm{HL2} \\
\mathrm{HL} 3\end{array}$ & $\begin{array}{l}141 \\
142 \\
142\end{array}$ \\
\hline $\begin{array}{l}\text { Cement Paste, } w / c=0.4,514 \text { days, } \\
\text { vacuum oven dried for } 240 \text { days }\end{array}$ & $\begin{array}{l}\mathrm{K} 2 \\
\mathrm{~K} 5 \\
\mathrm{~K} 7\end{array}$ & $\begin{array}{l}142 \\
142 \\
142\end{array}$ \\
\hline $\begin{array}{l}\text { Cement Paste, } w / c=0.4,1 \text { day, } \\
\text { saturated and never dried }\end{array}$ & $\begin{array}{l}1 \text { aND1 } \\
1 \text { aND2 } \\
1 \text { aND3 }\end{array}$ & $\begin{array}{l}143 \\
143 \\
143\end{array}$ \\
\hline $\begin{array}{l}\text { Cement Paste, } w / c=0.4,1 \text { day, } \\
\text { ' } D \text { ' dried }\end{array}$ & $\begin{array}{l}\text { T5 } \\
\text { T12 } \\
\text { T13 }\end{array}$ & $\begin{array}{l}143 \\
143 \\
144\end{array}$ \\
\hline $\begin{array}{l}\text { Cement Paste, } w / c=0.3,513 \text { days, } \\
\text { saturated and never dried }\end{array}$ & $\begin{array}{l}\text { B3ND1 } \\
\text { B3ND2 } \\
\text { B3ND3 }\end{array}$ & $\begin{array}{l}144 \\
144 \\
144\end{array}$ \\
\hline $\begin{array}{l}\text { Cement Paste, } w / c=0.3,513 \text { days, } \\
\text { ' } D \text { ' dried }\end{array}$ & $\begin{array}{l}\text { D3 } \\
\text { D7 } \\
\text { D8 }\end{array}$ & $\begin{array}{l}144 \\
145 \\
145\end{array}$ \\
\hline $\begin{array}{l}\text { Cement Paste, } w / c=0.6,512 \text { days, } \\
\text { saturated and never dried }\end{array}$ & $\begin{array}{l}\text { C6NDI } \\
\text { C6ND2 } \\
\text { C6ND3 }\end{array}$ & $\begin{array}{l}145 \\
145 \\
145\end{array}$ \\
\hline $\begin{array}{l}\text { Cement Paste, } w / c=0.6,512 \text { days, } \\
\text { ' } D \text { ' dried }\end{array}$ & $\begin{array}{l}\text { F2 } \\
\text { F3 } \\
\text { F5 } \\
\text { F } 8\end{array}$ & $\begin{array}{l}146 \\
146 \\
146 \\
146\end{array}$ \\
\hline $\begin{array}{l}\text { Alite Paste, } \mathrm{w} / \mathrm{s}=0.4, \\
\text { saturated and never dried }\end{array}$ & $\begin{array}{l}01 \\
03 \\
04\end{array}$ & $\begin{array}{l}146 \\
147 \\
147\end{array}$ \\
\hline $\begin{array}{l}\text { Alite Paste, } w / s=0.4, \quad \text { days, } \\
\text { 'D' dried }\end{array}$ & $\begin{array}{l}06 \\
08 \\
09\end{array}$ & $\begin{array}{l}147 \\
147 \\
147\end{array}$ \\
\hline
\end{tabular}


Table 25

Complete Listing of Scattering Test Data

\begin{tabular}{|c|c|c|c|c|c|}
\hline $\begin{array}{l}2 \theta \\
\text { Angle } \\
\text { degrees }\end{array}$ & $\begin{array}{l}\text { Test } \\
\text { IIlite } \\
\text { II } \\
\text { (cps) }\end{array}$ & $\begin{array}{l}\text { Test } \\
\text { Illite } \\
\text { III } \\
\text { (cps) }\end{array}$ & $\begin{array}{l}\text { Test } \\
\text { Illite } \\
\text { IV } \\
\text { (cps) }\end{array}$ & $\begin{array}{l}\text { Test } \\
\text { Illite } \\
\text { V } \\
\text { (cps) }\end{array}$ & $\begin{array}{l}\text { Test } \\
\text { Charcoal } \\
\text { I } \\
\text { (cps) }\end{array}$ \\
\hline 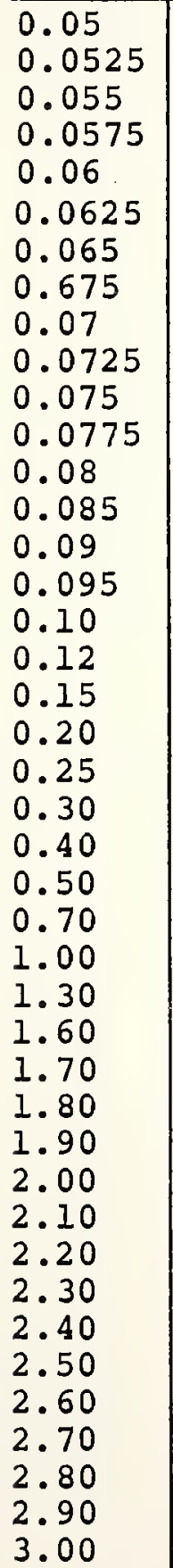 & $\begin{array}{c}8337 \\
14265 \\
18943 \\
23667 \\
24048 \\
22046 \\
20205 \\
17567 \\
15596 \\
14017 \\
12797 \\
11478 \\
10425 \\
8927 \\
7578 \\
6581 \\
5732 \\
3694 \\
2120 \\
1111 \\
681.8 \\
447.8 \\
236.2 \\
138.3 \\
62.18 \\
26.01 \\
13.55 \\
8.31 \\
7.21 \\
6.42 \\
5.79 \\
5.26 \\
4.93 \\
4.59 \\
4.35 \\
4.15 \\
4.02 \\
3.76 \\
3.74 \\
3.62 \\
3.54 \\
3.55\end{array}$ & $\begin{array}{c}7055 \\
13179 \\
16520 \\
21774 \\
22018 \\
20666 \\
18918 \\
16532 \\
14742 \\
13214 \\
12120 \\
10902 \\
9919 \\
8467 \\
7194 \\
6301 \\
5468 \\
3519 \\
2197 \\
1132 \\
689.7 \\
441.2 \\
230.8 \\
137.3 \\
60.30 \\
24.63 \\
12.86 \\
7.62 \\
6.64 \\
5.93 \\
5.32 \\
4.93 \\
4.55 \\
4.27 \\
4.10 \\
3.82 \\
3.77 \\
3.70 \\
3.58 \\
3.48 \\
3.48 \\
3.41\end{array}$ & $\begin{array}{r}3663 \\
7197 \\
9669 \\
16729 \\
19380 \\
20546 \\
19262 \\
16889 \\
14770 \\
13180 \\
11943 \\
10663 \\
9682 \\
8167 \\
6859 \\
5971 \\
5155 \\
3293 \\
1846 \\
937.5 \\
566.0 \\
368.1 \\
188.7 \\
110.1 \\
48.74 \\
19.35 \\
10.45 \\
6.32 \\
5.50 \\
4.99 \\
4.49 \\
4.17 \\
3.88 \\
3.58 \\
3.45 \\
3.35 \\
3.22 \\
3.09 \\
2.97 \\
3.02 \\
2.97 \\
2.98\end{array}$ & $\begin{array}{r}1728 \\
5847 \\
9438 \\
17180 \\
20935 \\
21406 \\
20026 \\
17290 \\
15262 \\
13510 \\
12330 \\
11004 \\
9969 \\
8418 \\
7094 \\
6170 \\
5348 \\
3375 \\
1974 \\
1017 \\
600.0 \\
394.7 \\
206.9 \\
122.7 \\
54.01 \\
22.36 \\
11.47 \\
6.97 \\
6.19 \\
5.51 \\
4.98 \\
4.53 \\
4.13 \\
3.93 \\
3.64 \\
3.45 \\
3.30 \\
3.20 \\
3.12 \\
3.06 \\
3.07 \\
3.04\end{array}$ & $\begin{array}{c}1487 \\
6326 \\
8700 \\
10692 \\
10057 \\
8440 \\
7708 \\
6688 \\
5955 \\
5336 \\
4975 \\
4510 \\
4214 \\
3723 \\
3305 \\
2991 \\
2699 \\
1987 \\
1423 \\
967.7 \\
769.2 \\
652.2 \\
531.0 \\
438.0 \\
310.9 \\
179.6 \\
102.9 \\
61.35 \\
52.59 \\
43.26 \\
38.00 \\
32.61 \\
27.76 \\
23.51 \\
20.74 \\
18.11 \\
15.74 \\
13.95 \\
12.10 \\
10.82 \\
9.92 \\
8.78\end{array}$ \\
\hline
\end{tabular}


Table 25, continued

\begin{tabular}{|c|c|c|c|c|c|}
\hline $\begin{array}{l}2 \theta \\
\text { Angle } \\
\text { degrees }\end{array}$ & $\begin{array}{l}\text { Test } \\
\text { Charcoal } \\
\text { II } \\
\text { (cps) }\end{array}$ & $\begin{array}{l}\text { Test } \\
\text { Charcoal } \\
\text { III } \\
\text { (cps) }\end{array}$ & $\begin{array}{l}\text { Test } \\
\text { Charcoal } \\
\text { IV } \\
\text { (cps) }\end{array}$ & $\begin{array}{l}\text { Test } \\
\text { Charcoal } \\
\mathrm{V} \\
\text { (cps) }\end{array}$ & $\begin{array}{l}\text { Test } \\
\text { Charcoal } \\
\text { VI } \\
\text { (cps) }\end{array}$ \\
\hline $\begin{array}{l}0.05 \\
0.0525 \\
0.055 \\
0.0575 \\
0.06 \\
0.0625 \\
0.065 \\
0.0675 \\
0.07 \\
0.0725 \\
0.075 \\
0.0775 \\
0.08 \\
0.085 \\
0.09 \\
0.095 \\
0.10 \\
0.12 \\
0.15 \\
0.20 \\
0.25 \\
0.30 \\
0.40 \\
0.50 \\
0.70 \\
1.00 \\
1.30 \\
1.60 \\
1.70 \\
1.80 \\
1.90 \\
2.00 \\
2.10 \\
2.20 \\
2.30 \\
2.40 \\
2.50 \\
2.60 \\
2.70 \\
2.80 \\
2.90 \\
3.00\end{array}$ & $\begin{array}{c}153 \\
4162 \\
6533 \\
7448 \\
6571 \\
5289 \\
4580 \\
3865 \\
3379 \\
2950 \\
2786 \\
2481 \\
2318 \\
2036 \\
1815 \\
1639 \\
1509 \\
1100 \\
825.4 \\
606.1 \\
483.9 \\
434.8 \\
359.3 \\
309.3 \\
209.1 \\
122.5 \\
75.19 \\
43.48 \\
36.52 \\
31.07 \\
26.32 \\
23.38 \\
19.96 \\
17.42 \\
15.03 \\
13.01 \\
11.65 \\
10.46 \\
9.15 \\
8.26 \\
7.54 \\
6.62\end{array}$ & $\begin{array}{c}1221 \\
4868 \\
6047 \\
5628 \\
4953 \\
4393 \\
3953 \\
3591 \\
3326 \\
3048 \\
2866 \\
2580 \\
2315 \\
2117 \\
1951 \\
1515 \\
1138 \\
810.8 \\
652.2 \\
576.9 \\
468.8 \\
405.4 \\
276.5 \\
164.8 \\
99.67 \\
60.36 \\
51.90 \\
45.05 \\
38.56 \\
32.52 \\
27.95 \\
24.55 \\
21.99 \\
18.75 \\
16.62 \\
14.74 \\
13.06 \\
11.58 \\
10.59 \\
9.32\end{array}$ & $\begin{array}{c}3062 \\
520 \\
2653 \\
4932 \\
13170 \\
13357 \\
13100 \\
10407 \\
8242 \\
7306 \\
6291 \\
5648 \\
4779 \\
4119 \\
3634 \\
3292 \\
2336 \\
1629 \\
1132 \\
909.1 \\
800.0 \\
645.2 \\
545.5 \\
368.1 \\
215.8 \\
122.7 \\
74.26 \\
61.73 \\
52.22 \\
45.35 \\
38.89 \\
34.17 \\
30.50 \\
25.72 \\
22.42 \\
19.72 \\
17.47 \\
15.38 \\
13.96 \\
12.54 \\
11.29\end{array}$ & $\begin{array}{c}4635 \\
4706 \\
8358 \\
11317 \\
15829 \\
20060 \\
20498 \\
17918 \\
13763 \\
10678 \\
9393 \\
8120 \\
7290 \\
6142 \\
5270 \\
4693 \\
4163 \\
2951 \\
2032 \\
1395 \\
1091 \\
952.4 \\
759.5 \\
638.3 \\
447.8 \\
252.1 \\
148.9 \\
90.91 \\
77.52 \\
64.17 \\
55.30 \\
48.66 \\
41.12 \\
35.03 \\
30.83 \\
26.87 \\
23.21 \\
20.60 \\
18.09 \\
16.33 \\
14.45 \\
12.79\end{array}$ & $\begin{array}{l}5656 \\
10150 \\
11912 \\
9475 \\
7358 \\
6478 \\
5573 \\
4953 \\
4208 \\
3595 \\
3246 \\
2851 \\
2050 \\
1463 \\
1034 \\
821.9 \\
722.9 \\
582.5 \\
491.8 \\
337.1 \\
191.7 \\
113.4 \\
65.15 \\
56.55 \\
48.54 \\
41.47 \\
35.15 \\
30.64 \\
26.86 \\
23.45 \\
20.70 \\
18.12 \\
16.05 \\
14.22 \\
12.68 \\
11.38 \\
10.52\end{array}$ \\
\hline
\end{tabular}


Table 25 , continued

\begin{tabular}{|c|c|c|c|c|c|}
\hline $\begin{array}{l}2 \theta \\
\text { Angle } \\
\text { degrees }\end{array}$ & $\begin{array}{l}\text { Test } \\
\text { Charcoal } \\
\text { VIII } \\
\text { (cps) }\end{array}$ & $\begin{array}{l}\text { Test } \\
\text { Charcoal } \\
\text { IX } \\
\text { (cps) }\end{array}$ & $\begin{array}{l}\text { Test } \\
\text { A4ND1 } \\
\text { (cps) }\end{array}$ & $\begin{array}{l}\text { Test } \\
\text { A4ND2 } \\
\text { (cps) }\end{array}$ & $\begin{array}{l}\text { Test } \\
\text { A4ND4 } \\
\text { (cps) }\end{array}$ \\
\hline $\begin{array}{l}0.05 \\
0.0525 \\
0.055 \\
0.0575 \\
0.06 \\
0.0625 \\
0.065 \\
0.0675 \\
0.07 \\
0.0725 \\
0.075 \\
0.0775 \\
0.08 \\
0.085 \\
0.09 \\
0.095 \\
0.10 \\
0.12 \\
0.15 \\
0.20 \\
0.25 \\
0.30 \\
0.40 \\
0.50 \\
0.70 \\
1.00 \\
1.30 \\
1.60 \\
1.70 \\
1.80 \\
1.90 \\
2.00 \\
2.10 \\
2.20 \\
2.30 \\
2.40 \\
2.50 \\
2.60 \\
2.70 \\
2.80 \\
2.90 \\
3.00\end{array}$ & \begin{tabular}{|l|}
2947 \\
4382 \\
7669 \\
8068 \\
8827 \\
7434 \\
6577 \\
5582 \\
4907 \\
4502 \\
4121 \\
3833 \\
3530 \\
3149 \\
2813 \\
2571 \\
2322 \\
1745 \\
1255 \\
923.1 \\
759.5 \\
674.2 \\
571.4 \\
476.2 \\
304.6 \\
152.3 \\
86.44 \\
49.53 \\
41.67 \\
35.17 \\
30.12 \\
26.37 \\
22.59 \\
20.07 \\
17.07 \\
14.85 \\
13.13 \\
11.88 \\
10.85 \\
9.75 \\
8.93 \\
8.07
\end{tabular} & $\begin{array}{c}2093 \\
4977 \\
7667 \\
10448 \\
9669 \\
8404 \\
7270 \\
6194 \\
5528 \\
5045 \\
4632 \\
4268 \\
3951 \\
3536 \\
3159 \\
2870 \\
2605 \\
1965 \\
1500 \\
1091 \\
869.6 \\
769.2 \\
618.6 \\
540.5 \\
342.9 \\
190.5 \\
107.9 \\
64.94 \\
53.48 \\
45.87 \\
38.17 \\
32.89 \\
29.07 \\
25.25 \\
21.65 \\
19.27 \\
17.12 \\
15.15 \\
13.42 \\
12.48 \\
10.87 \\
10.14\end{array}$ & $\begin{array}{l}1626 \\
1315 \\
1861 \\
1590 \\
1311 \\
1122 \\
1003 \\
877 \\
799 \\
727 \\
671 \\
605 \\
566 \\
500 \\
470 \\
397 \\
353 \\
246 \\
170.9 \\
112.8 \\
81.84 \\
65.50 \\
44.98 \\
34.25 \\
23.09 \\
15.53 \\
10.97 \\
9.29 \\
8.79 \\
8.02 \\
7.51 \\
6.75 \\
6.29 \\
5.89 \\
5.63 \\
5.19 \\
4.94 \\
4.62 \\
4.38 \\
4.11 \\
3.98 \\
3.86\end{array}$ & $\begin{array}{l}2450 \\
2488 \\
2767 \\
1709 \\
1440 \\
1030 \\
946 \\
819 \\
744 \\
661 \\
611 \\
555 \\
523 \\
408 \\
364 \\
325 \\
290 \\
214 \\
144.1 \\
96.31 \\
72.64 \\
57.36 \\
40.71 \\
31.71 \\
22.56 \\
15.31 \\
11.22 \\
8.09 \\
7.31 \\
6.91 \\
6.26 \\
5.98 \\
5.51 \\
5.13 \\
4.90 \\
4.43 \\
4.24 \\
4.07 \\
3.88 \\
3.67 \\
3.53 \\
3.36\end{array}$ & $\begin{array}{r}1256 \\
1055 \\
935 \\
838 \\
764 \\
706 \\
660 \\
596 \\
514 \\
444 \\
396 \\
355 \\
249 \\
172.1 \\
116.1 \\
82.19 \\
67.04 \\
47.39 \\
35.71 \\
24.57 \\
16.83 \\
12.21 \\
9.58 \\
8.88 \\
8.27 \\
7.76 \\
7.23 \\
6.69 \\
6.19 \\
5.79 \\
5.41 \\
5.13 \\
4.82 \\
4.55 \\
4.27 \\
4.05 \\
3.86\end{array}$ \\
\hline
\end{tabular}


Table 25, continued

\begin{tabular}{|c|c|c|c|c|c|}
\hline $\begin{array}{l}2 \theta \\
\text { Angle } \\
\text { degrees }\end{array}$ & $\begin{array}{l}\text { Test } \\
\text { MIl } \\
\text { (cps) }\end{array}$ & $\begin{array}{l}\text { Test } \\
\text { M14 } \\
\text { (cps) }\end{array}$ & $\begin{array}{l}\text { Test } \\
\text { MI5 } \\
\text { (cps) }\end{array}$ & $\begin{array}{l}\text { Test } \\
\text { K3 } \\
\text { (cps) }\end{array}$ & $\begin{array}{l}\text { Test } \\
\text { K4 } \\
\text { (cps) }\end{array}$ \\
\hline $\begin{array}{l}0.05 \\
0.0525 \\
0.055 \\
0.0575 \\
0.06 \\
0.0625 \\
0.065 \\
0.0675 \\
0.07 \\
0.0725 \\
0.075 \\
0.0773 \\
0.08 \\
0.085 \\
0.09 \\
0.09 \\
0.10 \\
0.12 \\
0.15 \\
0.20 \\
0.25 \\
0.30 \\
0.40 \\
0.50 \\
0.70 \\
1.00 \\
1.30 \\
1.60 \\
1.70 \\
1.80 \\
1.90 \\
2.00 \\
2.00 \\
2.10 \\
2.20 \\
2.30 \\
2.40 \\
2.50 \\
2.60 \\
2.70 \\
2.80 \\
2.90 \\
3.00\end{array}$ & $\begin{array}{c}3754 \\
5309 \\
7488 \\
7301 \\
6968 \\
6035 \\
5589 \\
4863 \\
4380 \\
3913 \\
3596 \\
3214 \\
2785 \\
2521 \\
2126 \\
1853 \\
1608 \\
1012 \\
573 \\
287.1 \\
168.1 \\
109.9 \\
57.75 \\
37.17 \\
21.63 \\
13.15 \\
9.66 \\
7.41 \\
6.91 \\
6.58 \\
6.12 \\
5.57 \\
5.28 \\
5.01 \\
4.68 \\
4.35 \\
4.24 \\
3.98 \\
3.82 \\
3.64 \\
3.51 \\
3.37\end{array}$ & $\begin{array}{c}749 \\
1598 \\
5305 \\
7141 \\
8177 \\
7664 \\
7268 \\
6186 \\
5518 \\
4879 \\
4447 \\
3964 \\
3588 \\
3032 \\
2537 \\
2229 \\
1907 \\
1164 \\
652.8 \\
309.3 \\
174.9 \\
110.7 \\
58.48 \\
37.22 \\
22.08 \\
13.65 \\
9.69 \\
7.26 \\
6.80 \\
6.44 \\
5.93 \\
5.57 \\
5.29 \\
4.98 \\
4.75 \\
4.54 \\
4.29 \\
4.07 \\
3.83 \\
3.72 \\
3.58 \\
3.43\end{array}$ & $\begin{array}{c}3791 \\
5832 \\
8744 \\
9389 \\
8989 \\
7621 \\
6922 \\
5920 \\
5231 \\
4579 \\
4187 \\
3717 \\
3352 \\
2837 \\
2378 \\
2060 \\
1770 \\
1094 \\
624.6 \\
304.6 \\
178.0 \\
116.5 \\
63.42 \\
39.74 \\
23.17 \\
14.27 \\
10.47 \\
8.19 \\
7.74 \\
7.15 \\
6.66 \\
6.25 \\
5.87 \\
5.65 \\
5.31 \\
5.01 \\
4.80 \\
4.44 \\
4.24 \\
4.08 \\
3.91 \\
3.78\end{array}$ & $\begin{array}{c}8930 \\
10633 \\
11376 \\
9827 \\
8639 \\
7648 \\
6846 \\
6253 \\
5695 \\
5247 \\
4898 \\
4525 \\
4212 \\
3751 \\
3305 \\
3004 \\
2705 \\
1850 \\
1280 \\
779.2 \\
526.3 \\
357.1 \\
198.7 \\
118.6 \\
52.68 \\
22.19 \\
12.40 \\
8.00 \\
7.18 \\
6.68 \\
6.28 \\
5.80 \\
5.46 \\
5.09 \\
4.89 \\
4.63 \\
4.46 \\
4.22 \\
4.02 \\
3.87 \\
3.73 \\
3.60\end{array}$ & $\begin{array}{l}5063 \\
7236 \\
8633 \\
9210 \\
8667 \\
7786 \\
7135 \\
6427 \\
5841 \\
5362 \\
4949 \\
4591 \\
4260 \\
3756 \\
3296 \\
2988 \\
2677 \\
1848 \\
1248 \\
759.5 \\
500.0 \\
350.9 \\
187.5 \\
112.8 \\
50.38 \\
20.72 \\
11.49 \\
7.71 \\
7.05 \\
6.41 \\
5.92 \\
5.58 \\
5.24 \\
4.92 \\
4.66 \\
4.38 \\
4.15 \\
4.00 \\
3.88 \\
3.71 \\
3.57 \\
3.53\end{array}$ \\
\hline
\end{tabular}


Table 25, continued

\begin{tabular}{|c|c|c|c|c|c|}
\hline $\begin{array}{l}2 \theta \\
\text { Angle } \\
\text { degrees }\end{array}$ & $\begin{array}{l}\text { Test } \\
\text { K6 } \\
\text { (cps) }\end{array}$ & $\begin{array}{l}\text { Test } \\
\text { H4 } \\
\text { (cps) }\end{array}$ & $\begin{array}{l}\text { Test } \\
\text { H5 } \\
\text { (cps) }\end{array}$ & $\begin{array}{l}\text { Test } \\
\text { H6 } \\
\text { (cps) }\end{array}$ & $\begin{array}{l}\text { Test } \\
E \in \\
\text { (cps) }\end{array}$ \\
\hline 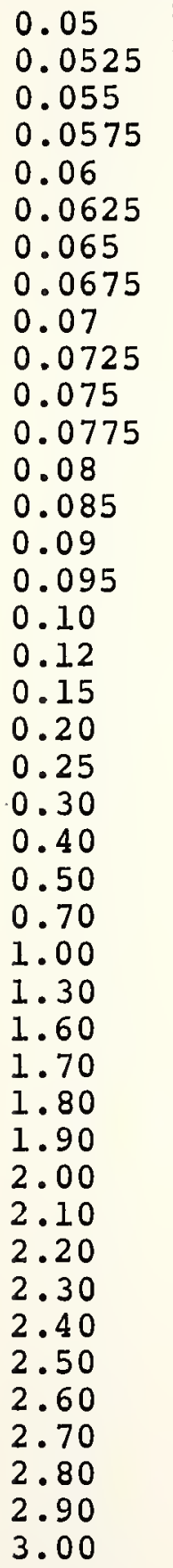 & $\begin{array}{c}966 \\
2536 \\
6892 \\
7244 \\
8617 \\
8002 \\
7434 \\
6711 \\
6173 \\
5674 \\
5212 \\
4820 \\
4216 \\
3678 \\
3334 \\
2975 \\
2092 \\
1434 \\
845.1 \\
555.8 \\
379.8 \\
203.4 \\
122.2 \\
55.92 \\
23.24 \\
12.47 \\
8.69 \\
7.92 \\
7.17 \\
6.69 \\
6.27 \\
5.78 \\
5.52 \\
5.16 \\
4.85 \\
4.60 \\
4.41 \\
4.27 \\
4.12 \\
3.93 \\
3.78\end{array}$ & $\begin{array}{c}4926 \\
7283 \\
8276 \\
8348 \\
7694 \\
6553 \\
6058 \\
5286 \\
4814 \\
4358 \\
4042 \\
3675 \\
3410 \\
2939 \\
2563 \\
2307 \\
2043 \\
1404 \\
924.4 \\
588.2 \\
419.6 \\
335.2 \\
223.9 \\
158.3 \\
90.23 \\
42.80 \\
22.26 \\
12.31 \\
10.46 \\
8.96 \\
8.10 \\
7.29 \\
6.52 \\
5.87 \\
5.25 \\
4.98 \\
4.53 \\
4.42 \\
4.01 \\
3.78 \\
3.65 \\
3.38\end{array}$ & $\begin{array}{l}1402 \\
4223 \\
4946 \\
6382 \\
6419 \\
5904 \\
5565 \\
4966 \\
4496 \\
4093 \\
3796 \\
3484 \\
3181 \\
2786 \\
2423 \\
2169 \\
1932 \\
1344 \\
897.3 \\
566.0 \\
416.7 \\
317.5 \\
212.0 \\
156.3 \\
84.99 \\
40.16 \\
21.31 \\
12.05 \\
10.38 \\
9.20 \\
8.15 \\
7.15 \\
6.36 \\
5.69 \\
5.29 \\
4.84 \\
4.38 \\
4.13 \\
3.77 \\
3.55 \\
3.39 \\
3.30\end{array}$ & $\begin{array}{l}5180 \\
7574 \\
8140 \\
7946 \\
7449 \\
6412 \\
5977 \\
5296 \\
4837 \\
4319 \\
4048 \\
3666 \\
3401 \\
2972 \\
2585 \\
2318 \\
2040 \\
1418 \\
940.9 \\
600.0 \\
425.5 \\
331.5 \\
223.1 \\
160.9 \\
88.89 \\
42.64 \\
22.22 \\
12.68 \\
10.76 \\
9.22 \\
8.33 \\
7.34 \\
6.50 \\
5.82 \\
5.46 \\
4.95 \\
4.63 \\
4.21 \\
4.08 \\
3.88 \\
3.66 \\
3.43\end{array}$ & $\begin{array}{c}784 \\
353 \\
3128 \\
5762 \\
9033 \\
8917 \\
8287 \\
7243 \\
6501 \\
5929 \\
5363 \\
4859 \\
4160 \\
3569 \\
3173 \\
2797 \\
1937 \\
1340 \\
833.3 \\
594.1 \\
447.8 \\
271.5 \\
176.0 \\
85.96 \\
36.65 \\
19.57 \\
12.53 \\
10.85 \\
9.68 \\
8.68 \\
7.73 \\
7.02 \\
6.55 \\
6.02 \\
5.55 \\
5.21 \\
4.79 \\
4.59 \\
4.38 \\
4.14 \\
3.98\end{array}$ \\
\hline
\end{tabular}


Table 25, continued

\begin{tabular}{|c|c|c|c|c|c|}
\hline $\begin{array}{l}2 \theta \\
\text { Angle } \\
\text { degrees }\end{array}$ & $\begin{array}{l}\text { Test } \\
\text { E8 } \\
\text { (cps) }\end{array}$ & $\begin{array}{l}\text { Test } \\
\text { E9 } \\
\text { (cps) }\end{array}$ & $\begin{array}{l}\text { Test } \\
\text { S2 } \\
\text { (cps) }\end{array}$ & $\begin{array}{l}\text { Test } \\
\text { s9 } \\
\text { (cps) }\end{array}$ & $\begin{array}{l}\text { Test } \\
\text { S10 } \\
\text { (cps) }\end{array}$ \\
\hline 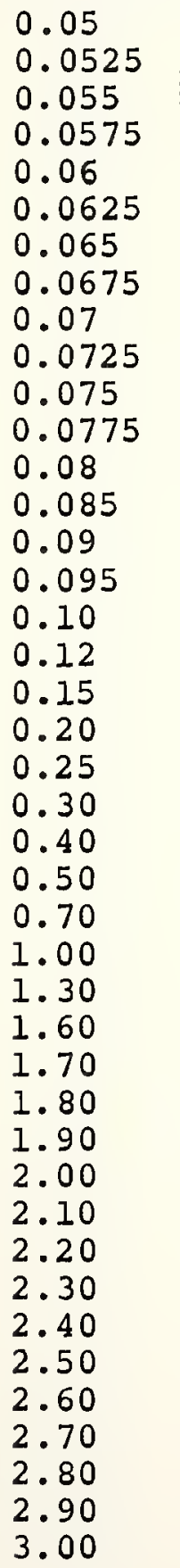 & $\begin{array}{c}2823 \\
2817 \\
4573 \\
5512 \\
8204 \\
8159 \\
9716 \\
8790 \\
7773 \\
6920 \\
6348 \\
5693 \\
5214 \\
4475 \\
3803 \\
3392 \\
2986 \\
2065 \\
1365 \\
869.6 \\
631.6 \\
461.5 \\
284.4 \\
188.1 \\
89.82 \\
38.61 \\
20.80 \\
12.95 \\
11.40 \\
10.07 \\
9.1 \\
8.1 \\
7.5 \\
6.67 \\
6.12 \\
5.69 \\
5.31 \\
4.94 \\
4.37 \\
4.51 \\
4.18 \\
4.06\end{array}$ & $\begin{array}{l}4528 \\
6227 \\
7581 \\
7757 \\
7469 \\
6690 \\
6158 \\
5459 \\
4902 \\
4449 \\
4129 \\
3739 \\
3471 \\
3025 \\
2639 \\
2365 \\
2105 \\
1463 \\
1017 \\
645.2 \\
454.6 \\
350.9 \\
215.8 \\
142.5 \\
70.59 \\
30.30 \\
16.16 \\
10.30 \\
9.10 \\
8.29 \\
7.15 \\
6.61 \\
6.04 \\
5.64 \\
5.17 \\
4.78 \\
4.46 \\
4.17 \\
3.90 \\
3.75 \\
3.59 \\
3.48\end{array}$ & $\begin{array}{r}6026 \\
7559 \\
9882 \\
10770 \\
10448 \\
9177 \\
8266 \\
7215 \\
6410 \\
5880 \\
5382 \\
4939 \\
4539 \\
3944 \\
3477 \\
3142 \\
2836 \\
2122 \\
1404 \\
923.1 \\
618.6 \\
444.4 \\
262.0 \\
162.6 \\
74.26 \\
31.53 \\
13.28 \\
9.78 \\
8.52 \\
7.51 \\
6.52 \\
5.96 \\
5.53 \\
5.02 \\
4.56 \\
4.32 \\
4.21 \\
3.80 \\
3.66 \\
3.50 \\
3.35 \\
3.24\end{array}$ & $\begin{array}{c}9997 \\
9557 \\
9930 \\
8419 \\
7415 \\
6565 \\
6033 \\
5380 \\
4877 \\
4496 \\
4162 \\
3841 \\
3594 \\
3172 \\
2820 \\
2544 \\
2319 \\
1706 \\
1175 \\
750.0 \\
512.8 \\
368.1 \\
205.5 \\
129.0 \\
58.94 \\
24.12 \\
12.71 \\
8.18 \\
7.03 \\
6.37 \\
5.60 \\
5.13 \\
4.68 \\
4.35 \\
4.03 \\
3.73 \\
3.55 \\
3.40 \\
3.34 \\
3.12 \\
2.97 \\
2.93\end{array}$ & $\begin{array}{l}9790 \\
9637 \\
9538 \\
8177 \\
7154 \\
6253 \\
5770 \\
5175 \\
4660 \\
4243 \\
3952 \\
3648 \\
3405 \\
3021 \\
2706 \\
2408 \\
2171 \\
1572 \\
1107 \\
705.9 \\
491.8 \\
357.1 \\
204.8 \\
125.8 \\
59.29 \\
26.29 \\
13.84 \\
9.14 \\
7.88 \\
7.06 \\
6.34 \\
6.31 \\
5.20 \\
4.93 \\
4.48 \\
4.22 \\
4.08 \\
3.78 \\
3.61 \\
3.46 \\
3.33 \\
3.25\end{array}$ \\
\hline
\end{tabular}


Table 25, continued

\begin{tabular}{|c|c|c|c|c|c|}
\hline $\begin{array}{l}2 \theta \\
\text { Angle }\end{array}$ & $\begin{array}{l}\text { Test } \\
\text { B6 }\end{array}$ & $\begin{array}{l}\text { Test } \\
\text { B7 }\end{array}$ & $\begin{array}{l}\text { Test } \\
\text { B9 }\end{array}$ & $\begin{array}{l}\text { Test } \\
\text { RB3 }\end{array}$ & $\begin{array}{l}\text { Test } \\
\text { RB5 }\end{array}$ \\
\hline degrees & (cps) & (cps) & (cps) & (cps) & (cps) \\
\hline 0.05 & & & 660 & & 360 \\
\hline 0.0525 & 1436 & 345 & 1229 & 649 & 94 \\
\hline 0.055 & 7013 & 1545 & 3866 & 1071 & 1035 \\
\hline 0.0575 & 4443 & 4363 & 6099 & 1253 & 1453 \\
\hline 0.06 & 8090 & 6764 & 8609 & 1330 & 1714 \\
\hline 0.0625 & 9588 & 9417 & 12064 & 1201 & 1656 \\
\hline 0.065 & 10221 & 10844 & 12390 & 1147 & 1511 \\
\hline 0.0675 & 9869 & 10333 & 11534 & 1041 & 1350 \\
\hline 0.07 & 8638 & 9218 & 9981 & 953 & 1227 \\
\hline 0.0725 & 6827 & 8108 & 8860 & 868 & 1104 \\
\hline 0.75 & 6844 & 7401 & 8039 & 805 & 1021 \\
\hline 0.0775 & 5580 & 6628 & 7252 & 753 & 927 \\
\hline 0.08 & 5555 & 6024 & 6577 & 686 & 864 \\
\hline 0.085 & 4748 & 5151 & 5680 & 609 & 745 \\
\hline 0.09 & 4080 & 4442 & 4901 & 553 & 662 \\
\hline 0.095 & 3615 & 3932 & 4368 & 498 & 589 \\
\hline 0.10 & 3211 & 3472 & 3875 & 446 & 532 \\
\hline 0.12 & 2255 & 2461 & 2736 & 322 & 364 \\
\hline 0.15 & 1481 & 1682 & 1846 & 213.8 & 240.5 \\
\hline 0.20 & 952.4 & 1091 & 1200 & 138.9 & 155.4 \\
\hline 0.25 & 645.2 & 740.7 & 821.9 & 98.36 & 109.7 \\
\hline 0.30 & 454.6 & 540.5 & 588.2 & 74.35 & 82.19 \\
\hline 0.40 & 255.3 & 309.3 & 339.0 & 47.89 & 53.43 \\
\hline 0.50 & 159.6 & 194.2 & 209.1 & 34.82 & 38.39 \\
\hline 0.70 & 73.62 & 87.72 & 91.60 & 22.19 & 24.20 \\
\hline 1.00 & 29.31 & 34.68 & 35.59 & 14.14 & 15.81 \\
\hline 1.30 & 14.73 & 17.06 & 17.37 & 10.22 & 11.39 \\
\hline 1.60 & 8.82 & 9.79 & 9.62 & 7.43 & 8.73 \\
\hline 1.70 & 7.68 & 8.42 & 8.60 & 7.04 & 8.10 \\
\hline 1.80 & 6.63 & 7.19 & 7.34 & 6.47 & 7.55 \\
\hline 1.90 & 5.99 & 6.56 & 6.50 & 6.14 & 6.84 \\
\hline 2.00 & 5.46 & 5.81 & 5.88 & 5.66 & 6.48 \\
\hline 2.10 & 4.89 & 5.22 & 5.21 & 5.41 & 6.05 \\
\hline 2.20 & 4.36 & 4.83 & 4.88 & 5.05 & 5.67 \\
\hline 2.30 & 4.17 & 4.40 & 4.48 & 4.81 & 5.29 \\
\hline 2.40 & 3.86 & 4.16 & 4.22 & 4.52 & 5.01 \\
\hline 2.50 & 3.55 & 3.96 & 3.95 & 4.21 & 4.83 \\
\hline 2.60 & 3.42 & 3.70 & 3.75 & 4.00 & 4.51 \\
\hline 2.70 & 3.24 & 3.56 & 3.55 & 3.84 & 4.34 \\
\hline 2.80 & 3.13 & 3.44 & 3.58 & 3.54 & 4.04 \\
\hline 2.9 & 3. & 3.2 & 3.38 & 3.41 & 3.94 \\
\hline 3.00 & 2.90 & 3.14 & 3.22 & 3.27 & 3.69 \\
\hline
\end{tabular}


Table 25, continued

\begin{tabular}{l|c|c|c|c|c}
$2 \theta$ & Test & Test & Test & Test & Test \\
Angle & RB8 & RS4 & RS7 & RS13 & RE2 \\
degrees & (cps) & (cps) & (cps) & (cps) & (cps) \\
\hline 0.05 & 799 & 292 & 2151 & & 710 \\
0.0525 & 1944 & 687 & 2514 & & 355 \\
0.055 & 1497 & 1077 & 2499 & & 1118 \\
0.0575 & 1316 & 1109 & 1681 & 38 & 1774 \\
0.06 & 1527 & 1292 & 1565 & 558 & 1696 \\
0.0625 & 1352 & 1156 & 1327 & 824 & 1614 \\
0.065 & 1251 & 1081 & 1250 & 888 & 1443 \\
0.0675 & 1102 & 1084 & 1088 & 880 & 1254 \\
0.07 & 1004 & 899 & 1002 & 846 & 1144 \\
0.0725 & 895 & 819 & 894 & 776 & 1031 \\
0.075 & 855 & 760 & 836 & 720 & 966 \\
0.0775 & 772 & 689 & 777 & 668 & 873 \\
0.08 & 724 & 643 & 742 & 628 & 812 \\
0.085 & 593 & 575 & 647 & 569 & 718 \\
0.09 & 526 & 498 & 563 & 480 & 616 \\
0.095 & 484 & 449 & 515 & 443 & 560 \\
0.10 & 434 & 410 & 453 & 406 & 492 \\
0.12 & 305 & 296 & 333 & 299 & 343 \\
0.15 & 214.5 & 195.9 & 221.0 & 211.1 & 234.0 \\
0.20 & 132.2 & 128.2 & 140.9 & 138.3 & 150.8 \\
0.25 & 96.15 & 88.89 & 98.20 & 95.39 & 104.5 \\
0.30 & 71.34 & 67.34 & 75.09 & 71.09 & 81.30 \\
0.40 & 45.66 & 42.86 & 47.85 & 46.69 & 53.43 \\
0.50 & 33.52 & 31.58 & 34.88 & 34.31 & 40.32 \\
0.70 & 20.73 & 20.38 & 22.49 & 21.94 & 25.38 \\
1.00 & 14.19 & 13.51 & 14.79 & 14.15 & 16.17 \\
1.30 & 10.30 & 9.91 & 10.87 & 10.54 & 11.85 \\
1.60 & 7.65 & 7.32 & 7.96 & 7.98 & 8.68 \\
1.70 & 6.95 & 6.78 & 7.36 & 7.27 & 8.30 \\
1.80 & 6.68 & 6.38 & 6.89 & 6.91 & 7.54 \\
1.90 & 6.22 & 5.99 & 6.51 & 6.49 & 7.20 \\
2.00 & 5.79 & 5.67 & 5.94 & 6.01 & 6.78 \\
2.10 & 5.39 & 5.13 & 5.62 & 5.54 & 6.12 \\
2.20 & 5.12 & 4.85 & 5.27 & 5.27 & 5.84 \\
2.30 & 4.92 & 4.66 & 4.95 & 5.01 & 5.43 \\
2.40 & 4.57 & 4.37 & 4.57 & 4.72 & 5.23 \\
2.50 & 4.29 & 4.22 & 4.37 & 4.48 & 4.89 \\
2.60 & 4.13 & 3.94 & 4.26 & 4.30 & 4.60 \\
2.70 & 3.81 & 3.74 & 4.05 & 4.03 & 4.38 \\
2.80 & 3.79 & 3.56 & 3.83 & 3.80 & 4.14 \\
2.90 & 3.59 & 3.41 & 3.72 & 3.59 & 4.02 \\
3.00 & 3.42 & 3.32 & 3.50 & 3.52 & 3.82
\end{tabular}


Table 25, continued

\begin{tabular}{|c|c|c|c|c|c|}
\hline $\begin{array}{l}2 \theta \\
\text { Angle } \\
\text { degrees }\end{array}$ & $\begin{array}{l}\text { Test } \\
\text { RE 3 } \\
\text { (cps) }\end{array}$ & $\begin{array}{l}\text { Test } \\
\text { RE4 } \\
\text { (cps) }\end{array}$ & $\begin{array}{l}\text { Test } \\
\text { RH7 } \\
\text { (cps) }\end{array}$ & $\begin{array}{l}\text { Test } \\
\text { RH8 } \\
\text { (cps) }\end{array}$ & $\begin{array}{l}\text { Test } \\
\text { HLI } \\
\text { (cps) }\end{array}$ \\
\hline $\begin{array}{l}0.05 \\
0.0525 \\
0.055 \\
0.0575 \\
0.06 \\
0.0625 \\
0.065 \\
0.0675 \\
0.07 \\
0.0725 \\
0.075 \\
0.0775 \\
0.08 \\
0.085 \\
0.09 \\
0.095 \\
0.10 \\
0.12 \\
0.15 \\
0.20 \\
0.25 \\
0.30 \\
0.40 \\
0.50 \\
0.70 \\
1.00 \\
1.30 \\
1.60 \\
1.70 \\
1.80 \\
1.90 \\
2.00 \\
2.10 \\
2.20 \\
2.30 \\
2.40 \\
2.50 \\
2.60 \\
2.70 \\
2.80 \\
2.90 \\
3.00\end{array}$ & $\begin{array}{c}611 \\
918 \\
1024 \\
942 \\
865 \\
780 \\
731 \\
675 \\
613 \\
559 \\
476 \\
441 \\
373 \\
280 \\
188.9 \\
122.7 \\
87.98 \\
67.42 \\
45.70 \\
34.54 \\
22.46 \\
14.79 \\
10.74 \\
8.26 \\
7.71 \\
7.30 \\
6.67 \\
6.32 \\
5.99 \\
5.59 \\
5.21 \\
4.93 \\
4.54 \\
4.48 \\
4.17 \\
3.94 \\
3.81 \\
3.61\end{array}$ & $\begin{array}{c}2061 \\
2039 \\
2867 \\
1979 \\
1898 \\
1341 \\
1255 \\
1073 \\
978 \\
884 \\
821 \\
756 \\
702 \\
583 \\
512 \\
468 \\
420 \\
299 \\
202.5 \\
130.4 \\
93.02 \\
72.99 \\
48.74 \\
35.59 \\
23.02 \\
14.82 \\
10.95 \\
8.50 \\
7.89 \\
7.42 \\
7.03 \\
6.43 \\
6.08 \\
5.61 \\
5.35 \\
5.04 \\
4.80 \\
4.49 \\
4.24 \\
4.02 \\
3.78 \\
3.67\end{array}$ & $\begin{array}{c}583 \\
1370 \\
1567 \\
1714 \\
1711 \\
1435 \\
1217 \\
1111 \\
985 \\
913 \\
829 \\
753 \\
656 \\
574 \\
494 \\
458 \\
311 \\
210.2 \\
134.8 \\
93.75 \\
74.26 \\
50.89 \\
39.16 \\
26.35 \\
17.46 \\
12.61 \\
9.49 \\
9.01 \\
8.39 \\
7.61 \\
7.25 \\
6.65 \\
6.28 \\
5.85 \\
5.53 \\
5.24 \\
4.93 \\
4.70 \\
4.43 \\
4.24 \\
4.09\end{array}$ & $\begin{array}{c}263 \\
971 \\
1165 \\
1180 \\
1074 \\
979 \\
894 \\
806 \\
736 \\
688 \\
590 \\
517 \\
474 \\
327 \\
211.6 \\
138.3 \\
99.50 \\
76.34 \\
52.40 \\
40.35 \\
26.89 \\
17.92 \\
12.88 \\
9.32 \\
8.46 \\
7.78 \\
7.27 \\
6.84 \\
6.41 \\
6.00 \\
5.63 \\
5.22 \\
5.02 \\
4.77 \\
4.51 \\
4.31 \\
4.11 \\
3.88\end{array}$ & $\begin{array}{c}711 \\
24 \\
311 \\
1946 \\
2307 \\
2533 \\
2338 \\
2064 \\
1888 \\
1707 \\
1559 \\
1311 \\
1150 \\
1024 \\
927 \\
653 \\
433.6 \\
263.2 \\
174.4 \\
126.9 \\
74.53 \\
50.55 \\
28.64 \\
15.91 \\
10.70 \\
7.87 \\
7.27 \\
6.70 \\
6.27 \\
5.95 \\
5.49 \\
5.30 \\
5.10 \\
4.70 \\
4.57 \\
4.28 \\
4.11 \\
3.96 \\
3.85 \\
3.74\end{array}$ \\
\hline
\end{tabular}


Table 25, continued

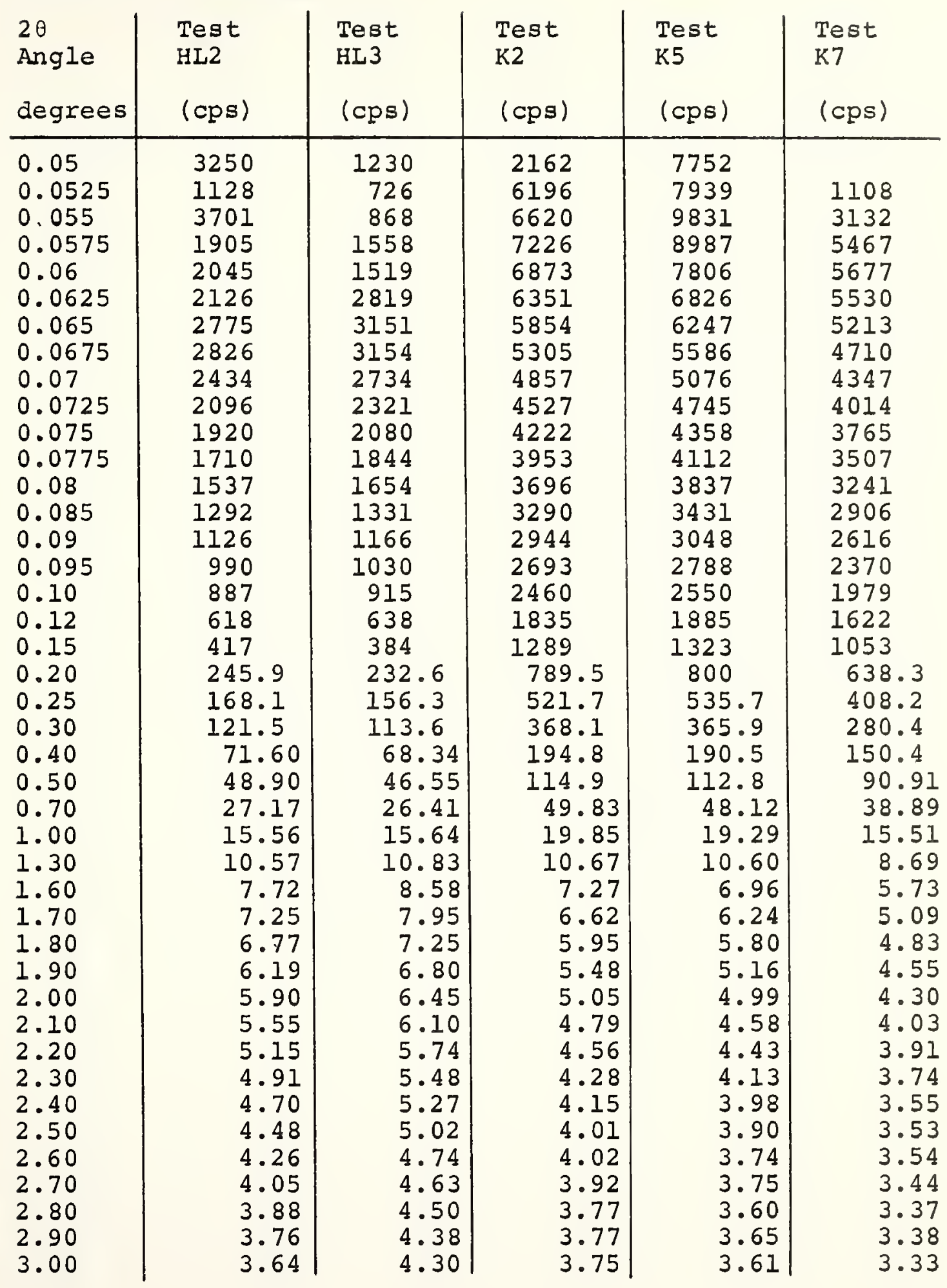


Table 25 , continued

\begin{tabular}{|c|c|c|c|c|c|}
\hline $\begin{array}{l}2 \theta \\
\text { Angle } \\
\text { degrees }\end{array}$ & $\begin{array}{l}\text { Test } \\
\text { ldND1 } \\
\text { (cps) }\end{array}$ & $\begin{array}{l}\text { Test } \\
\text { ldND2 } \\
\text { (cps) }\end{array}$ & $\begin{array}{l}\text { Test } \\
\text { ldND3 } \\
\text { (cps) }\end{array}$ & $\begin{array}{l}\text { Test } \\
\text { T5 } \\
\text { (cps) }\end{array}$ & $\begin{array}{l}\text { Test } \\
\text { T12 } \\
\text { (cps) }\end{array}$ \\
\hline 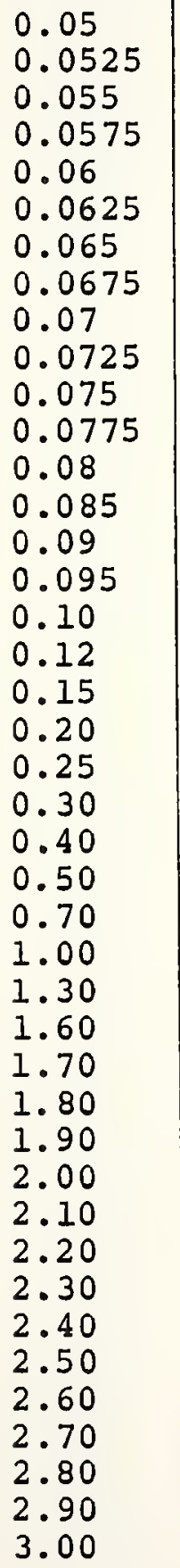 & $\begin{array}{c}338 \\
315 \\
500 \\
358 \\
1903 \\
1957 \\
2846 \\
2232 \\
1635 \\
1264 \\
1114 \\
945 \\
825 \\
696 \\
570 \\
490 \\
415 \\
261 \\
159.1 \\
99.72 \\
67.80 \\
50.70 \\
34.92 \\
24.98 \\
15.84 \\
9.65 \\
6.83 \\
5.18\end{array}$ & $\begin{array}{c}489 \\
1826 \\
2726 \\
1932 \\
1655 \\
1250 \\
1096 \\
931 \\
813 \\
631 \\
524 \\
451 \\
387 \\
254 \\
147.8 \\
94.24 \\
64.98 \\
50.92 \\
33.71 \\
25.39 \\
16.61 \\
10.11 \\
7.34 \\
5.44\end{array}$ & $\begin{array}{r}2766 \\
2460 \\
3209 \\
2717 \\
2126 \\
3104 \\
2663 \\
2574 \\
1750 \\
1348 \\
1176 \\
1004 \\
874 \\
697 \\
573 \\
509 \\
415 \\
271 \\
158 \\
99.17 \\
70.59 \\
54.96 \\
36.11 \\
25.55 \\
16.74 \\
10.27 \\
6.84 \\
5.28\end{array}$ & $\begin{array}{c}4534 \\
4002 \\
5280 \\
4880 \\
4543 \\
3944 \\
3557 \\
3130 \\
2911 \\
2634 \\
2418 \\
2178 \\
1936 \\
1664 \\
1493 \\
1341 \\
942 \\
599.1 \\
365.9 \\
244.9 \\
173.4 \\
94.79 \\
58.71 \\
25.68 \\
10.24 \\
5.50 \\
3.67 \\
3.21 \\
2.94 \\
2.69 \\
2.53 \\
2.39 \\
2.22 \\
2.15 \\
2.07 \\
1.97 \\
1.97 \\
1.92 \\
1.90 \\
1.88 \\
1.87\end{array}$ & $\begin{array}{l}1821 \\
4328 \\
5002 \\
4755 \\
4115 \\
3573 \\
3232 \\
2897 \\
2620 \\
2366 \\
2040 \\
1752 \\
1556 \\
1370 \\
940 \\
569.9 \\
342.9 \\
234.4 \\
167.6 \\
97.72 \\
60.61 \\
28.16 \\
11.75 \\
6.50 \\
4.36 \\
3.95 \\
3.53 \\
3.29 \\
3.07 \\
2.84 \\
2.83 \\
2.57 \\
2.52 \\
2.51 \\
2.37 \\
2.29 \\
2.34 \\
2.35 \\
2.42\end{array}$ \\
\hline
\end{tabular}


Table 25, continued

\begin{tabular}{|c|c|c|c|c|c|}
\hline $\begin{array}{l}2 \theta \\
\text { Angle } \\
\text { degrees }\end{array}$ & $\begin{array}{l}\text { Test } \\
\text { Tl3 } \\
\text { (cps) }\end{array}$ & $\begin{array}{l}\text { Test } \\
\text { B3NDl } \\
\\
\text { (cps) }\end{array}$ & $\begin{array}{l}\text { Test } \\
\text { B3ND2 } \\
\text { (cps) }\end{array}$ & $\begin{array}{l}\text { Test } \\
\text { B3ND3 } \\
\text { (cps) }\end{array}$ & $\begin{array}{l}\text { Test } \\
\text { D3 } \\
\text { (cps) }\end{array}$ \\
\hline 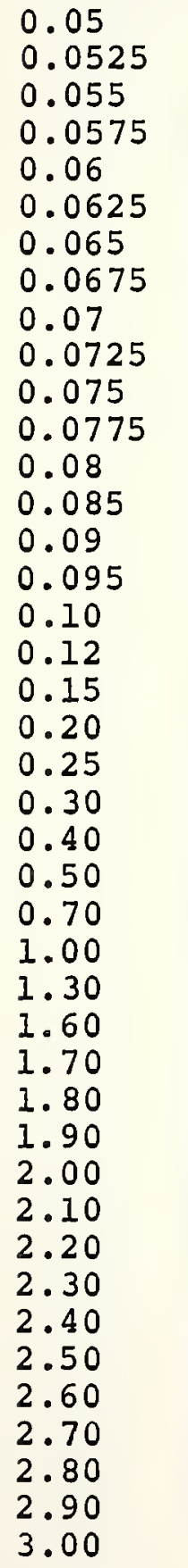 & $\begin{array}{c}2689 \\
3003 \\
4489 \\
4048 \\
3713 \\
3360 \\
3063 \\
2749 \\
2447 \\
2235 \\
2074 \\
1902 \\
1736 \\
1533 \\
1339 \\
1208 \\
1075 \\
765 \\
485.2 \\
307.7 \\
205.5 \\
144.6 \\
83.10 \\
52.04 \\
23.50 \\
9.49 \\
5.24 \\
3.52 \\
3.14 \\
2.93 \\
2.65 \\
2.49 \\
2.39 \\
2.25 \\
2.14 \\
2.12 \\
2.05 \\
1.99 \\
1.96 \\
1.92 \\
1.89 \\
1.89\end{array}$ & $\begin{array}{l}168 \\
241 \\
674 \\
488 \\
525 \\
457 \\
418 \\
368 \\
340 \\
310 \\
285 \\
166 \\
145 \\
126 \\
116 \\
97 \\
64.42 \\
45.88 \\
34.77 \\
28.87 \\
21.23 \\
17.03 \\
13.35 \\
9.57 \\
7.35 \\
5.55 \\
5.07 \\
4.85 \\
4.37 \\
3.84 \\
3.70 \\
3.56 \\
3.40 \\
3.31 \\
3.13 \\
2.99 \\
2.84 \\
2.69 \\
2.65\end{array}$ & $\begin{array}{l}2901 \\
3395 \\
4212 \\
3178 \\
1981 \\
1120 \\
879 \\
651 \\
552 \\
492 \\
451 \\
411 \\
370 \\
260 \\
234 \\
217 \\
183 \\
135 \\
95.66 \\
66.96 \\
52.95 \\
43.17 \\
31.85 \\
26.16 \\
19.33 \\
13.61 \\
11.08 \\
8.39 \\
7.70 \\
6.90 \\
6.88 \\
6.49 \\
6.11 \\
5.73 \\
5.48 \\
5.13 \\
4.96 \\
4.68 \\
4.50 \\
4.27 \\
4.19 \\
4.01\end{array}$ & $\begin{array}{l}673 \\
802 \\
773 \\
604 \\
575 \\
475 \\
427 \\
368 \\
341 \\
311 \\
290 \\
217 \\
187 \\
171 \\
161 \\
116 \\
80.48 \\
57.58 \\
43.86 \\
35.86 \\
26.92 \\
21.87 \\
16.38 \\
11.83 \\
9.47 \\
7.54 \\
7.09 \\
6.74 \\
6.35 \\
5.85 \\
5.67 \\
5.25 \\
5.00 \\
4.72 \\
4.46 \\
4.29 \\
4.08 \\
3.96 \\
3.77 \\
3.58\end{array}$ & $\begin{array}{c}15 \\
2534 \\
4156 \\
5274 \\
5410 \\
5372 \\
4799 \\
4378 \\
3944 \\
3656 \\
3304 \\
3067 \\
2668 \\
2296 \\
2030 \\
1809 \\
1253 \\
827.3 \\
540.5 \\
384.6 \\
294.1 \\
186.3 \\
122.7 \\
62.76 \\
27.92 \\
15.52 \\
9.28 \\
8.10 \\
7.14 \\
6.32 \\
5.88 \\
5.35 \\
4.91 \\
4.58 \\
4.18 \\
4.00 \\
3.75 \\
3.58 \\
3.37 \\
3.22 \\
3.15\end{array}$ \\
\hline
\end{tabular}


Table 25, continued

\begin{tabular}{|c|c|c|c|c|c|}
\hline $\begin{array}{l}2 \theta \\
\text { Angle } \\
\text { degrees }\end{array}$ & $\begin{array}{l}\text { Test } \\
\text { D7 } \\
\text { (cps) }\end{array}$ & $\begin{array}{l}\text { Test } \\
\text { D8 } \\
\text { (cps) }\end{array}$ & $\begin{array}{l}\text { Test } \\
\text { C6ND1 } \\
\text { (cps) }\end{array}$ & $\begin{array}{l}\text { Test } \\
\text { C6ND2 } \\
\text { (cps) }\end{array}$ & $\begin{array}{l}\text { Test } \\
\text { C6ND3 } \\
\text { (cps) }\end{array}$ \\
\hline $\begin{array}{l}0.05 \\
0.0525 \\
0.055 \\
0.0575 \\
0.06 \\
0.0625 \\
0.065 \\
0.0675 \\
0.07 \\
0.0725 \\
0.075 \\
0.0775 \\
0.08 \\
0.085 \\
0.09 \\
0.095 \\
0.10 \\
0.12 \\
0.15 \\
0.20 \\
0.25 \\
0.30 \\
0.40 \\
0.50 \\
0.70 \\
1.00 \\
1.30 \\
1.60 \\
1.70 \\
1.80 \\
1.90 \\
2.00 \\
2.10 \\
2.20 \\
2.30 \\
2.40 \\
2.50 \\
2.60 \\
2.70 \\
2.80 \\
2.90 \\
3.00\end{array}$ & $\begin{array}{c}612 \\
1613 \\
5514 \\
6530 \\
6959 \\
7059 \\
6347 \\
5578 \\
4915 \\
4507 \\
4041 \\
3683 \\
3135 \\
2662 \\
2362 \\
2061 \\
1395 \\
905.1 \\
582.5 \\
419.6 \\
320.9 \\
204.8 \\
138.6 \\
70.09 \\
31.33 \\
16.76 \\
10.71 \\
9.44 \\
8.41 \\
7.59 \\
7.02 \\
6.43 \\
5.89 \\
5.51 \\
5.07 \\
4.73 \\
4.43 \\
4.23 \\
4.04 \\
3.86 \\
3.70\end{array}$ & $\begin{array}{c}2637 \\
3526 \\
4137 \\
6415 \\
6097 \\
6370 \\
5943 \\
5393 \\
4845 \\
4358 \\
4036 \\
3628 \\
3337 \\
2856 \\
2456 \\
2175 \\
1927 \\
1299 \\
867.5 \\
555.6 \\
402.7 \\
312.5 \\
198.7 \\
133.3 \\
68.03 \\
30.06 \\
16.32 \\
10.08 \\
8.92 \\
7.88 \\
7.08 \\
6.52 \\
5.99 \\
5.44 \\
5.14 \\
4.75 \\
4.51 \\
4.19 \\
4.05 \\
3.89 \\
3.67 \\
3.58\end{array}$ & $\begin{aligned} 2512 \\
3148 \\
3975 \\
3209 \\
2897 \\
2166 \\
1967 \\
1668 \\
1533 \\
1360 \\
1261 \\
1132 \\
1037 \\
821 \\
598 \\
521 \\
483 \\
452 \\
266.4 \\
158.5 \\
113.8 \\
89.05 \\
62.46 \\
46.64 \\
28.30 \\
18.19 \\
13.67 \\
9.91 \\
9.07 \\
8.29 \\
7.52 \\
6.92 \\
6.36 \\
5.97 \\
5.43 \\
4.99 \\
4.76 \\
4.53 \\
4.12 \\
3.86 \\
3.64 \\
3.40\end{aligned}$ & $\begin{array}{c}399 \\
826 \\
1451 \\
1684 \\
2139 \\
1862 \\
1775 \\
1550 \\
1425 \\
1267 \\
1177 \\
1053 \\
964 \\
830 \\
745 \\
650 \\
589 \\
406 \\
279.6 \\
181.7 \\
133.0 \\
103.5 \\
71.88 \\
54.40 \\
36.23 \\
22.87 \\
16.16 \\
10.64 \\
9.71 \\
9.24 \\
8.65 \\
7.73 \\
7.22 \\
6.93 \\
6.42 \\
5.93 \\
5.55 \\
5.13 \\
4.96 \\
4.68 \\
4.31 \\
4.09\end{array}$ & $\begin{array}{l}1258 \\
1545 \\
2832 \\
3717 \\
3257 \\
2774 \\
2540 \\
2154 \\
1914 \\
1697 \\
1569 \\
1402 \\
1281 \\
1072 \\
895 \\
787 \\
692 \\
497 \\
328.1 \\
212.8 \\
150.8 \\
119.3 \\
83.22 \\
60.61 \\
39.22 \\
24.44 \\
17.05 \\
11.42 \\
10.64 \\
9.72 \\
8.90 \\
8.04 \\
7.50 \\
6.89 \\
6.34 \\
5.89 \\
5.51 \\
5.15 \\
4.82 \\
4.55 \\
4.33 \\
4.16\end{array}$ \\
\hline
\end{tabular}


Table 25, continued

\begin{tabular}{|c|c|c|c|c|c|}
\hline $\begin{array}{l}2 \theta \\
\text { Angle } \\
\text { degrees }\end{array}$ & $\begin{array}{l}\text { Test } \\
\text { F2 } \\
\text { (cps) }\end{array}$ & $\begin{array}{l}\text { Test } \\
\text { F3 } \\
\text { (cps) }\end{array}$ & $\begin{array}{l}\text { Test } \\
\text { F5 } \\
\text { (cps) }\end{array}$ & $\begin{array}{l}\text { Test } \\
\text { F8 } \\
\text { (cps) }\end{array}$ & $\begin{array}{l}\text { Test } \\
01 \\
\text { (cps) }\end{array}$ \\
\hline 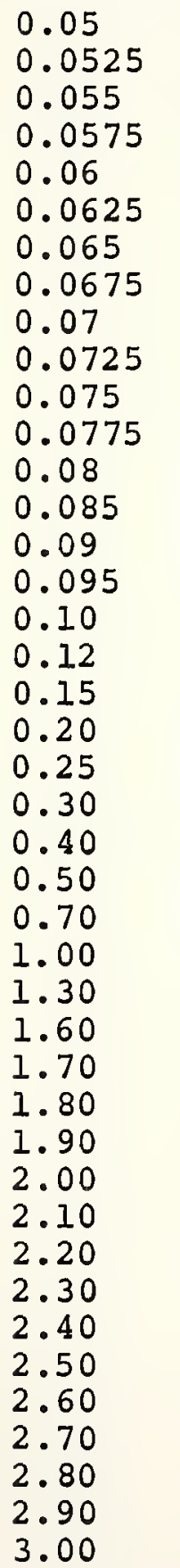 & $\begin{array}{c}5930 \\
10265 \\
12077 \\
13897 \\
12101 \\
11039 \\
10001 \\
8911 \\
7997 \\
7307 \\
6758 \\
6212 \\
5693 \\
4987 \\
4376 \\
3920 \\
3501 \\
2487 \\
1640 \\
1071 \\
759.5 \\
550.5 \\
322.6 \\
205.5 \\
93.75 \\
39.45 \\
20.58 \\
12.87 \\
11.44 \\
10.02 \\
8.80 \\
7.86 \\
7.31 \\
6.54 \\
6.03 \\
5.46 \\
5.24 \\
4.78 \\
4.50 \\
4.25 \\
3.94 \\
3.82\end{array}$ & $\begin{array}{r}13367 \\
12794 \\
11872 \\
10413 \\
9414 \\
8405 \\
7791 \\
6939 \\
6386 \\
5878 \\
5513 \\
5066 \\
4720 \\
4204 \\
3671 \\
3339 \\
2989 \\
2166 \\
1513 \\
937.5 \\
659.3 \\
495.9 \\
298.5 \\
186.9 \\
87.46 \\
36.70 \\
18.70 \\
10.80 \\
9.87 \\
8.48 \\
7.48 \\
6.73 \\
6.12 \\
5.67 \\
5.10 \\
4.87 \\
4.54 \\
4.15 \\
3.88 \\
3.61 \\
3.40 \\
3.22\end{array}$ & $\begin{array}{r}4824 \\
8320 \\
9785 \\
10212 \\
9675 \\
8843 \\
8211 \\
7452 \\
6809 \\
6225 \\
5775 \\
5373 \\
4936 \\
4373 \\
3867 \\
3497 \\
3144 \\
2274 \\
1552 \\
983.6 \\
697.7 \\
508.5 \\
309.3 \\
194.2 \\
91.46 \\
38.22 \\
20.68 \\
13.28 \\
11.72 \\
10.37 \\
9.06 \\
8.11 \\
7.38 \\
6.80 \\
6.16 \\
5.74 \\
5.33 \\
5.01 \\
4.66 \\
4.44 \\
4.18 \\
3.97\end{array}$ & $\begin{array}{r}5178 \\
8783 \\
11570 \\
14760 \\
13923 \\
13217 \\
11933 \\
10629 \\
9591 \\
8817 \\
8094 \\
7487 \\
6843 \\
5991 \\
5244 \\
4708 \\
4209 \\
2993 \\
1969 \\
1200 \\
845.1 \\
618.6 \\
359.2 \\
222.3 \\
103.1 \\
42.54 \\
21.83 \\
13.04 \\
11.27 \\
10.02 \\
8.88 \\
8.06 \\
7.11 \\
6.50 \\
6.03 \\
5.46 \\
4.52 \\
4.81 \\
4.54 \\
4.114 \\
4.08 \\
3.77\end{array}$ & $\begin{array}{l}854 \\
395 \\
140 \\
440 \\
958 \\
1189 \\
1181 \\
1043 \\
893 \\
799 \\
712 \\
636 \\
537 \\
449 \\
408 \\
370 \\
268 \\
187.7 \\
129.0 \\
97.40 \\
78.64 \\
55.81 \\
44.02 \\
30.83 \\
20.17 \\
14.01 \\
10.16 \\
9.22 \\
8.67 \\
7.78 \\
7.18 \\
6.65 \\
6.20 \\
5.68 \\
5.21 \\
5.01 \\
4.62 \\
4.36 \\
4.14 \\
3.85 \\
3.66\end{array}$ \\
\hline
\end{tabular}


Table 25, continued

\begin{tabular}{|c|c|c|c|c|c|}
\hline $\begin{array}{l}2 \theta \\
\text { Angle } \\
\text { degrees }\end{array}$ & $\begin{array}{l}\text { Test } \\
03 \\
\text { (cps) }\end{array}$ & $\begin{array}{l}\text { Test } \\
04 \\
\text { (cps) }\end{array}$ & $\begin{array}{l}\text { Test } \\
06 \\
\text { (cps) }\end{array}$ & $\begin{array}{l}\text { Test } \\
08 \\
\text { (cps) }\end{array}$ & $\begin{array}{l}\text { Test } \\
09 \\
\text { (cps) }\end{array}$ \\
\hline 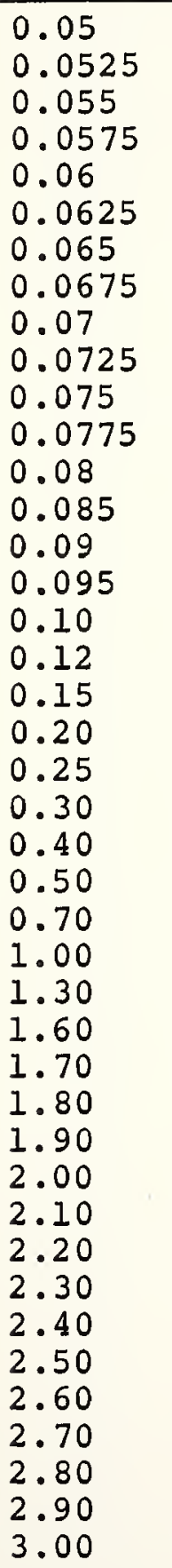 & $\begin{array}{c}891 \\
1021 \\
1061 \\
889 \\
830 \\
720 \\
653 \\
577 \\
494 \\
450 \\
397 \\
279 \\
195.5 \\
136.1 \\
99.67 \\
81.19 \\
58.71 \\
45.39 \\
31.68 \\
20.58 \\
14.57 \\
10.93 \\
9.80 \\
8.94 \\
8.24 \\
7.38 \\
6.90 \\
6.34 \\
5.93 \\
5.45 \\
5.16 \\
4.74 \\
4.46 \\
4.18 \\
3.87 \\
3.66\end{array}$ & \begin{tabular}{|c|}
748 \\
560 \\
688 \\
388 \\
375 \\
772 \\
969 \\
1067 \\
960 \\
840 \\
753 \\
672 \\
600 \\
545 \\
478 \\
417 \\
381 \\
263 \\
186.6 \\
128.5 \\
95.39 \\
77.32 \\
57.09 \\
44.68 \\
30.85 \\
20.37 \\
14.19 \\
10.18 \\
9.43 \\
8.43 \\
7.89 \\
7.15 \\
6.64 \\
6.02 \\
5.68 \\
5.28 \\
4.87 \\
4.59 \\
4.33 \\
4.02 \\
3.76 \\
3.60
\end{tabular} & $\begin{array}{c}4825 \\
3979 \\
3616 \\
3024 \\
2743 \\
2521 \\
2318 \\
2149 \\
1988 \\
1868 \\
1765 \\
1683 \\
1585 \\
1471 \\
1324 \\
1242 \\
1150 \\
931 \\
737.2 \\
508.5 \\
379.8 \\
287.1 \\
183.5 \\
122.5 \\
59.46 \\
26.71 \\
14.10 \\
8.82 \\
7.86 \\
6.87 \\
6.33 \\
5.71 \\
5.22 \\
4.78 \\
4.36 \\
4.09 \\
3.90 \\
3.73 \\
3.51 \\
3.39 \\
3.30 \\
3.21\end{array}$ & $\begin{array}{c}3946 \\
3345 \\
3163 \\
2727 \\
2610 \\
2344 \\
2226 \\
2057 \\
1907 \\
1788 \\
1702 \\
1599 \\
1519 \\
1398 \\
1285 \\
1199 \\
1112 \\
879 \\
659.4 \\
461.5 \\
346.8 \\
267.9 \\
170.9 \\
115.2 \\
55.71 \\
24.62 \\
12.88 \\
7.80 \\
7.13 \\
6.04 \\
5.50 \\
5.07 \\
4.73 \\
4.24 \\
4.01 \\
3.75 \\
3.49 \\
3.44 \\
3.22 \\
3.09 \\
3.01 \\
2.91\end{array}$ & $\begin{array}{l}1367 \\
2325 \\
3222 \\
3141 \\
2960 \\
2711 \\
2538 \\
2351 \\
2141 \\
2031 \\
1921 \\
1829 \\
1716 \\
1552 \\
1428 \\
1329 \\
1229 \\
980 \\
725 \\
504.2 \\
370.4 \\
289.9 \\
177.5 \\
119.5 \\
59.35 \\
25.64 \\
13.49 \\
7.83 \\
6.79 \\
6.07 \\
5.43 \\
4.92 \\
4.62 \\
4.20 \\
3.88 \\
3.70 \\
3.45 \\
3.24 \\
3.19 \\
3.02 \\
2.91 \\
2.94\end{array}$ \\
\hline
\end{tabular}


VITA 
VITA

Douglas Nathaniel Winslow was born 28 November 1942 in Cleveland, Ohio. He lived in Lakewood, Ohio where he attended primary and secondary school. He graduated from Lakewood High School in June 1960.

He then attended Purdue University, West Lafayette, Indiana, and received a Bachelor of Science in Civil Engineering degree in June 1964.

He was also commissioned as an officer in the United States Navy in June 1964 and spent two years on active duty. During that period he saw duty in the Pacific Ocean on an aircraft carrier and with the state Department, Washington, D. C.

In September 1966 he reentered Purdue University and received his Master of Science in Civil Engineering degree in January, 1969. He then continued his education, working toward a Doctor of Philosophy degree in the field of construction materials. He studied briefly at the University of Graz, Graz, Austria in the fall of 1971. 

